\title{
Caracterización de los Flujos Iónicos en Leucocitos y su Modulación Farmacológica como Estrategia Terapéutica
}

Miriam Soledad Giambelluca

Tesis Doctoral

2009

Director: Prof. Dr. Oscar Alfredo Gende

Asesor Científico: Prof. Dr. Gustavo Rinaldi 


\section{AGRADECIMIENTOS}

Quiero comenzar agradeciendo a la persona que fue fundamental para poder llevar a cabo este trabajo: a mi director de tesis el Dr. Oscar Alfredo Gende. El fue la persona que me enseñó, me acompañó, estuvo a mi lado en cada experimento cuando las cosas salían bien y cuando salían mal, siempre alentándome y exigiéndome para poder lograr siempre un poquito más. Agradezco mucho su paciencia y tolerancia. Por todo esto y por muchas cosas más, quiero decirle: "Muchas gracias".

Me gustaría agradecerle también a Angela Grassi, Mini, quien junto con Alfredo, me ayudaron mucho cuando recien llegue a La Plata con mi familia, casi sin conocerme me brindaron toda su confianza, cariño y protección. Nunca dejaron de estar cerca y me acompañaron en momentos muy importantes de mi vida. Por todo eso y mucho mas, quiero decirte: "Muchas gracias".

Quiero agradecer a las personas que trabajan en el Banco de Sangre de la Ciudad de La Plata. Ellos fueron quienes nos proporcionaron las muestras que utilizamos en nuestros experimentos y $\sin$ las cuales esta tesis no hubiese podido ser realizada.

También quiero darle las gracias a todas las personas que trabajan en el Centro de Investigaciones Cardiovasculares, a sus directivos (Alicia y Leti), secretarias (Albita y Rosana), investigadores (Ire, Ale, Gustavo, Claudia, Ceci, Martin, Susana, Mati, Marga, Celeste y Juli), becarios (Ale, Verito, Juliana, Romi, Lu, Caro, Mariela, Charli, Omar y Vero), a Ines y a Moni, que desde que llegue allí siempre hicieron todo lo posible por hacerme sentir parte de este grupo, con el que compartimos no solo reuniones científicas sino que también compartimos muchos lindos momentos.
Sin duda, esta tesis no solo es el final de un trabajo científico sino lleva con ella a cada una de las personas que colaboraron conmigo, aunque a veces pareciera que no hicieron nada, realmente hicieron mucho, cada ratito que compartieron conmigo, cada charla, cada mate, cada gesto de compañerismo y amistad, hicieron que este proyecto pudiera concretarse. A todos ellos quiero decirles: "Muchas gracias por compartir este tiempo conmigo".

Por último, quiero agradecerle a mi familia, a la que tengo cerca y a la que está lejos, sin duda mi familia fue importantísima en este proyecto, aunque no estuvieron conmigo en el laboratorio, estuvieron conmigo en todo los aspectos de mi vida, para apoyarme a pesar de las distancias. A mi familia, quiero decirles: "Muchas gracias"

Esta tesis está DEDICADA a las personas más importantes de mi vida:

MI ESPOSO, PABLO,

MIS SOLCITOS: MICA Y MILI,

MIS PAPAS, LILIANA Y JULIO, QUE SIEMPRE LOS LLEVO CONMIGO.

A todos: MUCHAS GRACIAS!!!!! 


\section{INDICE}

\section{RESUMEN}

\section{ABREVIATURAS}

\section{CAPÍTULO I}

\section{INTRODUCCIÓN}

1. EI PROCESO INFLAMATORIO

1.1. Respuesta Inmune

1.2. La Inflamación como Mecanismo de Defensa

1.3. Fases del Proceso Inflamatorio

\section{EL NEUTRÓFILO}

2.1. Características Generales

2.2. Ontogenia y Cinética de Formación en el Hombre

2.3. Apoptosis y Supervivencia

\section{RESPUESTAS FUNCIONALES}

3.1. Interacción con el Endotelio

3.1.1. Rodamiento y Adhesión Laxa

3.1.2. Expresión de Receptores de Membrana y Adhesión Firme

3.1.1. Transmigración Endotelial y Quimiotaxis

3.2. Fagocitosis y Acción Microbicida

3.2.1. Mecanismos Efectores Dependientes del Oxígeno

\section{NADPH oxidasa}

3.2.2. Mecanismos Efectores Independientes del Oxígeno

Gránulos

\section{Ectosomas o Micropartículas}

Factores Citosólicos

NETs

3.3. Grados de Activación

\section{CONTROL DE LA RESPUESTA FUNCIONAL}

4.1. Receptores de Formil Péptidos

4.2. Desensibilización de Receptores: Papel del Citoesqueleto

4.3. Control de las Cascadas Intracelulares
4.3.1. Fosfolipasa C
4.3.2. $\mathrm{PI}_{3}$ quinasa
4.3.3. GTPasas monoméricas
4.3.4. MAP quinasas
4.3.5. Otras Vías de Señalización

4.4. Control de la Concentración de Calcio Intracelular 4.4.1. Movilización de Calcio de los Depósitos Intracelulares

4.4.2. Ingreso de Calcio a través de la Membrana Plasmática

4.4.3. Intercambiador $\mathrm{Na}^{+} / \mathrm{Ca}^{2+}$

4.5. Control del $\mathrm{pH}$ Intracelular

\section{RESPUESTA INFLAMATORIA DISFUNCIONAL}

5.1. El Neutrófilo en la Respuesta Inflamatoria Disfuncional

5.2. Control Farmacológico de la Respuesta Inflamatoria

Disfuncional

\section{OBJETIVOS}

6.1. Objetivo General

6.2. Objetivos Específicos 


\section{CAPÍTULO II}

\section{MATERIALES Y MÉTODOS}

1. ENFOQUE EXPERIMENTAL

\section{REACTIVOS Y COMPOSICIÓN DE LAS SOLUCIONES} UTILIZADAS

\section{MÉTODOS Y PROTOCOLOS}

3.1. Aislamiento de Neutrófilos Humanos de Sangre Periférica

3.2. Determinación de la Entrada y Movilización de Calcio

3.3. Determinación de la Entrada de Manganeso

3.4. Determinación de la Producción de ROS

3.5. Determinación de los Cambios en el pH Intracelular

\section{VARIABLES ANALIZADAS Y ANÁLISIS ESTADÍSTICO}

CAPÍTULO III

RELACIÓN ENTRE LOS FLUJOS DE CALCIO Y EL ESTRÉS

\section{OXIDATIVO}

\section{ANTECEDENTES}

1.1. Efectos Autocrinos y Paracrinos de los ROS

1.2. Efecto del $\mathrm{H}_{2} \mathrm{O}_{2}$ Exógeno en Otras Células

1.3. $\mathrm{H}_{2} \mathrm{O}_{2}$ y TRPM2

1.4. Relación entre los ROS y la Entrada de Calcio

\section{RESULTADOS}

2.1. $\mathrm{El} \mathrm{H}_{2} \mathrm{O}_{2}$ produce aumento del calcio intracelular 2.2. El aumento de calcio fue inhibido por $\mathrm{Ni}^{2+}$ y $\mathrm{La}^{3+}$

\subsection{La entrada de calcio fue inhibida por manitol}

\section{DISCUSIÓN}

CAPÍTULO IV

\section{FLUJOS IÓNICOS EN MEDIOS HIPERTÓNICOS}

\section{ANTECEDENTES}

1.1. Mecanismos Propuestos para la Inmunomodulación y para los Efectos Antiinflamatorios de la Hipertonicidad

1.1.1. Efectos sobre la Producción de Citoquinas

1.1.2. Modificación de las Cascadas de Señalización Fosforilación de p38 MAPK

Concentración Intracelular de AMPc Expresión de HSP

Vías de Señalización Mediadas por Calcio

\section{RESULTADOS}

2.1. Citocalasina B incrementa la producción de ROS, la movilización y la entrada de calcio y la entrada de manganeso inducida por el $f M L P$

2.2. La hiperosmolaridad reduce la producción de ROS inducida por distintos agonistas

2.3. La disrupción del citoesqueleto no altera el efecto inhibitorio de la hiperosmolaridad

2.4. El efecto inhibitorio de la hiperosmolaridad es reversible

2.5. La hiperosmolaridad tardía tiene un efecto paradojal

2.6. El efecto inhibitorio es independiente del osmolito utilizado 2.7. La restitución del calcio extracelular no afecta la producción de ROS 
2.8. La hiperosmolaridad reduce el aumento en la concentración del calcio intracelular inducida por fMLP

2.9. La hiperosmolaridad reduce la movilización del calcio desde los depósitos intracelulares

2.10. El efecto inhibitorio de la hiperosmolaridad sobre el aumento en la $\left[\mathrm{Ca}^{2+}\right]_{i}$ es reversible

2.11. El efecto inhibitorio de la hiperosmolaridad sobre el aumento en la $\left[\mathrm{Ca}^{2+}\right]_{i}$ es independiente del osmolito utilizado

2.12. El efecto inhibitorio de las soluciones hipertónicas no es mediado por la alcalinización celular

3. DISCUSIÓN

\section{CAPÍTULO V}

\section{FLUJOS IÓNICOS EN MEDIOS SUPLEMENTADOS CON}

\section{GLICINA}

\section{ANTECEDENTES}

1.1. Reducción de la Producción de Citoquinas

1.2. Participación de Canales de Cloruro

1.3. Participación de los Flujos de Calcio

\section{RESULTADOS}

2.1. Glicina reduce la producción de ROS

2.2. Glicina previene y revierte la producción de ROS inducida por agonistas

2.3. El efecto inhibitorio de glicina es insensible a la estricnina

2.4. El efecto de glicina no está acoplado al transporte de sodio

2.5. Glicina reduce la carga ácida producida por la NADPH

oxidasa

2.6. Glicina aumenta la entrada de calcio inducida por $\mathrm{FL} P$
3. DISCUSIÓN

\section{CAPÍTULO VI}

\section{DISCUSIÓN GENERAL}

\author{
1. Modelo Elegido \\ 2. Agonistas Elegidos \\ 3. Medios Salinos Utilizados \\ 4. Concentraciones Utilizadas \\ 5. Importancia del Calcio Intracelular en los Mecanismos de \\ Señalización \\ 6. "Cross Talk" entre la NADPH Oxidasa y la Entrada de Calcio \\ 7. Conclusiones
}

CAPÍTULO VII

\section{BIBLIOGRAFÍA}

ANEXO

RESUMEN DE LOS TRABAJOS PUBLICADOS 


\section{RESUMEN}

En diversas situaciones clínicas la activación de los neutrófilos lleva a la liberación excesiva de mediadores citotóxicos que dañan los tejidos vecinos al tejido inflamado. Se han propuesto diversas estrategias para minimizar el daño producido por esta reacción inflamatoria disfuncional. El objetivo general de esta tesis fue examinar y caracterizar las alteraciones en los flujos iónicos que ocurren en situaciones similares a las que se producen durante el desarrollo de una respuesta inflamatoria disfuncional y determinar el efecto que producen algunas de las intervenciones recientemente propuestas para controlarla (utilización de soluciones hipertónicas y suplementadas con glicina).

Para ello nos propusimos estudiar el efecto del estrés oxidativo sobre la concentración de calcio intracelular $\left(\left[\mathrm{Ca}^{2+}\right]_{\mathrm{i}}\right)$. Es conocido que la estimulación de los receptores de fMLP produce un aumento de la $\left[\mathrm{Ca}^{2+}\right]_{\mathrm{i}}$ e induce la explosión respiratoria, sin embargo la posibilidad de que la producción de ROS afecte al aumento de la $\left[\mathrm{Ca}^{2+}\right]_{i}$ ya sea por retroalimentación positiva o negativa es controversial. En diversos trabajos se ha descripto el efecto de los ROS sobre la entrada capacitativa de calcio. En neutrófilos, cantidades elevadas de $\mathrm{O}_{2}{ }^{-}$ provocan una disminución en la entrada capacitativa y este efecto podría ser consecuencia de la despolarización de la membrana provocada por la activación de la NADPH oxidasa. Sin embargo, nosotros mostramos que el tratamiento con $\mathrm{H}_{2} \mathrm{O}_{2}$ exógeno aumentó la entrada de calcio en neutrófilos y que este efecto fue comparable a la entrada de calcio inducida por el fMLP. El $\mathrm{H}_{2} \mathrm{O}_{2}$ fue insuficiente para producir cambios significativos en la $\left[\mathrm{Ca}^{2+}\right]_{i}$ en ausencia de calcio extracelular y cuando se restauró la concentración de calcio extracelular, se produjo una importante entrada de calcio por una vía sensible al $\mathrm{Ni}^{2+}$ y al $\mathrm{La}^{3+}$. También encontramos que el manitol fue capaz de reducir la entrada de calcio inducida por el $\mathrm{H}_{2} \mathrm{O}_{2}$ de manera dependiente de la concentración. Sin embargo, la concentración de manitol necesaria para que se produzca este efecto fue alta por lo que no pudimos asegurar que en este efecto no participe el efecto inhibitorio de la hiperosmolaridad de la solución. En nuestros estudios mostramos la existencia de un mecanismo dependiente de ROS, que regula y controla la entrada de calcio en neutrófilos circulantes, aunque su función fisiológica no es clara.

Las soluciones hipertónicas modulan la respuesta inmune y poseen efectos antiinflamatorios ya que inhiben la activación de neutrófilos y macrófagos, pero los mecanismos moleculares aun no han sido dilucidados. Es por ello que nos propusimos estudiar y caracterizar el efecto del aumento de la osmolaridad del medio sobre los cambios en la producción de ROS, concentración de calcio intracelular y $\mathrm{pH}$ intracelular inducido por agonista. Nuestros experimentos mostraron que la hiperosmolaridad tiene una fuerte acción inhibitoria sobre la producción de ROS y sobre la vía de señalización iniciada por el fMLP. La adición de $25 \mathrm{mM}$ de $\mathrm{NaCl}$ ya producía una reducción estadísticamente significativa en la movilización de calcio desde los depósitos intracelulares, que se correlacionaba con el efecto supresor sobre la producción de ROS, y este tenía una dependencia similar con la concentración del osmolito. Se encontró que la producción de ROS y la movilización de calcio desde depósitos intracelulares fueron reducidas en similar magnitud 
cuando se utilizaban soluciones hipertónicas compuestas por $\mathrm{NaCl}$, sacarosa o $\mathrm{N}$-metilglucamina. El manitol tuvo un menor efecto inhibitorio sobre la movilización de calcio desde los depósitos intracelulares, lo que podría explicar su menor efecto inhibitorio sobre la producción de ROS.

Para evaluar el papel desempeñado por el citoesqueleto en este efecto inhibitorio de la hiperosmolaridad, los neutrófilos fueron tratados con Citocalasina B (CitB). La CitB aumentó la producción de ROS, aunque la despolimerización de actina no fue capaz de revertir los cambios producidos por las soluciones hipertónicas, las cuales redujeron la producción de ROS al mismo nivel en células tratadas y no tratadas con CitB. La CitB potenció la liberación de ROS inducida por PMA, pero esta respuesta fue escasamente reducida por las soluciones hipertónicas, sugiriendo que el principal efecto de la hipertonicidad está en un paso previo a la activación de PKC.

La reducción en la producción de ROS en neutrófilos tratados con CitB mostró una reversibilidad casi completa. Esto se correlacionó con la reversión de los efectos inhibitorios de la hiperosmolaridad sobre el aumento en la $\left[\mathrm{Ca}^{2+}\right]_{i}$ inducida por el fMLP.

Nuestros resultados mostraron que la respuesta obtenida en neutrófilos tratados con CitB fue inhibida por la hiperosmolaridad en un paso cercano al receptor. Sin embargo, esto no descarta la posibilidad de que la hiperosmolaridad estuviese provocando cambios en otros pasos que están más allá del aumento en la $\left[\mathrm{Ca}^{2+}\right]_{i}$ y que estarían participando en su efecto inhibitorio.

Se estudió si la inhibición de la producción de ROS por hiperosmolaridad podría ser mediada por su efecto alcalinizante ya que la adición de $\mathrm{NaCl} 100 \mathrm{mM}$ lleva el pH de 7.2 a 7.4. Nosotros probamos que si bien la alcalinización fue capaz de inhibir la producción de ROS, la inhibición del intercambiador $\mathrm{Na}^{+} / \mathrm{H}^{+}$no afectó el efecto inhibitorio de la hiperosmolaridad.

Por último, la adición de $\mathrm{NaCl} 100$ segundos después de la estimulación con fMLP produjo un incremento paradójico en la liberación extracelular de ROS. Estos resultados sugieren que la hiperosmolaridad no bloquea la vía citotóxica una vez que la señal producida desde el receptor de fMLP ha alcanzado su sitio de acción.

Finalmente nos propusimos analizar la relación entre los flujos de calcio y la producción de ROS en medios suplementados con glicina, con el fin de caracterizar su efecto protector en situaciones donde el daño de los tejidos se produce como consecuencia de la activación excesiva de los neutrófilos. Estudios recientes demostraron que el aumento de la concentración de glicina extracelular puede mitigar o revertir una gran variedad de patologías asociadas a la respuesta inflamatoria disfuncional por una reducción en la liberación sistémica de citoquinas y de otros mediadores inflamatorios. Los hallazgos más significativos que obtuvimos fueron que glicina inhibe la producción de ROS en neutrófilos por un mecanismo directo. Esto fue observado aun cuando la glicina se agregaba luego de que se iniciada la producción de ROS y este efecto era insensible a la presencia de estricnina. Este estudio mostró una menor activación de la producción de ROS por un efecto distal, presumiblemente a nivel de la membrana. En contraste con lo propuesto por otros autores que mostraron la supresión de la señal de calcio inducida por agonistas en neutrófilos adherente $y$ en otras células incubadas con glicina, nosotros mostramos un aumento de la entrada de calcio secundaria a la inhibición de la NADPH oxidasa. 


\section{ABREVIATURAS}

\begin{tabular}{|c|c|c|c|}
\hline$\left[\mathrm{Ca}^{2+}\right]_{\mathrm{i}}$ & Concentración de calcio libre intracelular & HBS & Solución salina tamponada con HEPES \\
\hline AA & Ácido araquidónico & HEPES & Ácido N`-2-etansulfonico -N-2- hidroxietilpiperazina \\
\hline ADP-R & Adenosindifosfato ribosa & HS & Solución salina hipertónica \\
\hline ADP-Rc & Adenosindifosfato ribosa cíclico & HSP & Proteínas de golpe térmico \\
\hline AMPc & Adenosin $3^{\prime}, 5^{\prime}$-monofosfato cíclico & I/R & Isquemia/ reperfusión \\
\hline ANCA & Anticuerpos anti neutrófilos & $\mathrm{IP}_{3}$ & Inositol trifosfato \\
\hline ANOVA & Análisis de varianza & $\mathrm{IP}_{3} \mathrm{R}$ & Receptores para $\mathrm{IP}_{3}$ \\
\hline ARDS & Síndrome de Distrés Respiratorio Agudo & LPS & Lipopolisacárido bacteriano \\
\hline \multirow[t]{2}{*}{ BCECF } & Tetra-acetoximetil 2-7'bis(carboxietil)-5(6) carboxi- & LTB4 & Leucotrieno B4 \\
\hline & fluoresceína & MO & Medula ósea \\
\hline BCECF-AM & Acetoximetilester de BCECF & MPO & Mieloperoxidasa \\
\hline BSA & Albúmina de suero bovino & $\mathrm{NADH}$ & Nicotinamida adenina dinucleótido (forma reducida) \\
\hline $\mathrm{Ca}^{2+}$ & lón calcio & NCX & Intercambiador $\mathrm{Na}^{+} / \mathrm{Ca}^{2+}$. \\
\hline CitB & Citocalasina B & $N F-\kappa B$ & Factor nuclear kappa B \\
\hline $\mathrm{Cl}^{-}$ & lón cloruro & NHE & Intercambiador $\mathrm{Na}^{+} / \mathrm{H}^{+}$ \\
\hline DAG & Diacilglicerol & NMG & $\mathrm{N}$-metilglucamina \\
\hline DPI & Difenilen iodonium & $\mathrm{O}_{2}^{-}$ & Radical superóxido \\
\hline EGTA & Ácido etilen glicol tetraacético & $\mathrm{OH}$ & Radical hidroxilo \\
\hline EIPA & 5-N-etil-N-isopropilamilorida & Oxiburst-BSA & OxyBURST Green H2HFF conjugado con BSA \\
\hline fMLP & $\mathrm{N}$-formil-metionil-leucil-fenilalanina & PAF & Factor activador de plaquetas \\
\hline FPR & Receptor de formil péptidos & PGE & Prostaglandina E \\
\hline FPR1 & Receptor de formil péptidos 1 & PKC & Proteína quinasa $\mathrm{C}$ \\
\hline GDP & Guanosina difosfato & PLC & Fosfolipasa C \\
\hline Gli & Glicina & PMA & Forbol-12 miristato 13 -acetato \\
\hline GliR & Receptor de glicina & RNS & Especies reactivas del nitrógeno \\
\hline \multirow[t]{2}{*}{ GM-CSF } & Factor estimulante de colonias de granulocitos y & ROCs & Canales operados por receptor \\
\hline & macrófagos & ROS & Productos reactivos del oxígeno \\
\hline $\mathrm{H}_{2} \mathrm{O}_{2}$ & Peróxido de hidrogenó & SEM & Error estándar de la media \\
\hline
\end{tabular}


SMOCs

SOCs

TMA

TNF $\alpha$

TRP

VOCs

VS
Canales operados por segundos mensajeros

Canales operados por el vaciamiento del depósito

Trimetilamina

Factor de necrosis tumoral alfa

Proteína vinculada a los potenciales transitorios del receptor

Canales operados por voltaje

Vesículas secretoras 


\section{CAPÍTULO I}

INTRODUCCIÓN 


\section{EL PROCESO INFLAMATORIO}

\subsection{Respuesta Inmune}

Los agentes infecciosos utilizan un amplio espectro de mecanismos para invadir al organismo huésped. Este a su vez utiliza distintas estrategias para destruir y eliminar a los agentes invasores y a las partículas extrañas evitando al mismo tiempo la destrucción de sus propios tejidos

Todos estos mecanismos de defensa se basan en el reconocimiento de patrones moleculares conservados en el patógeno que lo diferencian del huésped. La discriminación entre el huésped y el agente patógeno es esencial para permitir que el organismo elimine a estos agentes sin sufrir daño (Chaplin, 2006).

La inmunidad innata es la primera respuesta frente a un microorganismo mediante la cual se intenta eliminar la infección o contenerla hasta la aparición o el establecimiento de una respuesta inmune más específica y eficaz, la inmunidad adaptativa. No por ser la primera reacción frente a un patógeno, la inmunidad innata es sencilla o poco desarrollada. Algunos de los componentes de la inmunidad innata participan también en la inmunidad adaptativa. Los mecanismos de la inmunidad innata son inespecíficos: solo son capaces de distinguir estructuras moleculares compartidas por grupos de microorganismos relacionados. Además, la respuesta inmune innata no presenta memoria inmunológica, es decir, reacciona de igual forma e intensidad a exposiciones repetidas del mismo agente o moléculas extrañas.

Los principales componentes de la inmunidad innata son las barreras físicas, químicas y biológicas, las células fagocitícas (macrófagos y neutrófilos), ciertos linfocitos, células asesinas naturales o NK (Natural Killer) y factores solubles que incluyen a los componentes del complemento y a las citoquinas que median la fagocitosis y la inflamación.

Las barreras físicas, químicas y biológicas actúan constantemente, mientras que las células fagocíticas y $\mathrm{NK}$, el complemento o las citoquinas, se activan en presencia de un agente extraño.

En conjunto, los mecanismos innatos representan la respuesta inicial dirigida a la eliminación del agente potencialmente patógeno. Como se ha mencionado, se trata de una respuesta inespecífica, pues el mismo mecanismo actúa frente a diferentes moléculas o agentes extraños. Estos incluyen agentes infecciosos como virus, bacterias, y parásitos, así como otras amenazas generadas por el propio organismo, como son los tumores malignos. También la lesión celular es capaz de producir una movilización de los componentes del sistema inmune innato hacia el sitio del trauma ( $\mathrm{Ni}$ y Redmond, 2006). Normalmente es una respuesta protectora que mantiene la integridad del organismo, sin embargo respuestas inflamatorias disfuncionales pueden dañarlo

\subsection{La Inflamación como Mecanismo de Defensa}

La inflamación es un proceso tisular constituido por una serie de fenómenos moleculares, celulares y vasculares cuya finalidad es proteger al organismo frente a agresiones externas. La respuesta inflamatoria es inmediata, de urgencia y por lo tanto inespecífica, aunque puede favorecer el desarrollo posterior de una respuesta específica. El proceso inflamatorio es una respuesta focalizada que tiende a circunscribir la zona de lucha contra el agente agresor. El foco inflamatorio atrae a las células inmunes de los tejidos cercanos. Las alteraciones vasculares que se producen durante la respuesta 
inflamatoria van a permitir la llegada desde la sangre de moléculas proinflamatorias (Gallin y col., 1988; Male y col., 1991; Roit y col., 1992).

Clásicamente el foco inflamatorio presenta los cuatro signos de Cornelius Celsus (30 AC-38 DC): calor, rubor, tumor y dolor. El calor y rubor se deben a las alteraciones vasculares que determinan una acumulación sanguínea en el foco. El tumor se produce por el edema y acumulo de células inmunes, mientras que el dolor es producido por la acción de mediadores solubles sobre terminaciones nerviosas sensitivas.

\subsection{Fases del Proceso Inflamatorio}

El proceso inflamatorio puede dividirse en cuatro etapas:

\subsubsection{Iniciación}

Esta etapa comienza por la acción de estímulos que provocan la síntesis o liberación de moléculas de bajo peso molecular desde el lugar donde se está orquestando la respuesta inflamatoria. Estas moléculas pueden ser: productos de la degradación de la pared celular bacteriana, toxinas o citoquinas proinflamatorias provenientes de células del sistema inmune o de las células dañadas presentes en el lugar. La tabla I-1 resume las principales señales moleculares de peligro (Bianchi, 2007).

\subsubsection{Alteraciones Vasculares y Efectos Quimiotácticos}

Desde el punto de vista cronológico, los mediadores de la inflamación van a producir básicamente dos efectos. En la fase inicial las alteraciones vasculares producen edema y retienen células en el endotelio. En la segunda fase, más tardía, la liberación en el foco inflamatorio de factores quimiotácticos determina la llegada de células inmunes procedentes de la sangre y de los tejidos circundantes (Gallin y col., 1988; Male y col., 1991; Roit y col., 1992).

Tabla l-1: Señales moleculares de peligro para el sistema inmune.

Patrones moleculares asociados a daño (DAMPs)

\begin{tabular}{lll}
\hline \multicolumn{1}{c}{$\begin{array}{c}\text { Exógenas asociados a } \\
\text { patógenos (PAMPs) }\end{array}$} & \multicolumn{1}{c}{$\begin{array}{c}\text { Endógenas derivados de tejidos } \\
\text { (alarminas) }\end{array}$} \\
\hline LPS (Lipopolisacáridos & HMGB1 (proteína nuclear de & Defensinas \\
bacterianos) & alta movilidad) & Galectinas \\
Ácido lipotéico & HSPs & Timosinas \\
Peptidoglucanos & IL-1 & Nucleolina \\
Variantes de ácidos & Ácido úrico & Anexinas \\
nucleícos & S100s & Catelicidinas \\
normalmente asociado a & HDGF & \\
virus & EDN & \\
\hline
\end{tabular}

\subsubsection{Infiltración y Activación de Células en el Foco Inflamatorio}

Las células activadas provienen en su mayor parte de la sangre, pero también de las zonas cercanas al foco inflamatorio. La tabla I-2 resume sus principales características.

\subsubsection{Resolución del Proceso Inflamatorio y Reparación Tisular}

Cuando las causas de la agresión han desaparecido o han sido eliminadas por la respuesta inflamatoria, se inician los procesos de reparación. Estos procesos involucran la llegada a la zona de fibroblastos que van a proliferar y sintetizar colágeno, la proliferación de células epiteliales y la proliferación de vasos dentro de la lesión (Gallin, 1989; Gallin y col., 1988). 
Tabla I-2: Principales características de las células que intervienen en la respuesta inflamatoria.

\begin{tabular}{|c|c|}
\hline Células & Características \\
\hline $\begin{array}{l}\text { Monocitos y } \\
\text { macrófagos } \\
\text { activados }\end{array}$ & $\begin{array}{l}\text { Fagocitan, liberan proteínas y mediadores proinflamatorios y } \\
\text { complementan la función de los neutrófilos en la fase aguda. }\end{array}$ \\
\hline Eosinófilos & $\begin{array}{l}\text { Participan en la respuesta alérgica frente a alérgenos } \\
\text { respiratorios, gastrointestinales, dermatológicos y a parásitos } \\
\text { helmínticos. }\end{array}$ \\
\hline Plaquetas & $\begin{array}{l}\text { Liberan mediadores inflamatorios, activan neutrófilos, interactúan } \\
\text { con linfocitos aportando reactivos para síntesis prostaglandinas y } \\
\text { participan en la resolución del proceso inflamatorio. }\end{array}$ \\
\hline $\begin{array}{l}\text { Células } \\
\text { endoteliales }\end{array}$ & $\begin{array}{l}\text { Interactúan con los neutrófilos en la migración, sintetizan y } \\
\text { liberan numerosos mediadores inflamatorios. }\end{array}$ \\
\hline Neutrófilos & Fagocitosis y eliminación de patógenos \\
\hline
\end{tabular}

\section{EL NEUTRÓFILO}

\subsection{Características Generales}

Los neutrófilos son el principal subgrupo de leucocitos en sangre periférica y en médula ósea $(\mathrm{MO})$. Se caracterizan por la presencia de un núcleo lobulado y de cuatro tipos diferentes de gránulos citoplasmáticos (Borregaard, 1997, Gullberg y col., 1999). Los gránulos contienen enzimas (elastasa y mieloperoxidasa) y factores antimicrobianos (defensinas, lisozima y lactoferrina) los que contribuyen a hacer de los neutrófilos componentes esenciales de la primera línea de defensa de la inmunidad innata contra virus, bacterias, hongos y patógenos multicelulares.

Los neutrófilos pueden responder a una amplia variedad de señales y son fuente importante de moléculas de señalización (citoquinas, quimoquinas, factores de crecimiento) (Scapini y col., 2000), por lo tanto desempeñan un papel importante en la inflamación, la inmunidad tumoral, el rechazo de trasplantes y los síndromes autoinmunes.

Sin embargo, los mecanismos de defensa utilizados por estas células son potencialmente deletéreos para los tejidos del huésped, por lo cual es importante un adecuado control de su respuesta ante un estímulo inflamatorio para evitar una activación inadecuada y el daño de los tejidos o la inflamación crónica.

\subsection{Ontogenia y Cinética de Formación en el Hombre}

Los neutrófilos se originan a partir de precursores mieloides comunes que dan origen a otros granulocitos (eosinófilos y basófilos), monocitos, macrófagos y células dendríticas (Friedman, 2002).

En los humanos, los neutrófilos están presentes durante el desarrollo fetal, siendo producidos inicialmente en el hígado fetal y luego en la MO (Slayton y col., 1998).

A lo largo de la vida posnatal, los neutrófilos se originan en la $\mathrm{MO}$, donde existe un "pool" mitótico de mieloblastos, promielocitos y mielocitos, y un "pool" posmitótico de metamielocitos, neutrófilos en banda y neutrófilos segmentados maduros (Mary, 1985). El tiempo que permanecen en la $\mathrm{MO}$ desde el estadio de mieloblasto hasta que son liberados como neutrófilos maduros, se estima entre 11 y 14 días. Las células de este linaje constituyen aproximadamente el $65 \%$ de todas las células hemopoyéticas de la MO $\left(19 \times 10^{9}\right.$ células/ $\mathrm{Kg}$ de peso 
corporal) (Dancey y col., 1976) de los cuales $1 / 3$ son premitóticas y $2 / 3$ posmitóticas.

Una vez liberados de la $\mathrm{MO}$, los neutrófilos maduros circulan en la sangre, se marginan o se activan y migran hacia los tejidos donde se están orquestando reacciones inflamatorias.

En condiciones normales, los neutrófilos maduros constituyen entre el 50 y $70 \%$ del total de los leucocitos circulantes $\left(55 \times 10^{6}\right.$ células/ kg de peso corporal en el adulto) (Dancey y col., 1976; Mary, 1984).

En lo que respecta al flujo de neutrófilos entre los diferentes compartimentos, la MO parece ser no sólo el sitio a partir de la cual se originan los neutrófilos maduros, sino también un sitio donde los neutrófilos son aislados (Boxio y col., 2004) y eliminados (Suratt y col., 2001; Martin y col., 2003). Esta función de eliminación de neutrófilos senescentes fue anteriormente atribuida al hígado (Shi y col., 2001). Tal vez en la MO se procesen los neutrófilos no activados, mientras que en el hígado se destruyan preferentemente los neutrófilos que han luchado con agentes patógenos o están activados.

En los neutrófilos circulantes, parece haber una dinámica cruzada entre los que circulan y los que se encuentran marginados (Berkow y Dodson, 1987). Se estima que, en condiciones normales, el número de neutrófilos marginados sería tres veces mayor que el de los circulantes (Gee y Albertine, 1993). Sin embargo, las señales inflamatorias pueden permitir que los neutrófilos marginados recuperen su movilidad y vuelvan a introducirse en el torrente sanguíneo para alcanzar el foco inflamatorio. Los neutrófilos marginados pueden considerarse como una reserva fisiológica de neutrófilos listos para actuar, posiblemente antes de que se movilicen las reservas desde MO (Suwa y col., 2000). Este proceso puede tener importantes inconvenientes. Por ejemplo, el pulmón que es el principal órgano donde se marginan los neutrófilos está sujeto a daños generalizados por la inflamación aguda en sitios remotos. Durante la sepsis se han encontrado lesiones pulmonares en humanos (Fein y Calalang-Colucci, 2000) y en modelos animales (Villa y col., 2002).

\subsection{Apoptosis y Supervivencia}

Los neutrófilos activados pueden sobrevivir varios días en el foco inflamatorio, dependiendo de la producción local de factores de crecimiento (Seely y col., 2003). En contraste, los neutrófilos maduros, no activados, solo permanecen en circulación entre 6 y 9 horas antes de migrar a los tejidos, donde finalmente serán eliminados por apoptosis (Otsby y col., 2003; Kobayashi y col., 2003), un proceso de muerte celular programada que también afecta a los neutrófilos activados que han provocado la muerte de los patógenos y deben ser eliminados del sitio de la infección (Simon, 2003).

Los neutrófilos apoptóticos son eliminados localmente por los macrófagos vecinos o las células epiteliales, y remotamente en MO o en el hígado. En los casos en que la activación se produce de manera descontrolada o cuando los neutrófilos apoptóticos no son fagocitados, estas células pueden sufrir una muerte menos ordenada por un proceso llamado necrosis. Generalmente la apoptosis no es inmunogénica, mientras que la necrosis puede conducir a la inflamación crónica (Simon, 2003). Estudios in vitro han mostrado que los neutrófilos activados expuestos a citoquinas pueden desarrollar nuevas propiedades, adquiriendo un nuevo rol como moduladores de la respuesta inmune. Ellos pueden secretar factores pro-angiogénicos, remodelar la matriz extracelular, desarrollar la capacidad de presentar antígenos (Iking-Konert y col., 2005) o transdiferenciarse a células con características similares a los macrófagos (Araki y col., 2004). 


\section{RESPUESTAS FUNCIONALES}

Los neutrófilos que circulan en la sangre mantienen una estrecha vigilancia del organismo con el fin de detectar señales de peligro provenientes de infecciones, lesiones, o de sustancias extrañas.

Los agentes patógenos liberan en el área infectada una serie de moléculas pequeñas que se dispersan formando un gradiente y alertan al sistema inmunológico de su presencia. Cuando es detectada la presencia de productos microbianos o mediadores de la inflamación, el endotelio vascular sufre modificaciones y los neutrófilos se marginan y se unen a la superficie de los vasos sanguíneos cercanos para emigrar hacia el agente patógeno.

Los neutrófilos responden a una gran variedad de compuestos como: 1) productos bacterianos como el péptido $\mathrm{N}$-formil-metionilfenilalanina (fMLP); 2) productos del metabolismo de lípidos que son liberados de plaquetas activadas, células endoteliales, y leucocitos; 3) factores del complemento activados; y 4) otras moléculas como los complejos inmunes. Estas moléculas se unen a receptores en el neutrófilo y proveen señales para la migración y activación de estas células (Jesaitis, 1988; Burg y Pillinger, 2001).

Cuando los neutrófilos detectan estas señales, se adhieren al endotelio y migran hacia los tejidos donde se encuentra el foco inflamatorio. Una vez allí, los neutrófilos fagocitan al agente agresor y lo destruyen utilizando compuestos citotóxicos producidos o almacenados en su interior como los productos reactivos del oxígeno (ROS), las proteínas hidrolíticas y los pépticos catiónicos (Lee y col., 2003). Bajo las condiciones apropiadas, el agente agresor es destruido dentro de un fagolisosoma, minimizando la exposición de los tejidos sanos a estos compuestos citotóxicos. Los neutrófilos utilizan una serie de mecanismos protectores que reducen el daño oxidativo como la superoxido dismutasa, catalasa y enzimas pertenecientes al ciclo de las hexosa monofosfato.

\subsection{Interacción con el Endotelio y Migración}

Los neutrófilos se unen al endotelio activado y migran a través del tejido hacia el área infectada en un proceso conocido como extravasación. Este proceso, que terminará con la migración de los neutrófilos circulantes de la sangre hacia los tejidos inflamados, puede dividirse en varias etapas (Fig. I-1).

\subsubsection{Rodamiento y Adhesión Laxa}

La interacción inicial de los neutrófilos con el endotelio es un proceso aleatorio, que se incrementa notablemente en los sitios de inflamación o trauma, por una alteración en el flujo sanguíneo local. Cuando los neutrófilos ruedan sobre la pared vascular, la primera interacción con el endotelio se produce a través de moléculas de la familia de las selectinas; la L-selectina se expresa constitutivamente en la membrana de los leucocitos; la P-selectina se encuentra almacenada en el interior de las células endoteliales y las plaquetas, y se expresa en la superficie celular luego de la activación; la E-selectina se sintetiza de novo y se expresa en la membrana de las células endoteliales también cuando éstas han sido activadas; dicha activación para la expresión de las selectinas $\mathrm{P}$ y $\mathrm{E}$ se debe a sustancias como el PAF, la trombina, la histamina, la IL-1, el TNF $\alpha$ y otros mediadores.

Los ligandos de las selectinas son proteínas tipo mucinas que contienen carbohidratos sializados y fucosilados. El proceso de rodamiento de los neutrófilos sirve para poner a estas células en estrecho contacto con el endotelio y para disminuir la velocidad de su paso por las regiones de daño tisular e inflamación. 
Cuando los neutrófilos entran en contacto con el endotelio, la L-selectina interactúa por unos pocos milisegundos con sus ligandos expresados sobre el endotelio (CD34 y otras mucinas sializadas), mientras la P-selectina y la E-selectina hacen lo mismo con las lectinas expresadas en los neutrófilos (Sialil Lewis-X); a estas interacciones transitorias se las denominan adhesión laxa y permite el rodamiento del neutrófilo sobre el endotelio; sin embargo, no son lo suficientemente fuertes como para permitir la adhesión firme de los neutrófilos al endotelio y la transmigración a través de sus células.

\subsubsection{Expresión de Receptores de Membrana y Adhesión Firme}

En el proceso de rodamiento, los neutrófilos interactúan con sustancias activadoras secretadas por el endotelio y los tejidos subyacentes (citoquinas, derivados de la coagulación y el complemento) depositadas en el glicocálix de las células endoteliales. Los neutrófilos tienen en su superficie receptores de alta afinidad para estos factores activadores (en su mayoría receptores para agentes quimiotácticos, del tipo proteínas de siete pasos transmembrana acoplados a proteína G); como parte de las respuestas a esta activación, las cadenas de las $\beta 2$ integrinas leucocitarias que estaban dispersas en la membrana se agrupan en la zona de contacto con el endotelio y forman dímeros funcionalmente activos.

La adhesión firme, que detiene por completo el movimiento de los neutrófilos, se origina por la formación de uniones tipo ligandoreceptor fuertes y estables entre moléculas de la superfamilia de las inmunoglobulinas (ICAM-1, ICAM-2) expresadas en el endotelio activado y las $\beta 2$ integrinas (LFA-1, MAC-1 y p150,95) expresadas en los neutrófilos.

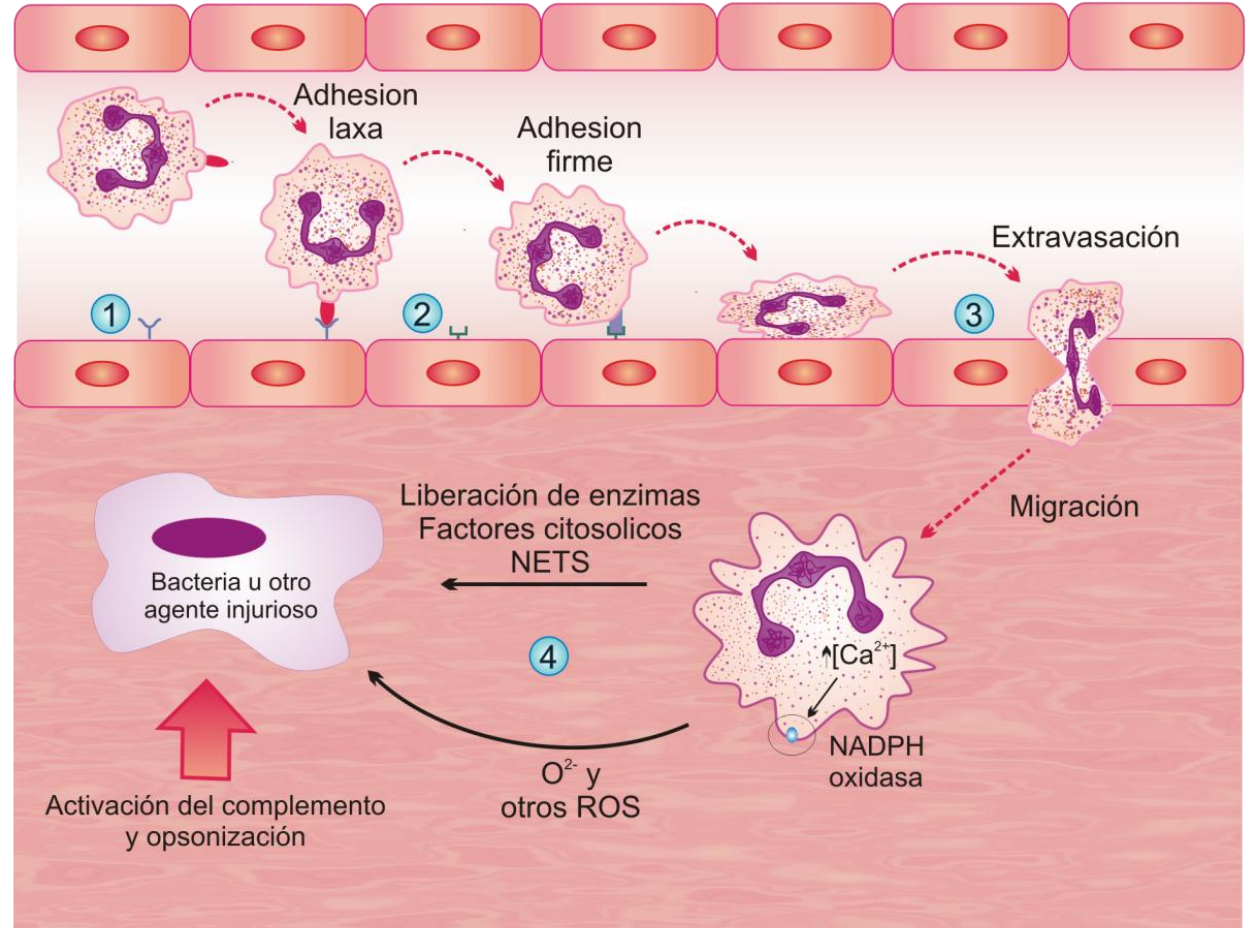

Figura l-1: Esquema de los múltiples pasos en el reclutamiento de los neutrófilos a los sitios de inflamación. 1. Rodamiento y adhesión laxa de los neutrófilos al endotelio activado mediada por selectinas. 2. Dimerización de integrinas y adhesión firme. 3. Transmigración endotelial y quimiotaxis. 4. Fagocitosis y acción microbicida

ICAM-1 se expresa en el endotelio luego de su activación, mientras que ICAM-2 es de expresión constitutiva en estas células.

MAC-1 está además involucrada en el proceso de transmigración endotelial y quimiotaxis por su interacción con moléculas del intersticio y de la matriz extracelular. 


\subsubsection{Transmigración Endotelial y Quimiotaxis}

El paso de los neutrófilos a través de los espacios intercelulares también se lleva a cabo por interacciones entre integrinas y moléculas de la superfamilia de las inmunoglobulinas. Las moléculas de adhesión más fuertemente involucradas en este proceso son MAC-1 (CD11b/CD18) y PECAM-1 (CD31).

La quimiotaxis es la migración dirigida de las células inducida por un estímulo químico. Cuando los receptores de la superficie celular del neutrófilo detectan un gradiente de concentración de un agente quimiotáctico la célula se polariza. La polarización resulta en la formación de un seudópodo que se dirige hacia la fuente del agente quimiotáctico. El mecanismo por el que se genera el movimiento involucra un control complejo del citoesqueleto y de la membrana celular para coordinar la extensión y la contracción de la célula (Van Haastert y Devreotes, 2004).

Los factores quimiotácticos pueden ser de origen exógeno o endógeno. Los exógenos incluyen oligopéptidos bacterianos (como el fMLP), lectinas, proteínas desnaturalizadas, lípidos y algunos lipopolisacáridos. Los endógenos son producidos por el organismo y pueden ser de origen humoral (fragmento C5a del complemento, fibrinopéptidos, kalicreína y activador del plasminógeno) o celular (citoquinas).

La interacción entre el factor quimiotáctico y su receptor desencadena una serie coordinada de eventos bioquímicos que incluyen cambios en el potencial transmembrana, alteración de los niveles de nucleótidos cíclicos, flujo de iones a través de la membrana plasmática, aumento en la utilización de la glucosa y del consumo de oxígeno. La composición fosfolípidica de la membrana se altera y el ácido araquidónico (AA) se metaboliza, dando origen a una serie de compuestos biológicamente activos y productos intermedios.

\subsection{Fagocitosis y Acción Microbicida}

La función primaria de los neutrófilos es llevada a cabo a través de una serie de respuestas rápidas y coordinadas que terminan con la fagocitosis y aniquilamiento de los patógenos (Nathan, 2002).

Los receptores de los neutrófilos reconocen moléculas que se encuentran en los agentes patógenos. Los receptores de Fc y C3b se unen a immunoglobinas y a moléculas de $\mathrm{C} 3 \mathrm{~b}$, respectivamente, que actúan como opsoninas, cubriendo a las partículas extrañas para que puedan ser reconocidas por las células del sistema inmune. Las partículas son reconocidas e incorporadas a un fagosoma donde van a ser destruidas por distintos procesos químicos y enzimáticos. Los agentes patógenos fagocitados pueden ser eliminados por dos procesos distintos pero relacionados que son los mecanismos dependientes y los independientes del oxígeno. Adicionalmente, se han descriptos nuevos mecanismos que utilizan los neutrófilos como estrategias para eliminar agentes patógenos.

\subsubsection{Mecanismos Efectores Dependientes del Oxígeno}

Los neutrófilos contienen un potente arsenal de mecanismos antimicrobianos que incluyen proteinasas y péptidos catiónicos. Además, ellos producen grandes cantidades de ROS y de especies reactivas del nitrógeno (RNS) a través de la actividad de sistemas generadores de sustancias oxidantes como la NADPH oxidasa (Sheppard, 2005) y la oxido nítrico sintetasa (Gebska y col., 2005). Durante la ingestión de patógenos, los ROS generados en la membrana son liberados dentro del fagosoma, donde se combinan rápidamente con proteínas y lípidos, oxidándolos. También pueden ser liberados en el citosol donde alteran el estado redox de la célula y oxidan componentes celulares modificando su función. Bajo condiciones patológicas, los ROS son liberados al medio extracelular, 
donde pueden ser responsables de la injuria producida a los tejidos durante las reacciones inflamatorias disfuncionales (Lee y col., 2001; Moraes y col., 2006).

\section{NADPH Oxidasa}

La NADPH oxidasa es un complejo multi-enzimático que se encuentra inactivo en las células en reposo y puede ser rápidamente activado por una amplia variedad de mediadores solubles (péptidos quimiotácticos y citoquinas) y estímulos particulados (bacterias y complejos inmunes) cuando interactúan con receptores de membrana Cuando esta enzima se activa genera una gran cantidad de ROS utilizando NADPH como donor de electrones y convirtiendo al oxígeno molecular en anión superóxido $\left(\mathrm{O}_{2}{ }^{-}\right)$(Babior y col., 2002; Lamberth, 2004)

$$
\mathrm{NADPH}+\mathrm{H}^{+}+2 \mathrm{O}_{2} \longrightarrow \mathrm{NADP}^{+}+2 \mathrm{H}^{+}+2 \mathrm{O}_{2}^{-}
$$

El peróxido de hidrogeno $\left(\mathrm{H}_{2} \mathrm{O}_{2}\right)$ se produce la dismutaciòn del superóxido catalizada por la superóxido dismutasa:

$$
2 \mathrm{O}_{2}^{-}+2 \mathrm{H}^{+} \longrightarrow \mathrm{H}_{2} \mathrm{O}_{2}+\mathrm{O}_{2}
$$

Entre otros ROS, se producen a partir de éstos el radical hidroxilo $(\mathrm{OH})$ y el ácido hipocloroso.

Mientras la NADPH oxidasa se encuentra inactiva, está desensamblada y sus componentes se encuentran distribuidos entre la membrana y el citosol de la célula. Los componentes que se encuentran en la membrana celular incluyen al citocromo $b_{558}$, una flavoproteína heterodimérica, compuesta por dos subunidades: gp9 $1^{\text {phox }}$ y $\mathrm{p} 22^{\text {phox }}$. Los componentes citosólicos incluyen cuatro factores solubles: $\mathrm{p} 67^{\text {phox }}, \mathrm{p} 47^{\text {phox }}, \mathrm{p} 40^{\text {phox }}$ y la proteína $\mathrm{G}$ pequeña Rac 2 (Bedard y Krause, 2007).

Diversos mediadores inflamatorios inducen la traslocación de los componentes citosólicos de la NADPH oxidasa a la membrana plasmática o a la del fagosoma, donde se unen a los componentes que se encuentran en la membrana iniciando la reducción de NADPH a $\mathrm{NADP}^{+}$y la generación de dos electrones, que fluyen al otro lado de la membrana y generan el $\mathrm{O}_{2}^{-}$(Clark, 1990; Babior, 1982), a partir del cual se producen otros productos con actividad bactericida como el $\mathrm{H}_{2} \mathrm{O}_{2}$.

La cantidad de anión superóxido que se produce puede aumentar en respuesta a un segundo estímulo activante cuando la NADPH oxidasa se ensambla completamente luego de un cebado previo (priming) (El-Benna y col., 2008). Los agentes cebadores no causan la activación de la oxidasa, pero por diferentes vías inducen modificaciones en componentes de la enzima facilitando su ensamblado y activación ante un estímulo subsiguiente.

\subsubsection{Mecanismos Efectores Independientes del Oxígeno}

Los neutrófilos contienen una gran variedad de moléculas activas, que se encuentran preformadas y almacenadas en su citoplasma, de manera tal que puedan ser utilizadas cuando es necesario, de manera rápida y finamente controlada. Estos mediadores activos se pueden encontrar: (1) pre-envasados en forma de gránulos, (2) en ectosomas o micropartículas, (3) libres en el citosol.

\section{Gránulos}

Las vesículas secretoras (VS) y los gránulos de los neutrófilos se generan durante la diferenciación celular. Su función no solo es almacenar proteínas bactericidas o proteolíticas, sino que también son importantes reservorios de proteínas de membrana, las que se incorporan en la superficie celular de los neutrófilos cuando los gránulos se funden con la membrana plasmática y exocitan su contenido (Borregaard y col., 1983; Todd y col., 1984). De este modo, 
los gránulos y VS pueden transformar radicalmente la capacidad de los neutrófilos para interactuar con su medio ambiente.

Los gránulos se pueden dividir en cuatro tipos principales de acuerdo con su función y con el contenido de enzimas en: VS, gránulos primarios o azurófilos, secundarios o específicos y terciarios o de gelatinasa.

Las VS son fácilmente movilizadas, se fusionan con la membrana plasmática durante el cebado o preactivación y sirven como un reservorio de receptores. Se movilizan cuando los neutrófilos establecen contacto con el endotelio activado a través de la interacción mediada por selectinas (Waddell y col., 1994; Crockett-Torabi y Fantone, 1995) o por mediadores inflamatorios liberados por el endotelio (Jeannin y col., 1994; Patel y col., 1994). Es más, se ha observado que las VS han sido completamente movilizadas en neutrófilos que se recogen en el exudado de una cavidad (Sengeløv y col., 1995). Por lo tanto, la movilización de VS transforma a los neutrófilos en células que contienen $\beta 2$-integrinas (Joiner y col., 1989; Borregaard y col., 1994) en su membrana y de esta manera cambia de una célula circulante pasiva a una célula altamente sensible, preparada para la migración (Zheng y col., 1996).

Los gránulos terciarios o de gelatinasa son morfológicamente similares a los específicos de los que se diferencian por su densidad levemente menor; contienen hidrolasas ácidas, gelatinasa y glicoproteínas de adherencia (Dewald y col., 1982). Se movilizan hacia la superficie celular en respuesta a estímulos leves (Petrequin y col., 1987).

Es probable que la exocitosis de gránulos de gelatinasa sea indispensable para la migración de los neutrófilos a través de las membranas basales (Delclaux y col., 1996). Son substratos de la gelatinasa el colágeno tipo IV, uno de los constituyentes principales de la membrana basal, y el tipo $\mathrm{V}$ presente en el espacio intersticial de los tejidos (Murphy y col., 1989; Hibbs y col., 1985; Murphy y col., 1982). Experimentos in vitro apoyan la necesidad de la actividad gelatinasa en la migración de neutrófilos a través de membrana amniótica y de las membranas Matrigel (Bakowski y Tschesche, 1992).

Los gránulos secundarios o específicos se sintetizan durante el estadio de mielocito. Contienen lisozima, lactoferrina, proteína fijadora de la vitamina B12, un alto porcentaje de los componentes del complejo enzimático de la NADPH oxidasa, fosfolipasa $\mathrm{A} 2$, factor quimiotáctico para monocitos, activadores del complemento y del plasminógeno. Además, en su membrana hay receptores para el C3bi (C3b inactivado), fMLP, laminina y otras moléculas involucradas en la adherencia y la quimiotaxis. La liberación de los gránulos específicos es crucial para el inicio de la respuesta inflamatoria (Gallin, 1984), por lo que durante la activación celular, son movilizados rápidamente y liberan su contenido al medio extracelular.

Las membranas de los gránulos específicos y de gelatinasa son las principales fuentes de Mac-1 (CD11b/CD18) y del flavocitocromo $b_{558}$ (gp91phox/p22phox) (Kjeldsen y col., 1994; Bainton y col., 1987, Jesaitis y col., 1990).

Los gránulos primarios aparecen durante el estadio de promielocito y comprenden un tercio de todos los gránulos. Contienen: mieloperoxidasa (MPO), proteínas catiónicas (defensinas, catepsina $\mathrm{G}$ ), proteínas bactericidas que incrementan la permeabilidad celular, proteasas neutras (elastasa, colagenasa), hidrolasas ácidas y lisozima (Root y Cohen, 1981), entre otras. Estos gránulos tienen una función predominantemente intracelular (en la vacuola fagolisosomal o fagosoma), ya que están involucrados en la eliminación y en la degradación de los microorganismos (Baggiolini, 1972; Spitznagel y Chi, 1963; Welsh y Spitznagel, 1971; Cohn y Hirsch, 1960). La MPO es 
una enzima crítica en la conversión de $\mathrm{H}_{2} \mathrm{O}_{2}$ a ácido hipocloroso, que es muy importante para la eliminación de los microorganismos.

La movilización de los gránulos se produce durante la activación y depende de una gran variedad de factores, como: la disponibilidad de ATP, la activación de canales iónicos, la producción de ROS, las interacciones electrostáticas, cambios en el $\mathrm{pH}$ intracelular y reordenamientos del citoesqueleto (Reeves y col., 2002; Grinstein y col., 1982; Ahluwalia y col., 2004).

En base a lo observado en ratones knock-out para elastasa y catepsina G (Tkalcevic y col., 2000), en los pacientes que sufren del síndrome de Chediak-Higashi (deficiencia de gránulos primarios) y con polimorfismos de MPO (Winterbourn y col., 2000), se ha postulado que los oxidantes generados por la NADPH oxidasa y MPO no tienen actividad microbicida significativa, sino que desempeñan una función mecánica en la liberación de proteasas catiónicas, que serian los verdaderos efectores. Este nuevo punto de vista es actualmente objeto de un intenso debate.

\section{Ectosomas o micropartículas}

Durante la activación, los neutrófilos liberan potentes agentes antimicrobianos a través de la degranulación. Simultáneamente, los neutrófilos liberan micropartículas (vesículas cubiertas por una membrana que son exocitadas durante la activación o la apoptosis) llamadas ectosomas. Estas micropartículas tienen un diámetro de entre 50 y $200 \mathrm{~nm}$ y exponen fosfatidilserina en su cara externa (Hess y col., 1999; Gasser y col., 2003)

No se conoce mucho de su papel fisiológico, sin embargo los resultados obtenidos in vitro sugieren que pueden interactuar y modular la función de las células endoteliales cercanas (Mesri y Altieri, 1998) y los monocitos (Gasser y Schifferli, 2004). Además, podrían participar en reacciones antimicrobianas, recapturando en su superficie las proteasas secretadas y la MPO, esta recaptura se ha visto en la superficie de los neutrófilos.

\section{Factores citosólicos}

Muchos factores citosólicos importantes son liberados por los neutrófilos incluyendo citoquinas, quimiocinas y factores de crecimiento, que desempeñan un importante papel en la regulación autocrina, paracrina y sistémica del sistema inmune.

Numerosos factores citosólicos se encuentran en los tejidos inflamados, líquido intersticial y en el plasma. Un ejemplo notable es el de las proteínas fijadoras del calcio S100A8 y S100A9 (Donato, 2001). Estas proteínas representan el $40 \%$ de todas las proteínas libres en el citosol de los neutrófilos y pueden formar homo o heterodímeros (Nacken y col., 2003). Estas proteínas participan en la movilización del AA hacia la NADPH oxidasa, para promover su activación completa (Berthier y col., 2003). Sin embargo existen homo y heterodímeros S100A8 y S100A9 extracelulares, que facilitan la absorción de AA por las células endoteliales (Kerkhoff y col., 2001) y la quimiotaxis (Roth y col., 2003); también tienen actividad antimicrobiana (Brandzaeg y col., 1995) e inducen apoptosis en fibroblastos y células tumorales (Yui y col., 2003)

NETS

Otro mecanismo no oxidativo que ha sido descripto recientemente es la formación de redes o NETs (del inglés "Neutrophil Extracellular Tramps") (Brinkmann y col., 2004).

Son estructuras extracelulares, excretadas por los neutrófilos, y cuya función es atrapar a las bacterias en una red de ADN y proteínas de unión. Las bacterias atrapadas en las NETs son expuestas a una 
alta concentración de agentes citotóxicos. Se ha demostrado que las histonas tienen propiedades bactericidas (Patat y col., 2004), y están presente en las NETs. Tanto las bacterias Gram positivas como las negativas son sensibles a las NETs. El examen de secciones de tejido obtenidas de pacientes con apendicitis mostró la presencia de NETs, lo que sugiere que éste es un mecanismo inmunológico fisiológicamente relevante (Brinkmann y col., 2004).

\subsection{Grados de Activación}

Una importante característica de los neutrófilos es la existencia del fenómeno de preactivación, cebado o "priming". Los neutrófilos maduros pueden estar inactivos (quiescentes), preactivados (primed) o completamente activados. Los neutrófilos quiescentes son aquellos que permanecen en circulación o forman parte del "pool" marginal, sin tener contacto con alguna sustancia que provoque su activación.

Las vías de señalización en los neutrófilos son complejas y pueden ser iniciadas por diferentes estímulos que comparten los últimos pasos de estas cascadas. Cuando los neutrófilos son estimulados por ciertos agentes, pueden quedar en una condición tal que desarrollan una respuesta mucho mayor a un segundo estímulo. Es decir, en el estado de preactivación la respuesta de los neutrófilos a un estímulo es potenciada por la exposición previa a un agente cebador. Los neutrófilos circulantes normalmente no expresan toda su capacidad microbicida cuando son activados por agentes como el tetrapéptido bacteriano: fMLP, a menos que hayan sido previamente preactivados. Después del cebado, la producción de especies reactivas del oxígeno generadas en respuesta a un agonista puede ser 20 veces mayor (Guthrie y col., 1984). Lo mismo ocurre con la dégranulación (Fittschen y col., 1988) y la generación de mediadores de lipídicos como el AA, el leucotrieno B4 (LTB4) y el factor activante de plaquetas
(PAF) (Doerfler y col., 1989; Doerfler y col., 1994). También se ha descripto un incremento en la fagocitosis, en la eliminación de bacterias y la expresión de receptores para fMLP, CR1 y CR3.

El fenómeno de "priming" es reversible y las células pueden ser "re-primed". En cambio los neutrófilos activados sufren cambios irreversibles y la célula no puede volver a su estado inactivo.

Los agentes cebadores deben ser presentados a la célula por un período de tiempo determinado antes de que la célula sea expuesta al estímulo activante. Los cambios promovidos por el cebado se desarrollan a distintos tiempos dependiendo del agente utilizado, que pueden ser desde segundos, por ejemplo para el ATP, a más de una hora para el LPS o el interferón gamma, lo que sugiere que los mecanismos involucrados pueden ser diferentes. En general, la preactivación no altera los niveles de calcio intracelular pero puede inducir la fosforilación de residuos de tirosina en moléculas de señalización. Algunos agentes preactivadores como el G-CSF y GMCSF inician procesos de transcripción y traducción de receptores de superficie y moléculas efectoras, pero la mayoría de los preactivadores no son afectados por la inhibición de la biosíntesis de macromoléculas e involucrarian la traslocación de receptores y de moléculas de citocromo $\mathrm{b}$ desde los gránulos citosólicos hacia la membrana.

Es posible que el proceso fisiológico de preactivación comience con la extravasación dado que la adhesión y transmigración son iniciadas por estímulos que inducen el "priming" de las respuestas citotóxicas como las inducidas por el TNF $\alpha$ e IL-1. La preactivación puede ser considerada como un mecanismo de control para focalizar la respuesta citotóxica de los neutrófilos al sitio donde se ha orquestado la repuesta inflamatoria. Los neutrófilos quiescentes serían sensibilizados durante el proceso de transmigración endotelial y de 
esta forma podrían responder localmente a bajas concentraciones de estimulantes directos como los péptidos formilados.

\section{CONTROL DE LA RESPUESTA FUNCIONAL}

La respuesta de los neutrófilos está controlada por varios tipos de receptores de membrana: 1) receptores de un solo dominio transmembrana que reconocen TNF $\alpha$, G-CSF, GM-CSF; 2) los receptores $\mathrm{FcR}$ que reconocen el componente $\mathrm{Fc}$ de los complejos inmunes; 3 ) los receptores $C R$ que reconocen complejos complementopatógeno (CR1) y también ICAM-1 celular (CR3, o $\beta 2$ integrina o $\mathrm{CD} 11 \mathrm{~b} / \mathrm{CD} 18)$; 4) los receptores de 7 dominios transmembrana que reconocen fMLP, C5a, PAF, LTB4 y IL-8.

\subsection{Receptores de Formil Péptidos}

El péptido bacteriano fMLP es el principal factor quimiotáctico producido por Escherichia coli (Marasco y col., 1984). El fMLP interacciona con un receptor que se encuentra en la membrana de los neutrófilos, está acoplado a una proteína $G$ y se caracteriza por presentar siete dominios transmembrana hidrofóbicos conectados por dominios hidrofílicos (Liu y col., 2004).

Se han clonado y caracterizado dos isoformas del receptor que se denominan receptor de formil péptidos (FPR) y receptor de formil péptidos 1 (FPR1), a los cuales se une el fMLP con alta y baja afinidad, respectivamente (Paclet y col., 2004). Los dos receptores tienen la misma distribución subcelular y están localizados en mayor proporción en los gránulos secundarios y terciarios que se traslocan a la superficie celular durante el cebado y la activación (Faurschou y Borregaard, 2003).

\subsection{Desensibilización de Receptores: Papel del Citoesqueleto}

Cuando los neutrófilos son expuestos a concentraciones crecientes de un agente quimiotáctico, gradualmente dejan de responder a ese estímulo. Este proceso es conocido como desensibilización homóloga (Ali y col., 1999), y es importante ya que limita o finaliza la respuesta a altas concentraciones del agente activante, impidiendo una respuesta prolongada. Cuando las células pierden la capacidad de responder al agonista para FPR o FPR1, también dejan de responder a una segunda estimulación con IL-8 o $\mathrm{PAF}$, lo cual sugiere que existe una conexión entre estos receptores (Fu y col., 2004; Heit y col., 2002).

La desensibilización del receptor es un proceso finamente regulado, y el mecanismo depende del tipo de receptor y del tipo de desensibilización. En el caso del FPR y FPR1, la unión de los receptores al citoesqueleto sería el mecanismo más importante, pero no el único (Bylund y col., 2003).

La importancia del citoesqueleto de actina en la regulación de procesos celulares se pone en evidencia cuando éste es disgregado ya que se inhiben procesos celulares como la locomoción, la fagocitosis y al mismo tiempo se facilita la secreción de los gránulos (Howard y Watts, 1994). La regulación de la remodelación del citoesqueleto se produce por múltiples mecanismos que involucran proteínas unidoras y reguladoras relacionadas con la actina, segundos mensajeros, GTPasas monoméricas, así como la formación y degradación de lípidos de fosfatidilinositol (Carlier, 1998).

Las citocalasinas son un grupo de productos derivados de hongos, los cuales se unen a la porción terminal del filamento de actina y previenen su polimerización (Maruyama y col., 1980). El tratamiento de los neutrófilos con citocalasina aumenta la producción de superóxido inducida por el fMLP. Contrariamente, el aumento de la 
respuesta oxidativa inducida por forbol-12 miristato-13 acetato (PMA), un activador de la proteína quinasa C (PKC) que esquiva al receptor, no es afectada por la presencia de citocalasina (Fu y col., 2004; Jesaitis. y col., 1986). Esto sugiere una relación entre el citoesqueleto, la desensibilización del FPR y la finalización de la actividad de la NADPH oxidasa.

La desensibilización del FPR dependiente del citoesqueleto consiste en la finalización de la señal cuando el complejo ligandoreceptor se une al citoesqueleto. Esta asociación del complejo ligandoreceptor al citoesqueleto segrega al receptor desde la proteína $G$ a diferentes dominios de la membrana (Klotz y Jesaitis, 1994).

El receptor desensibilizado puede ser reactivado para inducir la producción de ROS por tratamiento con un disruptor del citoesqueleto como la citocalasina B (CitB) (Fu y col., 2004; Bylund y col., 2003).

\subsection{Control de las Cascadas Intracelulares}

\subsubsection{Fospolipasa $C$}

Cuando el fMLP se une a su receptor, éste sufre un cambio conformacional e interacciona con la proteína $G_{i}$ que se activa intercambiando el GDP unido a la subunidad $\alpha$ por GTP y se disocian las subunidades $\beta \gamma$. La proteína $G$ activa inicia varias rutas de señalización intracelulares en neutrófilos (Niggli, 2003); la vía de la PLC $\beta$ provoca la hidrólisis de fosfatidilinositol bifosfato dando lugar a la formación de diacilglicerol (DAG) (activador de la PKC) e inositoltrifosfato $\left(\mathrm{IP}_{3}\right)$ que induce la liberación de calcio desde los depósitos intracelulares.

\subsection{2. $\mathrm{Pl}_{3}$ quinasa}

La PI3K $\gamma$ se activa cuando un ligando se une al FPR. Esta enzima es responsable de la conversión de fosfoinositol 4,5-bifosfato en inositol-3,4,5- trifosfato, el que regula la localización y posiblemente la estabilización de los filamentos de actina, aunque no se ha demostrado que intervenga en la polimerización de los filamentos.

\subsubsection{GTPasas monoméricas}

Estas proteínas se clasifican estructuralmente en 5 familias: Ras, Rho, Arf, Rab y Ran (Takai y col., 2001), las cuales se unen a GTP en su forma a activa y a GDP cuando están inactivas. Participan en la regulación de procesos celulares de supervivencia, regulación transcripcional, y tránsito de vesículas (Ridley, 2001). En general, Ras regula procesos de señalización celular en los cuales se producen modificaciones en la transcripción génica; Rho actúa como modulador en la reorganización del citoesqueleto, adhesión reversible y en la migración inducida por agentes quimiotácticos en neutrófilos; Rab y Arf controlan la formación, fusión y movimiento de vesículas entre distintos compartimentos celulares; y Ran está involucrada en la reorganización de los microtúbulos y transporte de proteínas nucleares.

\subsubsection{MAP quinasas}

La cascada MAP quinasa (MAPK) es un sistema de señalización intracelular ampliamente conservado en eucariotas que consiste en tres módulos paralelos de quinasas, compuestos a su vez de distintas quinasas que actúan en cascada y son las encargadas de transmitir al núcleo de las células en estado quiescente la información necesaria para iniciar el proceso de división celular. La relación de esta cascada con la reacción inflamatoria se debe a que tanto las citoquinas pro-inflamatorias, TNF $\alpha$ e IL-1, como fenómenos pro-inflamatorios como el shock térmico, la hiperosmolaridad o la radiación ultravioleta, son potentes activadores de alguno de los módulos de esta cascada. Los módulos de la cascada de las MAPK son el módulo ERK 1/2, el 
módulo JNK y el módulo p38. El módulo ERK 1/2 se activa cuando ligandos específicos ocupan receptores con actividad tirosin quinasa o de la familia de siete dominios transmembrana, mientras que los módulos JNK y p38 se activan preferentemente por citoquinas proinflamatorias y estrés ambiental (Irving y Bamford, 2002).

\subsubsection{Otras Vías de Señalización}

Otros efectores intracelulares acoplados al FPR incluyen a la fosfolipasa $A$ y $D$, y fosforilaciones mediadas por tirosin quinasas (Niggli, 2003). También se ha descripto la interacción directa entre el FPR, a través de la subunidad $\beta \gamma$ de la proteína $G_{i}$, y la adenilato ciclasa tipo II con un aumento transitorio del AMPc (Ferretti y col., 1994).

\subsection{Control de la Concentración de Calcio Intracelular}

El ion calcio es uno de los mensajeros intracelulares más importantes ya que interviene en una amplia variedad de procesos como la contracción, la trascripción de genes y el crecimiento celular (Berridge y col., 2000). En los neutrófilos se ha visto que el calcio está implicado en varias funciones celulares como activación, adhesión, cambios morfológicos y polarización, extravasación, quimiotaxis, fagocitosis, activación de la NADPH oxidasa y apoptosis (Tintinger y col., 2005).

La señal mediada por calcio implica un aumento en la concentración del calcio libre en el citosol $\left(\left[\mathrm{Ca}^{2+}\right]_{i}\right)$. Esta señal tiene dos componentes: la movilización de calcio de depósitos intracelulares y la entrada del medio extracelular a través de canales iónicos (Fig. I-2) (Rink y Sage, 1990; Parekh y Penner, 1997).

Luego del aumento en la $\left[\mathrm{Ca}^{2+}\right]_{i}$ inducido por agonistas, este ion debe volver a su concentración inicial. La expulsión del calcio del citoplasma es llevado a cabo por una serie de bombas e intercambiadores que reintroducen el calcio en los depósitos o lo sacan de la célula (Rosado y col., 2006), para mantener una baja concentración de este ion en el citosol cuando la célula está en reposo.

\subsubsection{Movilización de Calcio de los Depósitos Intracelulares}

Luego de la estimulación de los receptores de la membrana celular se produce un aumento inicial de la $\left[\mathrm{Ca}^{2+}\right]_{i}$ por el vaciamiento de los depósitos intracelulares. La vía clásica implica la unión de un ligando a un receptor de membrana, activación de la PLC, generación de $\mathrm{IP}_{3}$, unión a receptores para $\mathrm{IP}_{3}\left(\mathrm{IP}_{3} \mathrm{R}\right)$ y liberación de calcio de los depósitos intracelulares (Streb y col., 1983; Berridge, 1993). Una vía alternativa para la movilización del calcio desde el reservorio podría ser la activación de la esfingosina quinasa (Itagaki y Hauser, 2003).

\subsubsection{Ingreso de Calcio a través de la Membrana Plasmática}

La liberación de calcio de los depósitos intracelulares es a menudo insuficiente para lograr una activación completa de los procesos celulares. Por ejemplo, cuando se bloquean los canales por los que ingresa el calcio a la célula, se inhibe la activación de las $\beta 2$ integrinas (Schaff y col., 2008).

Los cationes di y trivalentes suprimen la producción de superóxido en el mismo orden $(\mathrm{Zn}>>\mathrm{Sr}=\mathrm{Cd}>\mathrm{Ba}>\mathrm{Co}>\mathrm{Ni}=\mathrm{Mg})$ que reducen la entrada del trazador $\mathrm{Ca}^{45}$ indicando una relación entre los flujos de calcio y la producción ROS.

En las células excitables, como neuronas, células musculares y algunas glándulas, la entrada de calcio ocurre a través de canales operados por voltaje, mientras que en las células no excitables la entrada de calcio ocurre principalmente a través de canales operados por interacción directa de la proteína que lo forma con agonistas 
extracelulares o segundos mensajeros formados por cascadas de señalización o por el vaciamiento del depósito.

El rellenado de los depósitos intracelulares luego de su vaciamiento también necesita de la entrada de calcio desde el medio extracelular para reponer lo que fue expulsado por las bombas de la membrana plasmática y mantener la capacidad de generar señales de calcio (Rosado y col., 2006).

El principal mecanismo de entrada de calcio en células no excitables es la entrada capacitativa inducida por el vaciamiento de los depósitos intracelulares (Morales y col., 2005). Esta entrada es regulada por el grado de vaciamiento de los depósitos intracelulares, aunque todavía no está claro cómo el vaciamiento de los depósitos es comunicado a la membrana para inducir la apertura de canales de calcio. Se ha propuesto que entre ambas estructuras se produciría la difusión de un mensajero soluble (Berridge, 1995), o una interacción transitoria (Rosado y col. 2000) o una vinculación estructural permanente (Irvine, 1990). Se ha mostrado que la esfingosina 1 fosfato vincula la depleción del reservorio a la entrada de calcio en neutrófilos actuando como un mediador soluble (Itagaki y Hauser, 2003).

La entrada capacitativa de calcio también puede ser activada por el vaciamiento pasivo del reservorio con tapsigargina, un sesquiterpeno derivado de Tapsia garganica (Putney, 2007). El correlato electrofisiológico de la entrada de calcio accionada por reservorio es la existencia de una corriente despolarizante activada por la liberación del calcio almacenado ( $I_{c r a c}$, del inglés "calcium release activated current"). Esta conductancia se encontró en células que expresan homólogos de la proteína TRP (del inglés "transient receptor potentials") descubierta en la Drosofila melanogaster. Se cree que las proteínas TRP podrían estar formando parte de canales de calcio metabotrópicos u operados por segundos mensajeros y así censarían

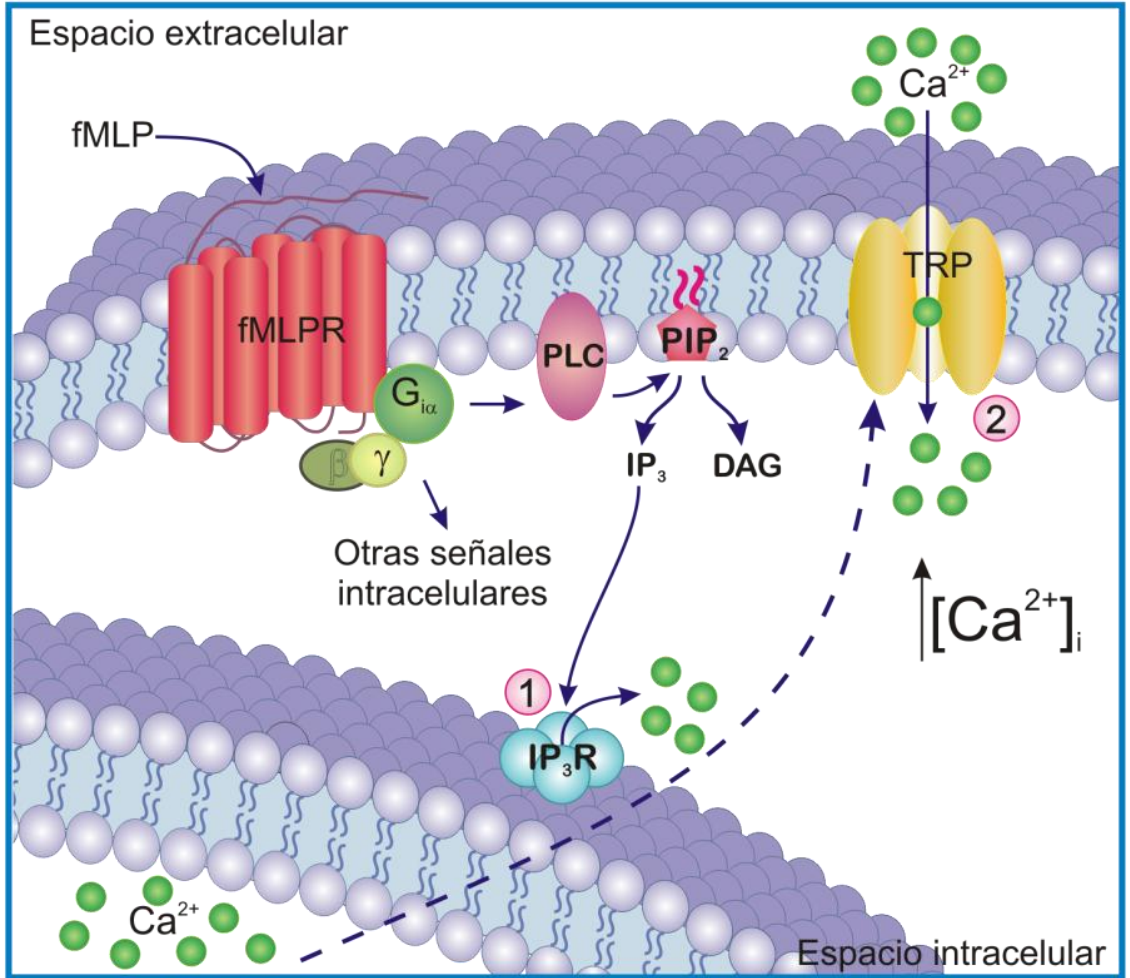

Figura l-2: Aumento en la concentración de calcio intracelular mediada por la activación del receptor de fMLP. 1. Liberación de calcio desde los depósitos intracelulares, 2. Entrada capacitativa de calcio.

estímulos del medio extracelular o intracelular (Claphan, 2003). Forman subunidades proteicas que se ensamblan en tetrámeros para formar canales catiónicos inespecíficos. Estudios estructurales sobre la base de homología, llevaron a subdividir los TRPs en siete subfamilias: canónica (TRPC), vaniloide (TRPV), melastatina (TRPM), policistina (TRPP), mucolipina (TRPML), anquirina (TRPA) y NOMP (TRPN) (Montell, 2005; Nilus y Voets, 2005; Pedersen y col., 2005; Owsianik y 
col., 2006; Nilius, 2007). Recientemente se ha vinculado las proteínas TRP como mediadoras de la entrada capacitativa de calcio en tejidos humanos (Kohler y col., 2001; Nilius y col., 2001; Vazquez y col., 2001; Lockwich y col., 2000; Lockwich y col., 2001; Den Dekker y col., 2001). En neutrófilos, se han encontrado 4 proteínas TRP distintas lo que justificaría que la entrada de calcio refleje la contribución de múltiples vías reguladas independientemente (Itagaki y col., 2002).

La entrada de calcio se puede producir también por mecanismos no capacitativos. EI DAG, un producto del desdoblamiento de fosfatidilinositol-4,5-bifosfato producido por PLC, modula un canal de calcio no selectivo formado por TRPC6 (Hofmann y col., 1999, Lemonnier y col., 2008). Recientemente, se ha demostrado en neutrófilos humanos la expresión del ARNm para TRPC6 (Heiner y col., 2003, Itagaki y col., 2004, McMeekin y col., 2006). Los neutrófilos de MO de ratón carentes de TRP6 y estimulados con MIP-2, una quimioquina, muestran un lento aumento de la concentración de calcio intracelular y una menor velocidad de migración, sugiriendo que este canal podría participar en la migración del neutrófilo a sangre periférica (Damann y col., 2009).

\subsubsection{Intercambio $\mathrm{Na}^{+} / \mathrm{Ca}^{2+}$}

El potencial de membrana del neutrófilo es aproximadamente -75 mV (Majander y Wikström, 1989). La estimulación con fMLP provoca una rápida despolarización (unos $60 \mathrm{mV}$ ) debida a la actividad de NADPH oxidasa. En el neutrófilo despolarizado la fuerza impulsora para la entrada de calcio a través de canales es muy reducida. Esta despolarización es compensada rápidamente por la expulsión de $\mathrm{H}^{+}$a través de canales activados por pH y voltaje (Krause y col., 1993). Más recientemente, se ha señalado que la entrada de $\mathrm{Cl}^{-}$a través de canales activados por hinchazón podría contrarrestar este efecto despolarizante (Salmon y Ahluwalia, 2009). Aunque esta hipótesis es controvertida (Perez-Cornejo y col., 2004)

El intercambiador $\mathrm{Na}^{+} / \mathrm{Ca}^{2+}$ (NCX) también podría funcionar como repolarizador restituyendo la fuerza impulsora para la entrada capacitativa. EI NCX es un transportador electrogénico que intercambia $3 \mathrm{Na}^{+}$por cada $\mathrm{Ca}^{2+}$. El NCX se expresa en neutrófilos donde es el principal mecanismo de entrada de calcio durante el reposo. Se ha atribuido al bloqueo de este intercambiador la supresión de la producción de superóxido por análogos de la amilorida (Simchowitz y col., 1990). Se ha sugerido que aun en el neutrófilo en reposo, polarizado, se produce la entrada de calcio por el intercambiador, contribuyendo a aumentar las cargas negativas del interior (modo inverso de operación). De modo que un inhibidor especifico, el KBR7943, provoca despolarización espontánea (Tintinger y Andersen, 2004).

Cuando el fMLP despolariza, el intercambio $\mathrm{Na}^{+} / \mathrm{Ca}^{2+}$ en modo reverso (entrada de calcio y cargas negativas) está favorecido y va contribuyendo a la repolarización. En este caso la inhibición del intercambiador o la supresión del calcio extracelular reducen la velocidad de repolarización.

\subsection{Control del pH Intracelular}

El intercambiador $\mathrm{Na}^{+} / \mathrm{H}^{+}$(NHE) es un importante regulador de la respuesta inmune activa por diversos mecanismos que han sido objeto de una revisión reciente (De Vito, 2006).

La isoforma del intercambiador $\mathrm{Na}^{+} / \mathrm{H}^{+}$expresada en neutrófilos, identificada como NHE1 (Fukushima y col., 1996), cumple funciones de mantenimiento homeostático ("housekeping") del $\mathrm{pH}$ intracelular $(\mathrm{pHi})$. En estado basal el intercambiador está casi inactivo ya que el $\mathrm{pH}_{\mathrm{i}}$ está en su punto de ajuste ("set point"). Cuando se aplica 
una carga ácida, que reduce el $\mathrm{pH}_{\mathrm{i}}$ y lo aleja del "set point", el intercambiador aumenta la velocidad de expulsión de $\mathrm{H}^{+}$tratando de que el $\mathrm{pH}_{\mathrm{i}}$ retorne al valor preestablecido.

Tanto el PMA como el fMLP producen una carga ácida inicial que aleja el $\mathrm{pH}_{\mathrm{i}}$ del "set point" y hacen que el intercambiador expulse $\mathrm{H}^{+}$. En el caso de la estimulación con PMA la recuperación tiende a alcanzar el valor basal mientras que en la estimulación con fMLP produce una cascada de señalización que eleva el "set point" haciendo que el $\mathrm{pH}_{\mathrm{i}}$ alcance un estado estacionario a un valor más alto.

La activación de los neutrófilos por diversos agonistas produce una carga ácida generada en gran parte por la activación de la NADPH oxidasa (Borregaard y col., 1984; Grinstein y Furuya, 1986) que debe ser compensada por el intercambiador $\mathrm{Na}^{+} / \mathrm{H}^{+}$para que progrese la formación de ROS, la adhesión firme y la quimotaxis (Demareux y col., 1996; Hayashi y col., 2008). Secundariamente la expulsión de $\mathrm{H}^{+}$ produce acidificación extracelular.

El efecto de la carga ácida intracelular producida por la NADPH oxidasa activada es reducido por DPI y desenmascarado con inhibidores del intercambiador ya que la cascada de activación que lleva a la producción de ROS alcanza al NHE1 posiblemente a través de la activación de PKC (Nanda y Grinstein, 1991; Nanda y col., 1992).

Diversas estrategias se han usado para determinar el papel del intercambiador en la respuesta de los neutrófilos: la supresión del sodio, el uso de inhibidores o la alteración de la actividad del NHE1.

La omisión de sodio en el medio extracelular (reemplazado isoosmóticamente con $\mathrm{N}$-metilglucamina) puede incluso invertir el funcionamiento del intercambiador transformándolo en un mecanismo acidificante. Esta maniobra reduce la producción de ROS en neutrófilos tratados con CitB (Simchowitz, 1985).
Para inhibir al intercambiador se ha usado amilorida (Araki y col., 1991), sus derivados y más recientemente el HOE 694, un inhibidor específico de la isoforma NHE1 (Scholz y col., 1993). La amilorida inhibe la respuesta a diversos agonistas (Araki y col., 1991), en cambio el HOE 694 no altera la adhesión, la fagocitosis, ni la actividad bactericida (Demareux y col., 1996; Fukushima y col., 1996).

Generalmente se asume que el cambio del "set point" del intercambiador y la alcalinización celular subsiguiente tiene un efecto facilitador sobre la actividad del neutrófilo. La alcalinización intracelular provocada artificialmente con el ionóforo monensina aumenta la citotoxicidad y la producción de $\mathrm{H}_{2} \mathrm{O}_{2}$ (Araki y col., 1991).

Experimentos in vitro del grupo de Geffner sugieren que la acidez del medio podría desencadenar la activación, aumentar la citotoxicidad, el calcio intracelular, la expresión de CD18 y estimular la endocitosis en los neutrófilos (Martinez y col., 2006; Trevani y col., 1999, Geffner y col., 1993) así como la actividad de otras células del sistema inmune (Vermeulen y col., 2004). Esta activación ocurriría conjuntamente con una acidificación intracelular.

Por el contrario la mayoría de los autores encuentran que la acidosis intracelular reduce la producción de superóxido (Simchowitz, 1985) y otras actividades (Gabig y col., 1979; Lardner, 2001).

Sería importante caracterizar los efectos del cambio de $\mathrm{pH}_{i}$ ya que en el intersticio de los tejidos sometidos a isquemia, en los focos inflamatorios y en los tumores sólidos el medio es más ácido que en los tejidos sanos.

Los neutrófilos poseen un intercambiador cloro/ bicarbonato que participa en la regulación del equilibrio ácido base y está acoplado funcionalmente a anhidrasa carbónica, lo que lo hace sensible a inhibición por acetazolamida (Giambelluca y Gende, experimentos no publicados). 


\section{RESPUESTA INFLAMATORIA DISFUNCIONAL}

Las moléculas citotóxicas generadas por los neutrófilos activados son tóxicas tantos para los agentes patógenos como para el organismo. Por lo tanto, la activación de los neutrófilos debe ser finamente regulada para asegurar que estas células cumplan con su función sin causar un daño excesivo de los tejidos. Comprender qué mecanismos intervienen en la activación descontrolada de los neutrófilos puede permitir el diseño de compuestos que disminuyan estas respuestas descontroladas mitigando las consecuencias para tejidos sanos del huésped.

\subsection{El Neutrófilo en la Inflamación Disfuncional}

La respuesta inflamatoria normal se encuentra estrechamente regulada, para evitar una activación perjudicial. En ciertas ocasiones la activación descontrolada de los neutrófilos puede dar una respuesta disfuncional que daña a los tejidos. Por ejemplo, las lesiones por isquemia/reperfusión se asocian con una afluencia y posterior activación de neutrófilos al tejido afectado. (Mihelcic y col., 1994). Esta respuesta es desencadenada por sustancias liberadas por las células dañadas del huésped o como consecuencia de la generación de superóxido a través de xantino-oxidasa (Kloner y col., 1989; Kukreja y col., 1992).

Otros estímulos no sépticos inducen la liberación de citoquinas, quimoquinas, mediadores lipídicos y proteínas MRP (del inglés "mieloid related proteins") ante los cuales los neutrófilos reaccionan de manera no específica y se acumulan rápidamente en el sitio de origen. Las enzimas leucocitarias elastasa, colagenasa y los ROS son tan nocivos para las bacterias como para el huésped. Muchas patologías se asocian a una sobreactivación de los neutrófilos como la artritis reumatoidea, gota, el infarto de miocardio, el asma, enfermedades intestinales y de la piel. Se pueden producir inmunopatologías asociadas a traumas, cirugía de puentes coronarios y en pancreatitis (Brown y col., 2006).

Los neutrófilos pueden dañar al tejido del huésped a través de varios mecanismos. Estos incluyen: la activación prematura durante la migración, el fracaso de la finalización de la respuesta inflamatoria aguda y la liberación extracelular de productos tóxicos utilizados para eliminar a patógenos, desechos de tejidos y células del huésped infectadas o dañadas.

Una subpoblación de los neutrófilos preactivados se ha detectado en la sangre de los pacientes adultos con el síndrome de distrés respiratorio agudo (ARDS). Los neutrófilos se han visto implicados en esta patología debido a la gran afluencia de estas células al pulmón donde se activan y causan daño tisular al liberar oxidantes y enzimas hidrolíticas (Abraham y col., 2000; Weis, 1989; Windsor y col., 1993). Además, se han encontrado neutrófilos preactivados en personas con hipertensión esencial, enfermedad de Hodgkin, enfermedad inflamatoria intestinal, psoriasis, sarcoidosis, y en septicemia; se ha correlacionado la preactivación con altas concentraciones circulantes de TNF $\alpha$.

En el líquido aislado de los focos inflamatorios además de las enzimas hidrolíticas leucocitarias pueden ser detectados inhibidores de proteasas inactivados por mecanismos oxidativos. El daño a los tejidos del huésped sólo puede ocurrir cuando las defensas antioxidantes y antiproteasas están desbordadas. El estrés oxidativo inicia el daño tisular mediante la reducción de la concentración extracelular de antiproteasas por debajo del nivel necesario para inhibir las proteasas liberadas (Hawkins y Davies, 2005). Cloratos y oxidantes pueden inactivar antiproteasas tales como el inhibidor endógeno de la elastasa, 
pero al mismo tiempo activar metaloproteasas latentes como colagenasa y gelatinasa, que contribuyen a la inactivación de más antiproteasas. Muchas antiproteasas son miembros de la familia de inhibidores de proteasas de serina. Aunque la circulación es rica en antiproteasas, estas grandes proteínas pueden ser excluidas selectivamente. La deficiencia de antiproteasas está involucrada en el desarrollo del enfisema pulmonar.

Se han demostrado que los oxidantes originados en los neutrófilos oxidan las lipoproteínas de baja densidad que entonces son apresadas más eficazmente por la membrana plasmática de los macrófagos a través de receptores específicos y pueden iniciar la aterosclerosis (Malle y col., 2006).

La fase aguda de la lesión térmica también se asocia con la activación de neutrófilos, aunque esto es seguido por un deterioro en la función de los neutrófilos (Chen y col., 2006). En los pacientes que sufren de quemaduras graves, existe una reducción en la proporción y en el número absoluto de neutrófilos positivos para receptores de anticuerpos y complemento lo que se correlaciona con la aparición de bacteremia.

Los neutrófilos activados por complejos inmunes presentes en el líquido sinovial contribuyen a la patología de la artritis reumatoidea (Edwards y Hallet, 1997). El desarrollo de tumores puede ser inducido por la activación de los neutrófilos debido al daño del ADN por agentes oxidantes y a que las proteasas promueven la migración de células.

Los componentes citoplásmicos de los neutrófilos pueden inducir la formación de anticuerpos anti-neutrófilos. Estos anticuerpos están dirigidos contra las enzimas que se encuentran principalmente en los gránulos de los neutrófilos y están estrechamente relacionados con el desarrollo de vasculitis sistémica y glomérulonefritis (Reumaux y col., 2004).

\subsection{Control Farmacológico de la Respuesta Inflamatoria Disfuncional}

Como hemos visto, los neutrófilos son importantes efectores celulares durante la respuesta inflamatoria. Algunas de sus funciones son controladas por receptores de membrana y diversas vías de transducción de señales que proveen múltiples oportunidades para modular farmacológicamente respuestas no deseadas.

Se han propuesto diversas estrategias para minimizar el daño en los tejidos producido por una respuesta exagerada de los neutrófilos: 1) reducir la abundancia de estas células 2 ) reducir su actividad 3) inactivar los productos arrojados al medio extracelular que son dañinos para las células vecinas (ROS, enzimas proteolíticas, entre otros).

Para reducir la abundancia se ha propuesto la supresión selectiva de la producción de neutrófilos en la MO (Van Furt, 1977), la inducción de apoptosis selectiva (Ward y col., 1999), o la eliminación de estas células utilizando filtros (Treacher y col., 2001).

Para reducir la actividad de los neutrófilos se puede limitar la producción de citoquinas pro-inflamatorias. Los corticoesteroides bloquean la transcripción de citoquinas como TNF $\alpha$ o IL-8 (Tintinger y col., 2005). Se ha estudiado la terapia génica con vectores adenovirales que expresan IL-10 (Oberholzer y col., 2006, Oberholzer y col., 2001), inhibidores de la cascada del complemento (Thurman y col., 2006; Qiao y col., 2006) o el tratamiento con IL-11 y IL-13 recombinantes. Otra estrategia es reducir el reclutamiento y la transmigración mediante la utilización de anticuerpos monoclonales contra las integrinas de los neutrófilos (Li y col., 2006), o sus ligandos endoteliales.

Para reducir la actividad leucocitaria se han propuesto inhibidores de las vías de señalización de la p38 MAPK o NFkb 
(Saklatvala, 2004; Ipaktchi y col., 2006) o agentes que elevan el AMPc (Moore y Willoughby, 1995) como los inhibidores de la fosfodiesterasa 4 (Bahra y col., 2001). Recientemente se ha descripto una vía de activación gatillada por calcio que involucra una adenilato ciclasa soluble para la que se ha desarrollado un inhibidor especifico (Han y col., 2005).

Dado que la señalización por calcio es crítica para el inicio de procesos pro-inflamatorios, la modulación de los mecanismos utilizados por los neutrófilos para movilizar y disponer de este catión pueden ser blancos potenciales para una terapia anti-inflamatoria alternativa (Tintinger y col., 2005). La inhibición de la entrada de calcio reduce las funciones pro-inflamatorias de los neutrófilos como lo muestran diversos estudios en los que se utilizaron medios libre de calcio o bloqueadores de los canales de calcio (Philipson y Nicoll, 2000; Steel y Anderson, 2004). La inhibición indirecta de la entrada estaría relacionada con la inhibición de las funciones citotóxicas de los neutrófilos humanos por glicina (Wheeler y col., 2000a) o por carvedilol (Mačičková y col., 2005). Nos ocuparemos en los capítulos siguientes más extensamente de la regulación del proceso inmune por transfusión de soluciones hipertónicas o suplementadas con glicina (Griffiths y col., 2002; Hasenboehler y col., 2006).

Por último, también se han ensayado inhibidores de los productos citotóxicos y de enzimas que son liberadas al medio extracelular por los neutrófilos como la colagenasa, elastasa (Luisetti y col., 1996) o catepsina G (de Garavilla y col., 2005). Sin embargo, su utilización en el tratamiento del trauma severo ha sido muy cuestionado (Stahel y col., 2007).

\section{OBJETIVOS}

\subsection{Objetivo General}

El objetivo general fue examinar y caracterizar las alteraciones en los flujos iónicos que ocurren en situaciones similares a las que se producen durante el desarrollo de una respuesta inflamatoria disfuncional y determinar el efecto que producen algunas de las intervenciones recientemente propuestas para controlarla (utilización de soluciones hipertónicas y suplementadas con glicina).

\subsection{Objetivos Específicos}

1) Determinar el efecto del estrés oxidativo sobre la concentración de calcio intracelular. Es conocido que la estimulación de los receptores de fMLP produce un aumento del $\left[\mathrm{Ca}^{2+}\right]_{i}$ e induce la explosión respiratoria, sin embargo la posibilidad de que la producción de ROS afecte al aumento del $\left[\mathrm{Ca}^{2+}\right]_{i}$ ya sea por retroalimentación positiva o negativa es controversial.

2) Estudiar y caracterizar el efecto del aumento de la osmolaridad del medio sobre los cambios en la producción de ROS, concentración de calcio intracelular y $\mathrm{pH}$ intracelular inducido por agonistas. Estudiar el papel desempeñado por el citoesqueleto en este efecto.

3) Analizar la relación entre los flujos de calcio y la producción de ROS en medios suplementados con glicina, con el fin de caracterizar su efecto protector en situaciones donde el daño de los tejidos se produce como consecuencia de la activación excesiva de los neutrófilos. 


\section{CAPÍTULO II}

MATERIALES Y

MÉTODOS 


\section{ENFOQUE EXPERIMENTAL}

Utilizamos como modelo el estudio in vitro de respuestas de neutrófilos aislados. Preferimos trabajar con células humanas. El aislamiento desde la sangre periférica nos permite obtener cantidades apreciables de neutrófilos (entre $0.5-1 \mathrm{ml}$ de $2.10^{7}$ células $/ \mathrm{ml}$ ) con elevada pureza (98\%). La separación se hace en un solo paso y sin utilizar la lisis hipotónica de los eritrocitos. Realizamos algunos experimentos en neutrófilos peritoneales de rata, sólo para descartar que las diferencias con resultados descriptos en otros trabajos sean debidas a la especie.

Se analizaron varias respuestas fisiológicas de los neutrófilos: la movilización de calcio intracelular, modificaciones en el $\mathrm{pH}$ intracelular y la producción de ROS. Las determinaciones de fluorescencia se realizaron en un espectrofluorómetro AmincoBowman serie 2 termostatizado a $37^{\circ} \mathrm{C}$ y con agitación continua.

Algunas intervenciones farmacológicas como el uso de la Citocalasina B (inhibidor de la polimerización de la actina), o el PMA (ester de forbol activador de PKC) nos permitieron definir mejor las vías de señalización implicadas en las distintas respuestas.

\section{REACTIVOS Y COMPOSICIÓN DE LAS SOLUCIONES UTILIZADAS}

OxyBURST Green $\mathrm{H}_{2} \mathrm{HFF}$ BSA (Oxiburst-BSA) es un compuesto fluorogénico utilizado para la detectar la liberación de especies reactivas del oxigeno con alta sensibilidad. El reactivo consiste en dihidro-2', 4,5,6,7,7'-hexafluoro-fluoresceina acoplada a albúmina de suero bovina. Fue adquirido a Molecular Prbes
(Eugene, OR, USA) que también proveyó el acetometil ester de FURA 2 (FURA 2-AM) y el ester de tetra-acetoximetil 2'7'bis (carboxietil)-5(6) carboxifluoresceína (BCECF-AM)

Las soluciones Histopaque 1119 y 1077 (H-1119 y H-1077), glicina (Gli), N-formil-metionil-leucil-fenilalanina (fMLP), forbol-12 miristato 13-acetato (PMA), albúmina de suero bovino (BSA), difenilen iodonium (DPI), ácido $\mathrm{N}$-2-etansulfónico $\quad \mathrm{N}-2$ hidroxietilpiperazina (HEPES), ácido etilen glicol tetra acético (EGTA) y N-metilglucamina (NMG) fueron provistas por SigmaAldrich (St. Louis, MO). La citocalasina B (CitB) fué provista por Biomol (Plymouth Meeting, PA, USA).

Manitol, sacarosa, $\mathrm{NaCl}, \mathrm{H}_{2} \mathrm{O}_{2}, \mathrm{LaCl}_{3}, \mathrm{NiCl}_{2}$, y demás reactivos de otros proveedores fueron de grado analítico.

La composición de las soluciones utilizadas es la siguiente:

Solución salina tamponada con HEPES (HEPES buffered saline, $H B S$ ): es una solución salina isotónica que contiene $\mathrm{NaCl}$ $140 \mathrm{mM}, \mathrm{KCl} 5 \mathrm{mM}, \mathrm{MgCl}_{2} 1 \mathrm{mM}$, glucosa $10 \mathrm{mM}, \mathrm{CaCl}_{2} 1 \mathrm{mM}$, Hepes $20 \mathrm{mM}$, titulada a pH 7.4 con $\mathrm{NaOH} 2 \mathrm{M}$.

Solución salina tamponada con HEPES nominalmente libre de calcio (HBSs /Ca): es una solución salina isotónica de la misma composición que la $\mathrm{HBS}$, sin el agregado de $\mathrm{CaCl}_{2}$.

Solución salina tamponada con HEPES, libre de calcio (HBS /EGTA): es una solución salina isotónica de la misma composición que la HBS, a la cual se le ha adicionado EGTA 0.1 $\mathrm{mM}$ y no se ha agregado de $\mathrm{CaCl}_{2}$.

Solución salina tamponada con HEPES, con reemplazo del sodio por NMG, Li, etc (HBS /Li, HBS /NMG etc): es una solución salina isotónica de la misma composición que la HBS, en la cual se han reemplazado los $140 \mathrm{mM}$ de $\mathrm{NaCl}$ por una cantidad equivalente de NMG o LiCl. 
Solución salina tamponada con HEPES, con reemplazo de sodio por $K$ y con nigericina (HBS /K/Nigericina): es una solución salina isotónica que contiene $\mathrm{KCl} 140 \mathrm{mM}, \mathrm{NaCl} 5 \mathrm{mM}, \mathrm{CaCl}_{2} 1 \mathrm{mM}$, $\mathrm{MgCl}_{2} 1 \mathrm{mM}$, Hepes $20 \mathrm{mM}$, nigericina $10 \mu \mathrm{M}$.

Solución salina tamponada con fosfato (PBS): es una solución salina isotónica que contiene $\mathrm{NaCl} 154 \mathrm{mM}, \mathrm{NaH}_{2} \mathrm{PO}_{4} 1.6$ $\mathrm{mM}, \mathrm{Na}_{2} \mathrm{HPO}_{4} 8.1 \mathrm{mM}$, titulada a $\mathrm{pH} 7.4$ con $\mathrm{NaOH} 1 \mathrm{M}$ o HCl $1 \mathrm{M}$.

\section{MÉTODOS Y PROTOCOLOS}

\subsection{Aislamiento de Neutrófilos Humanos de Sangre Periférica}

Los neutrófilos se aislaron de sangre venosa, obtenida de dos voluntarios sanos $(15 \mathrm{ml} \mathrm{c} / \mathrm{u})$ recogidos en tubos con $15 \mathrm{U}$ de heparina/ml. Las muestras se centrifugaron a $1400 \mathrm{x} \mathrm{g}(3000 \mathrm{rpm})$ durante $15 \mathrm{~min}$. Se descartaron $3 / 4$ partes del plasma sobrenadante y se separaron $4 \mathrm{ml}$ de la interfase entre la capa de células blancas y eritrocitos. La porción separada de ambas muestras se combinó y depositó sobre un gradiente discontinuo de Histopaque $(3 \mathrm{ml}$ de $1.119 \mathrm{~g} / \mathrm{ml}$ y $3 \mathrm{ml}$ de $1.077 \mathrm{~g} / \mathrm{ml}$ ) que se centrifugó a $1400 \mathrm{x} \mathrm{g}$ (3000 rpm) durante $30 \mathrm{~min}$. Se descartó la capa superior (plasma) y las $3 / 4$ partes de la capa de densidad 1.077 en la que sobrenadan linfocitos y plaquetas. Un pequeño volumen de la interfase (1-2 $\mathrm{ml})$ se diluyó con $10 \mathrm{ml}$ de HBS y se centrifugó a 700 x g (2100 rpm) por $10 \mathrm{~min}$. El "pellet" se resuspendió en $1 \mathrm{ml}$ de HBS para realizar el recuento de células en la cámara de Neubauer y luego se ajustó el volumen final para tener una concentración de $2.10^{7}$ leucocitos $/ \mathrm{ml}$.

La pureza se determinó por recuento diferencial en un extendido coloreado por la técnica de May-Gründwald-Giemsa. Para realizar esta coloración, los frotis fueron cubiertos con la solución de May-Gründwald durante 3 minutos. El metanol contenido en esta solución fijó por deshidratación las distintas estructuras celulares. Luego se le agregaron 20 gotas de agua destilada neutra y se lavó luego de 1 minuto. Por último se cubrió con la solución de Giemsa durante 15 minutos y se lavó. En el extendido coloreado y seco se realizó el recuento diferencial de 100 elementos con el objetivo de 45X.

La viabilidad celular se determinó por el método de exclusión del Trypan Blue. Las células son muy selectivas a las sustancias que pasan a través de la membrana, el Trypan Blue no es absorbido por las células viables, sin embargo atraviesa la membrana de las células muertas. Por consiguiente, las células muertas son vistas en el microscopio teñidas de color azul.

Se utilizó una solución de Trypan Blue al $0.4 \%$ en solución salina que se diluyó con igual volumen de muestra y se incubó por 5 minutos a temperatura ambiente antes de realizar el recuento de las células coloreadas.

\subsection{Determinación de la Entrada y Movilización de Calcio}

Para realizar las mediciones de la $\left[\mathrm{Ca}^{2+}\right]_{\mathrm{i}}$, los neutrófilos se lavaron con $10 \mathrm{ml}$ de HBS y se incubaron en presencia de $10 \mu \mathrm{l}$ de FURA 2-AM por 30 minutos a $37^{\circ} \mathrm{C}$ en oscuridad. Luego se lavaron y resuspendieron en $1 \mathrm{ml}$ de HBS y se incubaron 15 minutos a $37^{\circ} \mathrm{C}$ en oscuridad para que se complete la hidrólisis del FURA 2-AM. Las células se separaron por centrifugación (10 min a $1000 \mathrm{rpm}$ ) y se resuspendieron a una densidad de $10^{7}$ células $/ \mathrm{ml}$. Alícuotas de 50 $\mu \mathrm{l}$ de la suspensión de células cargadas con el indicador fluorescente se resuspendieron en $2 \mathrm{ml}$ de $\mathrm{HBS}$ a $37^{\circ} \mathrm{C}$ en la cubeta del espectrofluorómetro. Para realizar la determinación de $\left[\mathrm{Ca}^{2+}\right]_{\mathrm{i}}$ los neutrófilos se excitaron alternadamente con haces luminosos de 

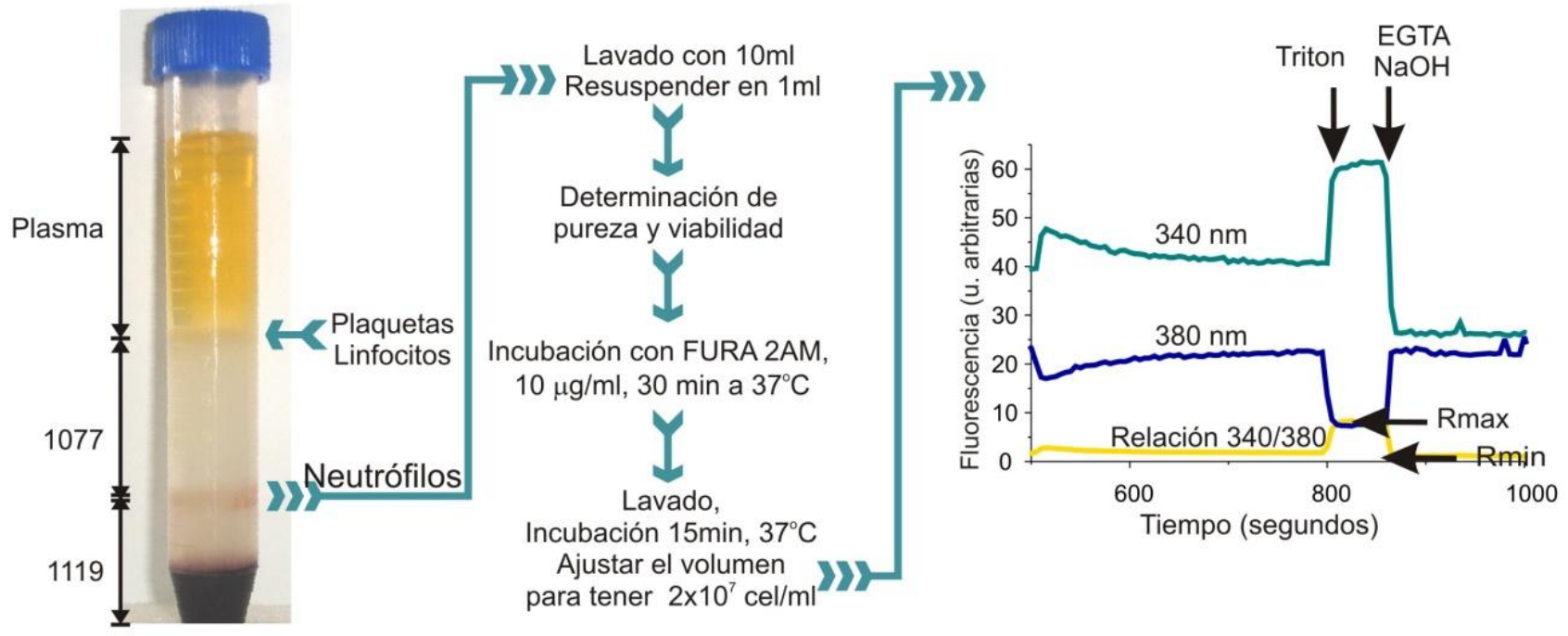

Figura II-1: Protocolo seguido para el aislamiento de los neutrófilos y la medición del calcio intracelular de 340 y $380 \mathrm{~nm}$, y se midió la luz emitida a $510 \mathrm{~nm}$.

Luego de cada experimento se realizó una calibración agregando Tritón X-100 (concentración final 0.025\%) para lisar las células, saturar el indicador y obtener el valor máximo de la relación de fluorescencia (Rmax) seguido por la quelación del calcio (utilizando una concentración final de $2.5 \mathrm{mM}$ de EGTA y $25 \mathrm{mM}$ de $\mathrm{NaOH}$ ) para obtener el valor mínimo de la relación de fluorescencia (Rmin) (Fig. II-1). La $\left[\mathrm{Ca}^{2+}\right]_{i}$ se calculó a partir de la relación de fluorescencia medida en cada punto $(R)$ según el método de Grynkiewicz et al. (1985) utilizando la relación:

$$
\left[\mathrm{Ca}^{2+}\right]=\mathrm{Kd} \beta(\mathrm{R}-\mathrm{Rmin}) /(\mathrm{Rmax}-\mathrm{R})
$$

donde el Kd para el FURA 2 es $225 \mathrm{nM}$ y $\beta$ es la relación de fluorescencia a 380nm del FURA libre y saturado con calcio.

Para discriminar entre la entrada y la movilización de $\mathrm{Ca}^{2+}$ desde los depósitos intracelulares, los neutrófilos se lavaron y resuspendieron en HBSs /Ca a una concentración de $2.10^{7}$ células /ml y se realizó la determinación de $\left[\mathrm{Ca}^{2+}\right]_{i}$ en HBS /EGTA. Luego de incubar las células por 600 segundos, los neutrófilos se activaron con un agente estimulante, como el fMLP, que produce un aumento de la $\left[\mathrm{Ca}^{2+}\right]_{i}$ debido al vaciamiento de los depósitos intracelulares. 100 segundos después se reestableció la $\left[\mathrm{Ca}^{2+}\right]$ extracelular por el agregado de $20 \mu \mathrm{l}$ del $\mathrm{CaCl}_{2} 100 \mathrm{mM}$, y se detectó un aumento del calcio intracelular que es debida a la entrada de este catión.

\subsection{Determinación de la Entrada de Manganeso}

Esta determinación se utilizó como otra estrategia metodológica para caracterizar el influjo de calcio en los neutrófilos. Se basa en que el manganeso $\left(\mathrm{Mn}^{2+}\right)$ ingresa por los mismos mecanismos que el calcio y reduce la fluorescencia del FURA 2 al combinarse con él. 
Se utilizó una suspensión de neutrófilos cargados con FURA 2 suspendidos en HBS /sCa. Luego alícuotas de $50 \mu \mathrm{l}$ se resuspendieron en $2 \mathrm{ml}$ de $\mathrm{HBS} / \mathrm{sCa}$ a $37^{\circ} \mathrm{C}$ en la cubeta del espectrofluorómetro y se agregó $30 \mathrm{mM}$ de $\mathrm{MnCl}_{2} 5$ minutos antes que a las células fueran estimuladas.

Para calcular el influjo de $\mathrm{Mn}^{2+}$ se midió la extinción de la fluorescencia emitida a $510 \mathrm{~nm}$ por los neutrófilos cuando se los excitaba a $358 \mathrm{~nm}$ (longitud de onda isoemisiva para FURA libre o unido a calcio). La pendiente de extinción se determinó luego del agregado del estímulo.

\subsection{Determinación de la Producción de ROS}

Para realizar la cuantificación de la producción y liberación de ROS al medio extracelular se utilizó la técnica del Oxyburst-BSA, este método se basaba en la utilización de un reactivo fluorescente (dihidro -2',4,5,6,7,7'- hexafluorofluoresceína) unido a albúmina sérica bovina. Al estar el reactivo unido a albúmina no ingresa en las células y nos asegura que medimos producción y liberación de ROS al medio extracelular.

Este método nos permitió reproducir las condiciones experimentales que utilizamos durante la determinación de la señal de calcio. Los neutrófilos $\left(10^{6}\right.$ células $/ \mathrm{ml}$ ) se incubaron a $37^{\circ} \mathrm{C}$ durante 10 minutos en $2 \mathrm{ml}$ en distintas soluciones (según el protocolo experimental) tamponadas con HEPES, a las que se le agregó $5 \mu \mathrm{g} / \mathrm{ml}$ oxyburst-BSA.

La liberación de ROS al medio extracelular se detectó por el aumento continuo de la fluorescencia emitida a $530 \mathrm{~nm}$ cuando el compuesto fue excitado a $488 \mathrm{~nm}$. Se asumió que la cantidad liberada de ROS era proporcional a la velocidad de aumento de la fluorescencia y se expresó como porcentaje de la pendiente del control obtenida en el mismo "pool" de neutrófilos.

\subsection{Determinación de los Cambios en el pH Intracelular}

Para incorporar el indicador de $\mathrm{pH}$ intracelular, los neutrófilos aislados se incubaron con $10 \mu \mathrm{g} / \mathrm{ml}$ de BCECF-AM por 30 minutos a $37^{\circ} \mathrm{C}$ en oscuridad. Luego las células cargadas con el compuesto fluorescente se separaron por centrifugación $(700 \times \mathrm{g}$, durante 10 minutos), se suspendieron en HBS y se incubaron 10 minutos a $37^{\circ} \mathrm{C}$ para completar la hidrólisis del indicador. Posteriormente las células se lavaron y resuspendieron a una densidad de $10^{7} / \mathrm{ml}$.

Para realizar la determinación de los cambios en el $\mathrm{pH}$ intracelular, se resuspendieron $50 \mu \mathrm{l}$ de la suspensión de células teñidas en $2 \mathrm{ml}$ de $\mathrm{HBS}$ a $37^{\circ} \mathrm{C}$. Los neutrófilos cargados con BCECF se excitaron alternativamente con haces luminosos de 503 y $440 \mathrm{~nm}$, y la luz emitida se midió a $535 \mathrm{~nm}$. El pH intracelular se calculó a partir de una curva de calibrado en HBS/K/nigericina. El fundamento del método de calibración consiste en igualar con el ionóforo el $\mathrm{pH}$ intracelular $(\mathrm{pHi})$ con el extracelular $(\mathrm{pHe})$ y modificar este último con agregados de $\mathrm{KOH} 2 \mathrm{M}$ o $\mathrm{HCl} 0.1 \mathrm{M}$, midiendo el $\mathrm{pHe}$ y la fluorescencia en cada punto como muestra el esquema presentado en la tabla II-1 y Fig. II-2. La relación entre la relación de fluorescencia $503 \mathrm{~nm} / 440 \mathrm{~nm}$ y el pH intracelular en cada punto fue lineal en el rango de $\mathrm{pH}$ utilizado. 
Tabla II-1: Curva de calibrado del pH intracelular

\begin{tabular}{lccccc}
\hline Reactivo & KOH 2M & \multicolumn{5}{c}{$\mathrm{HCl} 0.1 \mathrm{M}$} \\
\hline Volumen $(\mu \mathrm{L})$ & 15 & 50 & 40 & 30 & 20 \\
$\mathrm{pH}$ & 7.64 & 7.3 & 7.01 & 6.66 & 6.4 \\
Fluorescencia & 12.19 & 10.10 & 7.90 & 6.25 & 5.00 \\
\hline
\end{tabular}

\section{VARIABLES ANALIZADAS Y ANÁLISIS ESTADÍSTICO}

Los datos de fluorescencia en función del tiempo fueron adquiridos cada segundo en los casos en que se utilizaba una sola longitud de onda (determinación de ROS, extinción de fluorescencia por $\mathrm{Mn}^{2+}$ ) y cada 5 segundos cuando se obtenían relaciones de dos longitudes de onda $\left(\left[\mathrm{Ca}^{2+}\right]_{\mathrm{i}}, \mathrm{pH}_{\mathrm{i}}\right)$.

Los flujos de calcio fueron cuantificados por el mayor cambio en la concentración después de los estímulos (valor pico) o por el área bajo la curva desde el valor pico hasta un lapso predeterminado para cada caso. En general se muestra en los resultados el valor del área bajo la curva, ya que fue menos afectado por determinaciones ruidosas.

Para calcular el área se programó en Visual Basic un algoritmo

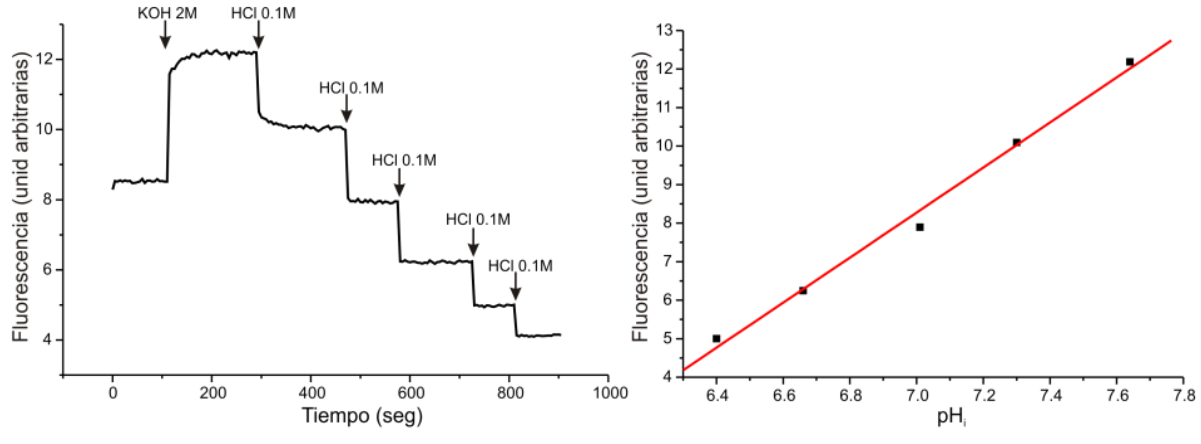

Figura II-2. Construcción de la curva de calibrado del pH intracelular en un experimento típico.

cuyo resultado podía corroborarse visualmente. La Fig. II-3 muestra un ejemplo.

En todos los casos se obtuvo cada día una determinación control con la que se aparearon los resultados de las maniobras experimentales realizadas en otras alícuotas de la misma preparación. Frecuentemente los valores se expresaron como porcentaje del valor control para reducir la variabilidad entre preparaciones.

Los valores se expresaron como media \pm error estándar de la media (SEM). Se usó el test de $\mathrm{t}$ de "Student" para comparar un tratamiento con el control o análisis de varianza (ANOVA) seguido del test de Duncan cuando había múltiples tratamientos. Se consideraron significativos los valores con $\mathrm{P}<0.05$. 
Figura II-3: Medición del área bajo la curva de aumento de calcio inducido por fMLP en neutrófilos aislados en un experimento típico. Panel A: se realizó el experimento en presencia de calcio $1 \mathrm{mM}$. El área bajo la curva se calculó tomando como base el valo previo al agregado del fMLP y se midió desde el máximo hasta 100 segundos después del agregado. Panel B: los neutrófilos fueron incubados en soluciones carentes de calcio, el área debida a la movilización de calcio desde los depósitos intracelulares se midió hasta 50 segundos después del máximo alcanzado al agregar el fMLP y el área correspondiente a la entrada de calcio del medio extracelular se midió hasta 200 segundos luego del agregado de calcio $1 \mathrm{mM}$.
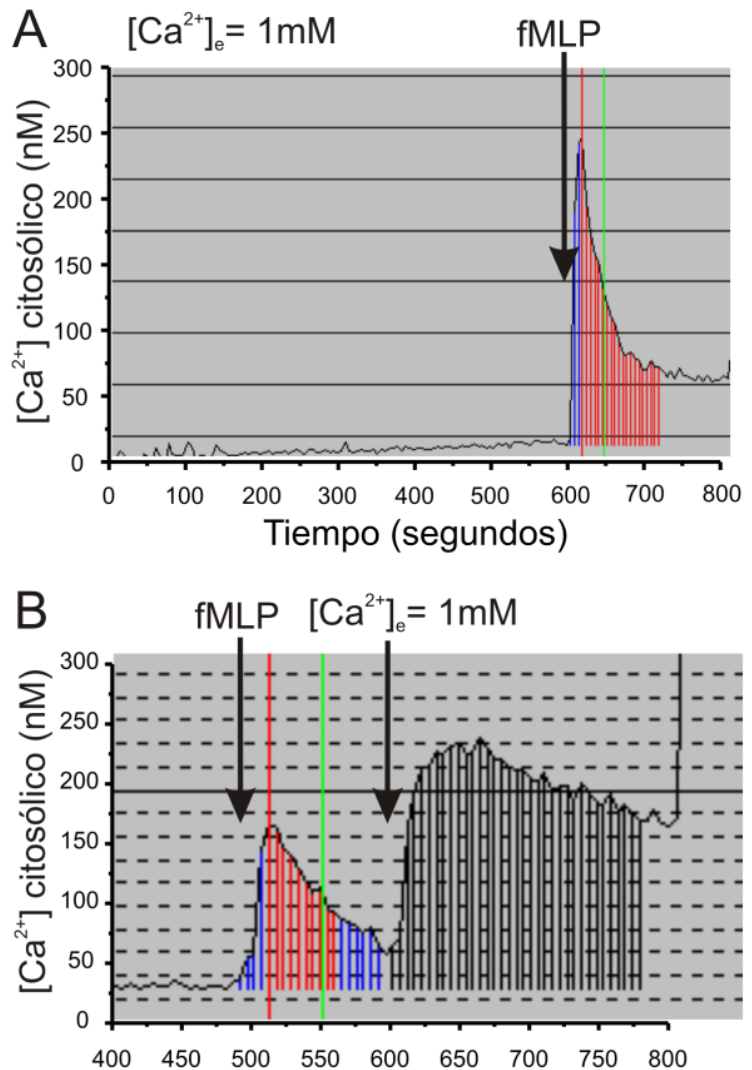

Tiempo (segundos) 


\title{
CAPÍTULO III
}

\author{
RELACIÓN ENTRE LOS \\ FLUJOS DE CALCIO Y EL \\ ESTRES OXIDATIVO
}




\section{ANTECEDENTES}

\subsection{Efectos Autocrinos y Paracrinos de los ROS}

Desde hace mucho tiempo se conoce que ROS y RNS tienen efectos deletéreos sobre las células. Más recientemente se ha demostrado que estos compuestos actúan como señales intracelulares involucradas en la homeostasis, la proliferación y diferenciación celular, así como en la inflamación y la respuesta inmune (Wenger y col., 2005; Touyz, 2005; Korhonen y col., 2005).

Los ROS son moléculas pequeñas y ubicuas que pueden ser rápidamente sintetizadas y destruidas, lo que les confiere especificidad espacial y temporal en procesos de señalización, en los cuales pueden actuar como segundos mensajeros (Tonks, 2005).

En el foco inflamatorio células epiteliales, macrófagos y neutrófilos expresan la NADPH oxidasa y generan ROS los que pueden ser liberados al espacio extracelular donde difunden, atraviesan la membrana de otras células y actúan sobre las vías de señalización intracelulares (Maher y col., 1993; Cao y col., 1993). Los ROS pueden actuar como señales autocrinas o paracrina es decir sobre la misma célula que lo produce o sobre células vecinas. La mayor proporción de los ROS provienen de la NADPH oxidasa (Root y col., 1975).

Existen evidencias del rol señalizador de los ROS sobre otros neutrófilos, macrófagos y células residentes de los tejidos, como fibroblastos y células endoteliales o epiteliales. Por ejemplo, durante la migración a través del endotelio, los neutrófilos liberan pequeñas cantidades de ROS, los que disparan respuestas en las células endoteliales. Se ha visto que cuando las células endoteliales son expuestas a los ROS se produce la activación de la fosfolipasa $D$ (Natarajan y col., 1993), se induce la expresión de P-selectinas y la fijación de neutrófilos a ellas (Patel y col., 1991).

La acumulación de neutrófilos activados ha sido relacionada con la patogénesis de la injuria pulmonar aguda, un desorden caracterizado por la agresión inflamatoria al endotelio y al epitelio pulmonar. Los ROS producidos por la NADPH oxidasa podrían estar contribuyendo a la amplificación de la injuria inflamatoria en esta patología (Kinnula y col., 2005)

\subsection{Efecto del $\mathrm{H}_{2} \mathrm{O}_{2}$ Exógeno en Otras Células}

La posibilidad de que el $\mathrm{H}_{2} \mathrm{O}_{2}$ liberado por los neutrófilos actúe como un mensajero intercelular fue estudiada en diversas células.

En el endotelio venoso el $\mathrm{H}_{2} \mathrm{O}_{2}$ exógeno produce liberación de calcio de los depósitos intracelulares y entrada de este ion a través de canales sensibles a niquel y a SKF-96365, un bloqueante de SOCs. (Doan y col, 1994).

El tratamiento de las plaquetas con bajas concentraciones de $\mathrm{H}_{2} \mathrm{O}_{2}$ (entre $10 \mu \mathrm{M}$ y $100 \mu \mathrm{M}$ ) favorece la liberación de calcio desde los depósitos y la subsiguiente entrada capacitativa. El efecto del $\mathrm{H}_{2} \mathrm{O}_{2}$ sobre la entrada de calcio estaría mediado por la reorganización del citoesqueleto de actina, ya que bajas concentraciones induce una remodelación de la actina similar a la inducida por la depleción del retículo endoplasmático por agonistas. La correlación entre la entrada, la liberación de calcio y el reordenamiento de la actina inducida por bajas concentraciones de $\mathrm{H}_{2} \mathrm{O}_{2}$ y agonistas fisiológicos sugiere que el $\mathrm{H}_{2} \mathrm{O}_{2}$ debe participar de la activación de la entrada capacitativa en condiciones fisiológicas (Rosado y col., 2006). El $\mathrm{H}_{2} \mathrm{O}_{2}$ exógeno tiene 
un efecto bifásico sobre la activación de la entrada de calcio (Redondo y col., 2004). Concentraciones mayores a $100 \mu \mathrm{M}$ despolarizan la membrana reduciendo la entrada de calcio sin afectar la actina.

\section{3. $\mathrm{H}_{2} \mathrm{O}_{2}$ y TRPM2}

La proteína TRPM2, es un miembro de la familia TRP, que tiene una alta expresión en células inflamatorias tales como linfocitos $T$, monocitos y neutrófilos (Perraud y col., 2001; Hara y col., 2002; Massullo y col., 2006). Esta proteína forma canales permeables a calcio activados por mensajeros intracelulares como $\mathrm{NAD}^{+}, \mathrm{ADP}$-ribosa (ADP-R) y su forma cíclica (ADPc-R). Estos canales pueden ser activados por $\mathrm{H}_{2} \mathrm{O}_{2}$, lo que los convierte en un sensor potencial de ROS y del "stress" oxidativo (Hara y col., 2002). La activación puede deberse a una oxidación directa de la proteína (Massullo y col., 2006) o a la liberación de ADP-R.

Hasta el presente no existen evidencias de que los ROS afecten la entrada de calcio a través de canales mediados por voltaje o por segundos mensajeros. En cambio se ha reportado activación de entrada de calcio a través de TRPM2 en granulocitos por un aumento de NAD $^{+}$(Heiner y col., 2003).

Se ha descripto que la entrada de calcio a través de TRPM2 media procesos patológicos que llevan a la muerte celular (Hara y col., 2002, Kaneko y col., 2006), pero se desconoce su participación como mecanismo fisiológico de señalización. Se ha propuesto que la entrada de calcio a través de TRPM2 controla la expresión de CXCL8, una quimioquina que lleva a la infiltración de neutrófilos (Sonoda y col.,
1998). Esta infiltración está reducida en ratones knokout para trpm2.

TRPM2 es necesario para la quimiotaxis ya que neutrófilos deficientes en trpm2 tienen supresión de la señal de calcio y de la migración inducidas por el fMLP (Massullo y col., 2006; Yamamoto y col., 2008).

Los neutrófilos poseen una ecto ADP-ribosilciclasa (el CD38), que produce la síntesis extracelular de ADPc-R, el cual entraría a la célula a través de un transportador de nucleósidos e induciría la movilización de calcio desde los depósitos intracelulares. (Morita y col., 2008; Partida-Sanchez y col., 2001). Además, la ADPR y la ADPc-R estarían involucradas en la entrada de calcio desde el medio extracelular por activar los canales TRPM2 (Heiner y col., 2006).

\subsection{Relación entre los ROS y la Entrada de Calcio}

En diversos trabajos se ha descripto el efecto de otros ROS, como el $\mathrm{O}_{2}^{-}$sobre la entrada capacitativa. En neutrófilos, cantidades elevadas de $\mathrm{O}_{2}^{-}$provocan una disminución en la entrada capacitativa de calcio (Rada y col., 2003). Este efecto podría ser consecuencia de la despolarización de la membrana provocada por NADPH oxidasa, como se discutió en la introducción.

Los neutrófilos pretratados con CitB, muestran un aumento bifásico de la concentración de calcio intracelular inducida por fMLP. Existe una correlación entre el aumento en la producción de $\mathrm{H}_{2} \mathrm{O}_{2}$ y el aumento en la entrada de calcio que estaría de acuerdo con el rol de los ROS endógenos reforzando la señal de calcio por un mecanismo de "feedback" positivo. 


\section{RESULTADOS}

\section{1. $\mathrm{El} \mathrm{H}_{2} \mathrm{O}_{2}$ produce aumento del calcio intracelular}

En estos experimentos los neutrófilos incubados en HBS fueron estimulados por el agregado de fMLP $0.1 \mu \mathrm{M} \circ \mathrm{H}_{2} \mathrm{O}_{2} 1 \mathrm{mM}$. Se utilizó la estimulación con fMLP como control positivo para descartar la posibilidad de que algún resultado pudiera deberse a que las células estuviesen deterioradas o a malas condiciones experimentales. El agregado del $\mathrm{fMLP}$ produjo un aumento de la $\left[\mathrm{Ca}^{2+}\right]_{i}$ debido tanto a la liberación de calcio desde los depósitos intracelulares como a su entrada desde el medio extracelular. Este rápido aumento fue seguido por una disminución progresiva de la $\left[\mathrm{Ca}^{2+}\right]_{i}$ debida a la acción de diversas bombas que se encargan de almacenar nuevamente el calcio en los depósitos intracelulares o lo expulsan hacia el medio externo. Dentro del límite de tiempo registrado, la $\left[\mathrm{Ca}^{2+}\right]_{i}$ disminuyó sin volver a los valores previos a la estimulación.

En cambio, cuando se les agregó $\mathrm{H}_{2} \mathrm{O}_{2}$, los neutrófilos mostraron un aumento lento y sostenido de la concentración de calcio intracelular (Fig. III-1A).

Para poder dilucidar si el aumento en la concentración de calcio intracelular producido por los estímulos utilizados se debía a un aumento en la liberación de calcio desde los depósitos intracelulares o a una mayor entrada desde el medio extracelular o a ambos, se incubaron los neutrófilos en HBS/EGTA, un medio libre de calcio, con $0.1 \mathrm{mM}$ EGTA. En estas condiciones experimentales el aumento de la $\left[\mathrm{Ca}^{2+}\right]_{i}$ que se observó luego del agregado de fMLP $0.1 \mu \mathrm{M}$ fue debido a la liberación de este catión desde los depósitos intracelulares. Cuando 100 segundos después del agregado del fMLP se restableció la concentración extracelular de calcio a $1 \mathrm{mM}$, por el agregado de $\mathrm{CaCl}_{2}$, se produjo un segundo aumento de la $\left[\mathrm{Ca}^{2+}\right]_{i}$ que fue debido a su entrada desde el medio extracelular. En ausencia de agonistas el agregado de calcio extracelular produce un artefacto inespecífico que fue restado para calcular el efecto neto.

La Fig. III-1B muestra que el $\mathrm{H}_{2} \mathrm{O}_{2}$ no causó un aumento de la liberación de $\mathrm{Ca}^{2+}$ desde los depósitos intracelulares, en cambio indujo un aumento de la entrada de calcio de $75 \pm 9 \mathrm{nM}$ (diferencia entre el valor pico y la concentración medida previamente a la estimulación) un valor similar al que se alcanza en las células estimuladas con fMLP (86 $\pm 10 \mathrm{nM})$ y significativamente más alto que la entrada de calcio inespecífica en ausencia de estimulo ( $47 \pm 7 \mathrm{nM})$.

Se estudió la relación entre la concentración de $\mathrm{H}_{2} \mathrm{O}_{2}$ y la entrada neta de calcio (aumento de la $\left[\mathrm{Ca}^{2+}\right]_{i}$ inducida por $\mathrm{H}_{2} \mathrm{O}_{2}$ - el aumento de la $\left[\mathrm{Ca}^{2+}\right]_{i}$ en ausencia de $\mathrm{H}_{2} \mathrm{O}_{2}$ ). La entrada neta de calcio fue $36 \pm 3 \mathrm{nM}$ con $\mathrm{H}_{2} \mathrm{O}_{2} 1 \mathrm{mM}$ y no se encontraron cambios en la entrada neta de calcio con $\mathrm{H}_{2} \mathrm{O}_{2} 10 \mu \mathrm{M}$. La concentración de $\mathrm{H}_{2} \mathrm{O}_{2}$ utilizada para producir un cambio significativo fue alta, pero en el mismo orden de la que fue utilizada en otros estudios de acuerdo con el gran poder reductor que poseen los neutrófilos. La entrada de calcio neta producida por $\mathrm{H}_{2} \mathrm{O}_{2}$ fue similar a la obtenida cuando los neutrófilos fueron estimulados con fMLP.

De acuerdo con esto, en los neutrófilos incubados en presencia de $\mathrm{Mn}^{2+}$, la estimulación con $\mathrm{H}_{2} \mathrm{O}_{2}$ resultó en una rápida disminución de la fluorescencia reflejando la entrada de este catión a través de la membrana (Fig. III-1C). 
Figura III-1. Efecto del $\mathrm{H}_{2} \mathrm{O}_{2}$ sobre los cambios en la concentración de calcio intracelular a lo largo del tiempo. En el panel A los neutrófilos se incubaron $10 \mathrm{~min}$ a $37^{\circ} \stackrel{\circ}{\mathrm{C}}$ en HBS, un medio que contiene $1 \mathrm{mM}$ de $\mathrm{CaCl}_{2}$ y fueron estimulados con $\mathrm{H}_{2} \mathrm{O}_{2}$ (línea verde) o $f M L P$ (línea rosa) en el momento indicado por la flecha. En $B$ se muestra el efecto del $\mathrm{H}_{2} \mathrm{O}_{2}$ sobre la concentración de calcio intracelular en neutrófilos incubados en un medio libre de calcio. Los neutrofilos se incubaron en HBS/EGTA, un medio que no tiene calcio libre, y fueron estimulados con $\mathrm{H}_{2} \mathrm{O}_{2}$ (línea verde) o fMLP (línea rosa) en el momento indicado por la primer flecha. La segunda flecha indica el agregado de $\mathrm{CaCl}_{2}$ para llevar la concentración extracelular de calcio a $1 \mathrm{mM}$ en las condiciones citadas y en un ensayo blanco (línea punteada celeste), sin estímulo, para observar los cambios inespecíficos. El aumento neto, es decir el que resulta de restar el valor pico del trazo con $\mathrm{H}_{2} \mathrm{O}_{2}$ del blanco se represento en el grafico insertado en función del logaritmo de la concentración molar de $\mathrm{H}_{2} \mathrm{O}_{2}$ utilizada en la misma preparación. En $\mathrm{C}$ se muestran los cambios en la fluorescencia del Fura 2, excitado a la longitud de onda isoemisiva para la forma libre y la combinada con calcio tomando como unidad arbitraria el valor en el momento de la estimulación. Los neutrófilos se incubaron en $\mathrm{HBS} / \mathrm{sCa}$, un medio nominalmente libre de calcio, se adiciono con $\mathrm{MnCl}_{2} 30 \mathrm{mM} 5$ min antes del estimulo. En el momento indicado por la flecha se estimulo con $\mathrm{H}_{2} \mathrm{O}_{2}$ (línea verde) o fMLP (línea rosa). Se agrego un ensayo blanco, sin estímulo (línea punteada celeste), para mostrar los cambios inespecíficos. El apagamiento de la fluorescencia indica la entrada de $\mathrm{Mn}^{2+}$, que se usó como subrogante de la entrada de calcio. Resultados similares se obtuvieron en al menos 3 preparaciones diferentes.

\section{2. El aumento de calcio fue inhibido por $\mathrm{Ni}^{2+}$ y $\mathrm{La}^{3+}$}

Para confirmar que el aumento de $\left[\mathrm{Ca}^{2+}\right]_{i}$ se debía a la entrada del calcio a través de la membrana, las células se estimularon con $\mathrm{H}_{2} \mathrm{O}_{2}$ en presencia de niquel ,un bloqueador de los canales de calcio.

La Fig. III-2 muestra que en presencia de $\mathrm{Ni}^{2+} 1 \mathrm{mM}$ se produce una atenuación de la entrada de calcio cuando se agrega $\mathrm{CaCl}_{2} 1 \mathrm{mM}$. Este inhibidor también provocó una reducción de la entrada de calcio inespecífica en células no tratadas con $\mathrm{H}_{2} \mathrm{O}_{2}$. Los valores obtenidos (28 \pm 2 vs. $14 \pm 3 \mathrm{nM}$ ) muestran un efecto inhibitorio sobre la entrada

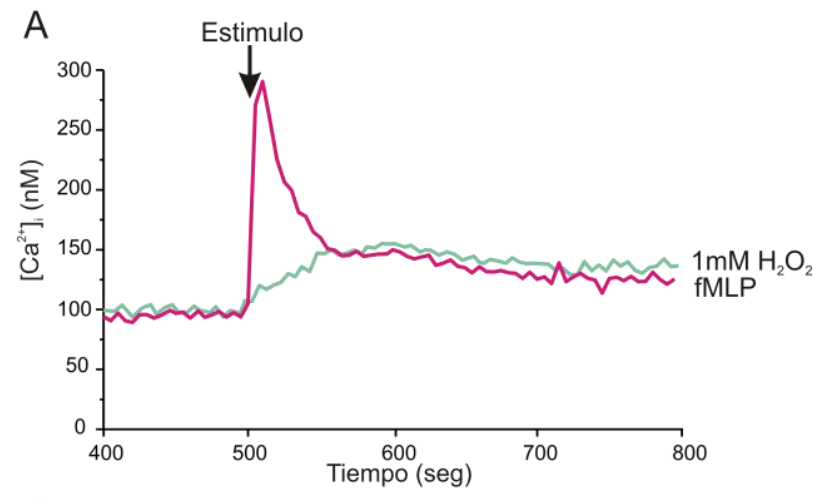

B
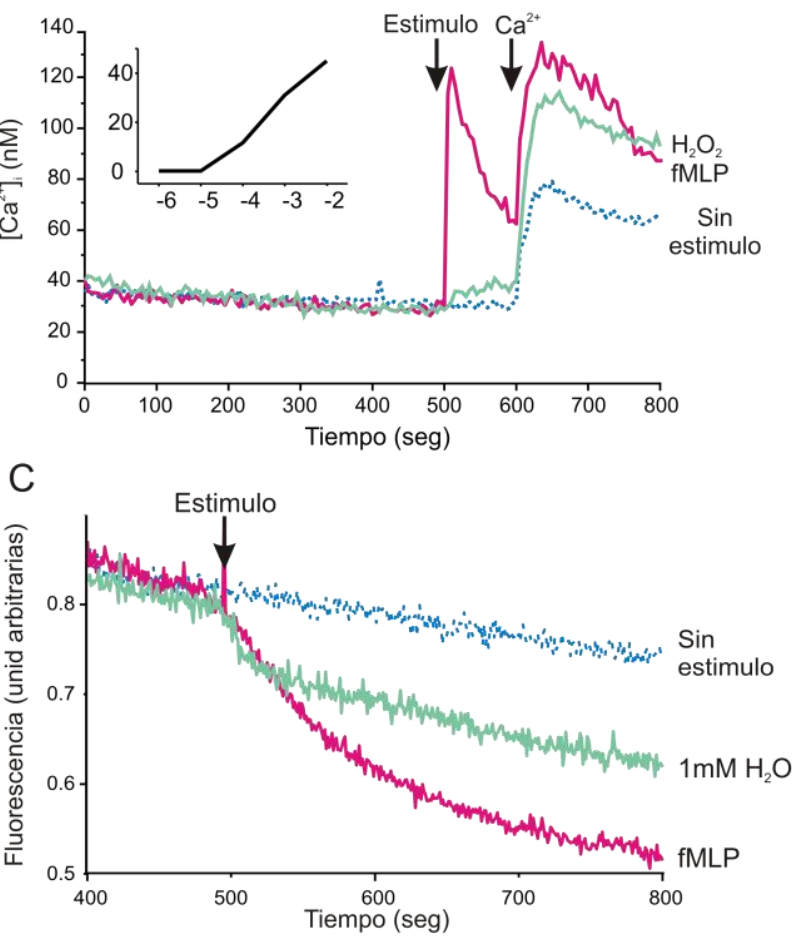
Figura III-2. Efecto de bloqueadores de los canales de calcio sobre el aumento en la concentración de calcio intracelular inducida por el $\mathrm{H}_{2} \mathrm{O}_{2}$. La figura muestra los cambios en la concentración intracelular de calcio a lo largo del tiempo en una preparación representativa. Los neutrófilos se incubaron en HBS/EGTA, un medio libre calcio, y fueron estimulados con fMLP (Panel A) o $\mathrm{H}_{2} \mathrm{O}_{2}$ (Panel B) en el momento indicado por la primer flecha. La segunda flecha indica el agregado de $\mathrm{CaCl}_{2}$ para llevar su concentración extracelular a $1 \mathrm{mM}$. Como se indica a la derecha de los trazos el ensayo se repitió en presencia de $\mathrm{NiCl}_{2} 1 \mathrm{mM}$ (línea punteada gruesa) o $\mathrm{LaCl}_{3} 1 \mathrm{mM}$ (línea punteada fina). El aumento, es decir la diferencia de concentración antes y después del agregado de $\mathrm{CaCl}_{2}$ se representó en el panel C. Cada columna indica la media y error estándar de la media de al menos 4 preparaciones diferentes. Los asteriscos indican diferencias significativas con respecto al grupo sin bloqueador.

específica. Estos hallazgos son consistentes con una vía de entrada de calcio, a través de la membrana, sensible al bloqueo con $\mathrm{Ni}^{2+}$.

Resultados similares fueron obtenidos cuando la entrada de calcio fue bloqueada con otro inhibidor de los canales de calcio: $\mathrm{La}^{3+}$.

\subsection{La entrada de calcio fue inhibida por manitol}

Para dilucidar si el $\mathrm{H}_{2} \mathrm{O}_{2}$ era el responsable directo del efecto sobre la entrada de calcio o este efecto era producido por otra especie reactiva del oxigeno originada a partir del $\mathrm{H}_{2} \mathrm{O}_{2}$, los neutrófilos se incubaron en soluciones con el agregado de manitol (5-200 mM). El manitol produjo una reducción de la entrada neta de calcio inducida por $\mathrm{H}_{2} \mathrm{O}_{2}$. El manitol es un carroñero ("scavenger") selectivo, que neutraliza o elimina radicales $\mathrm{OH}$ más selectivamente que a otros ROS. Dada la alta concentración de manitol utilizada en los ensayos, no es posible descartar que el efecto inhibitorio del manitol no sea debido a la hipertonicidad de la solución ya que su efecto fue parcialmente mimetizado por soluciones preparadas con otros osmolitos como:
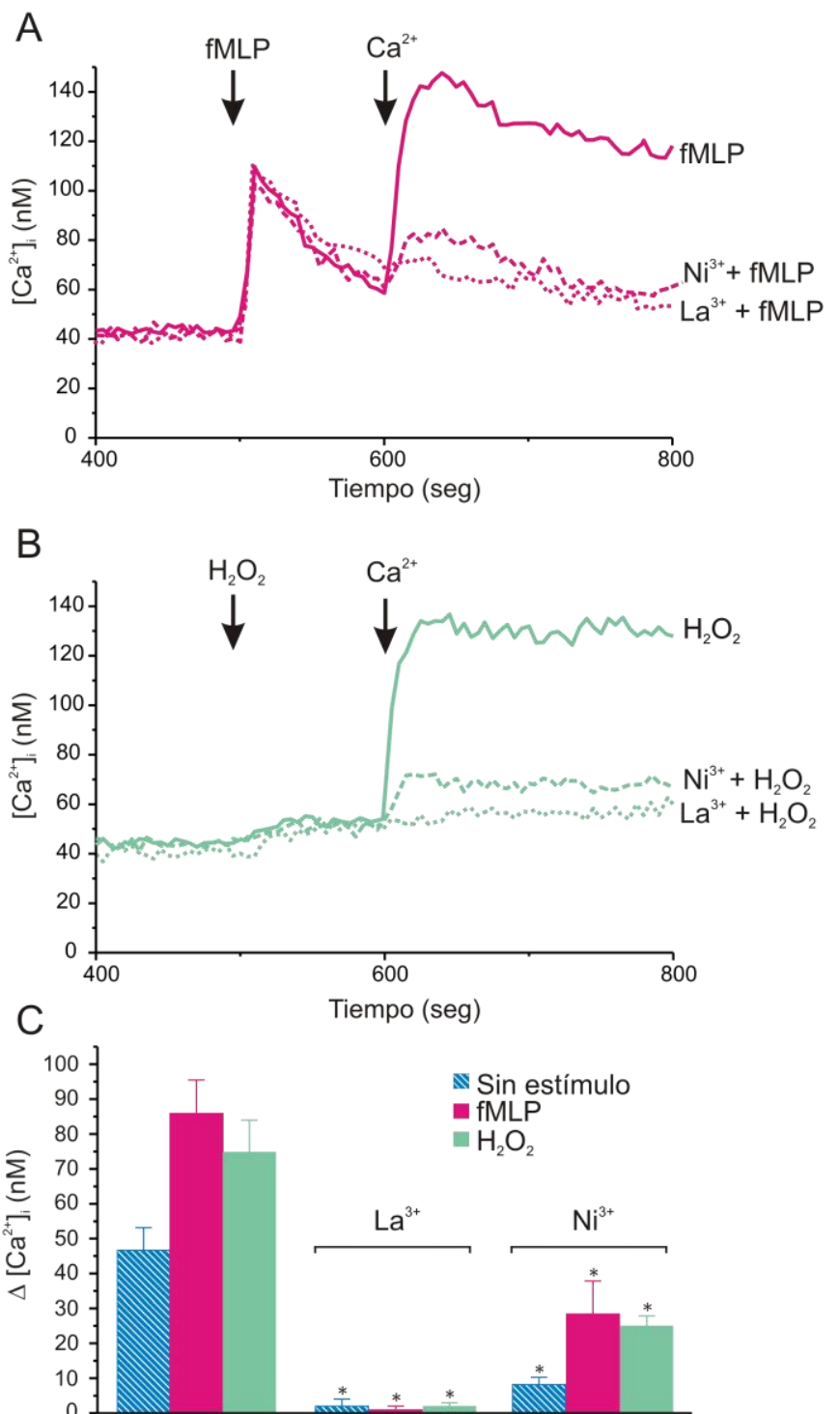
A

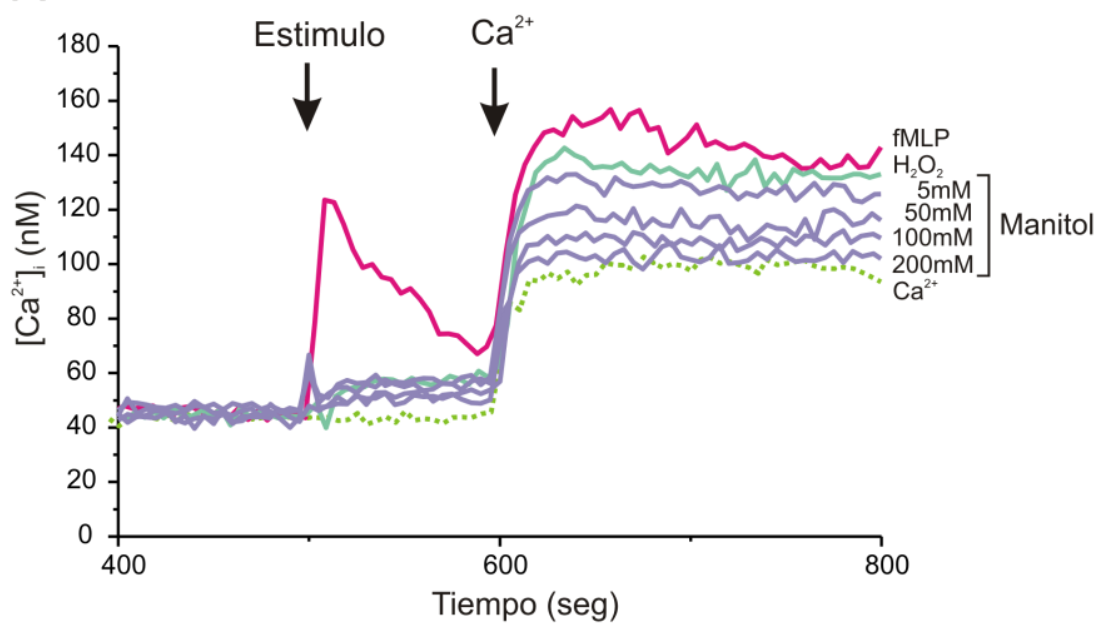

$B$

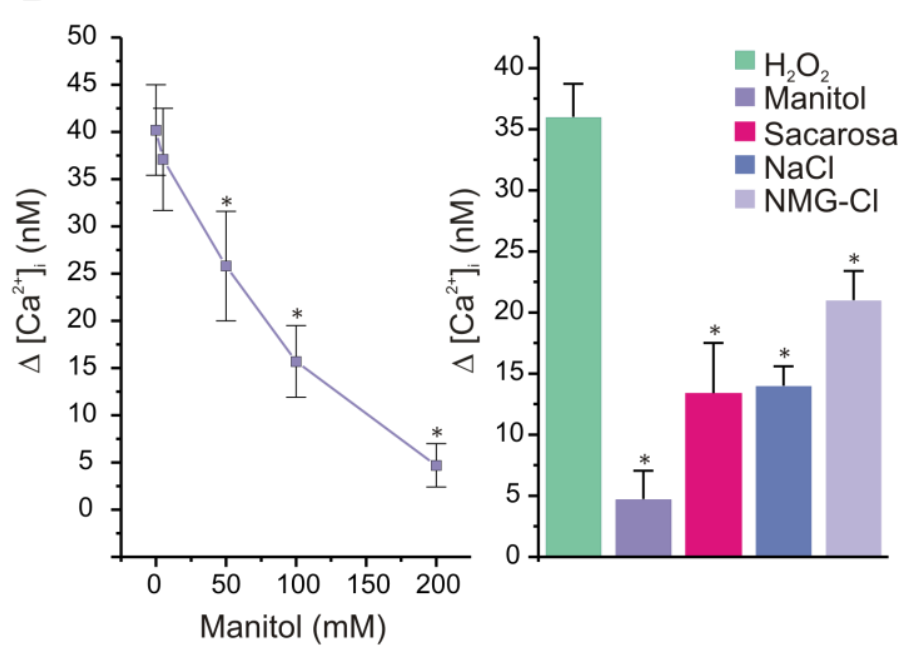

Figura III-3. Efecto del manitol y de soluciones hipertónicas sobre el aumento en la concentración de calcio intracelular inducida por el $\mathrm{H}_{2} \mathrm{O}_{2}$. En A se muestran los cambios en la concentración intracelular de calcio a lo largo del tiempo en una preparación representativa. Los neutrófilos se incubaron en HBS/EGTA, y fueron estimulados con fMLP (línea rosa) $0 \mathrm{H}_{2} \mathrm{O}_{2}$ (línea verde y violetas) en el momento indicado por la primer flecha. La segunda flecha indica el agregado de $\mathrm{CaCl}_{2}$ para llevar su concentración extracelular a $1 \mathrm{mM}$ en las suspensiones citadas y en un ensayo blanco, es decir sin estímulo (línea punteada verde), para observar los cambios inespecíficos. Como se indica a la derecha de los trazos el ensayo se repitió en presencia de diferentes concentraciones de manitol. El aumento, es decir la diferencia de concentración antes y después del agregado de $\mathrm{CaCl}_{2}$ se representó en el panel $B$ en función de la concentración del manitol. Cada punto indica la media y el error estándar de la media de 3 preparaciones diferentes. El panel $C$ muestra el aumento en la concentración de calcio provocado por $\mathrm{H}_{2} \mathrm{O}_{2}$ en presencia de 200 mOsmoles/l adicionales de diferentes osmolitos. Cada columna indica la media y el error estándar de la media de 4 preparaciones diferentes. El asterisco indica diferencias significativas respecto del control isotónico.

$\mathrm{NaCl}$, sacarosa y cloruro de N-metilglucamina (NMG-Cl) (Fig. III-3).

\section{DISCUSIÓN}

Dado que la entrada de calcio a través de canales catiónicos depende de la existencia de una diferencia de potencial electroquímico, la intensa despolarización de la membrana plasmática asociada a la activación de la NADPH oxidasa reduce la fuerza impulsora para la entrada del calcio (Henderson y col., 1987; Schrenzel y col., 1998; Jankowski y Grinstein, 1999). 
¿La activación de la NADPH oxidasa reduce la entrada de calcio, solo por ser electrogénica, o además hay una contribución de los ROS generados? Algunos autores sostienen que los ROS potencian el efecto inhibitorio. El soporte experimental para esta conclusión es que el tratamiento con $\mathrm{H}_{2} \mathrm{O}_{2}$ y $\mathrm{HClO}$ impide la repolarización de la membrana de células estimuladas previamente mientras que la azida sódica, la metionina y la catalasa ejercen un efecto opuesto, potenciando tanto la tasa de repolarización como la entrada de calcio. Además, el tratamiento de neutrofilos con $\mathrm{H}_{2} \mathrm{O}_{2} 10$ $\mu \mathrm{M}$ luego de la estimulación con fMLP reduce la velocidad y la magnitud de repolarización y también reduce la entrada de $\mathrm{Mn}^{2+}$ (Tintinger y Anderson, 2004).

Por el contrario otros trabajos muestran que luego de la estimulación con fMLP los neutrófilos cebados por migración peritoneal y por tratamiento con CitB, maniobras que aumentan la producción de ROS, presentan un aumento mayor y bifásico de la $\left[\mathrm{Ca}^{2+}\right]_{i}($ Kazilek y col., 1988). De acuerdo con estos últimos hallazgos, nuestros resultados muestran que el tratamiento con $\mathrm{H}_{2} \mathrm{O}_{2}$ exógeno aumenta la entrada de calcio en neutrófilos y que este efecto es comparable a la entrada de calcio inducida por el fMLP. El aumento en la entrada de calcio puede relacionarse con un efecto facilitador de los ROS, similar al que ha sido descripto en otros tejidos. Por ejemplo, en plaquetas el $\mathrm{H}_{2} \mathrm{O}_{2}$ induce la activación de vías de señalización involucradas en la entrada de calcio (Redondo y col., 2004, Ben-Amor y col., 2006). En células HEK transfectadas (Wehage y col., 2002; McHugh y col., 2003), microglia (Kraft y col., 2004) y en cultivo de neuronas (Kaneko y col., 2006) se ha reportado que el $\mathrm{H}_{2} \mathrm{O}_{2}$ regula la apertura o la expresión de canales formados por proteínas TRP. La fenilarsina aumenta la entrada de calcio y $\mathrm{Mn}^{2+}$ por una vía independiente al vaciamiento del reservorio (Wang y col., 2005), sugiriendo una posible vía de señalización sensible al estado redox de la célula.

¿La eliminación de otros ROS afecta el efecto facilitador de $\mathrm{H}_{2} \mathrm{O}_{2}$ ? Se ha descripto que el manitol, un "scavenger" de los ROS, impide que se produzca la corriente de calcio inducida por $\mathrm{H}_{2} \mathrm{O}_{2}$ en células transfectadas con TRPM2 (Wehage y col., 2002). De acuerdo con estos hallazgos, nosotros encontramos que el manitol reduce la entrada de calcio inducida por el $\mathrm{H}_{2} \mathrm{O}_{2}$ de manera dependiente de la concentración. Sin embargo, la concentración de manitol necesaria para que se produzca este efecto es alta y dado que hemos encontrado que la hiperosmolaridad reduce el aumento en la $\left[\mathrm{Ca}^{2+}\right]_{i}$, no podemos asegurar que en este efecto no participe el efecto inhibitorio de la hiperosmolaridad de la solución.

¿El calcio que aumenta en el citosol, proviene de depósitos intracelulares o entra por canales de la membrana? Benjarano y col. (2007) demostraron un leve y sostenido aumento de la $\left[\mathrm{Ca}^{2+}\right]_{i}$ en neutrófilos luego del agregado de $\mathrm{H}_{2} \mathrm{O}_{2} 1 \mathrm{mM}$. Ellos atribuyen este aumento a la liberación desde reservorios intracelulares, los cuales se vacían y responden menos a un posterior estímulo por agonistas como el fMLP. Por el contrario, nosotros mostramos que el $\mathrm{H}_{2} \mathrm{O}_{2}$ es insuficiente para producir cambios significativos en la $\left[\mathrm{Ca}^{2+}\right]_{i}$ en ausencia de calcio extracelular. En cambio, cuando se restauró la concentración de calcio extracelular, se produjo una importante entrada de calcio por una vía sensible al $\mathrm{Ni}^{2+}$ y al $\mathrm{La}^{3+}$. 


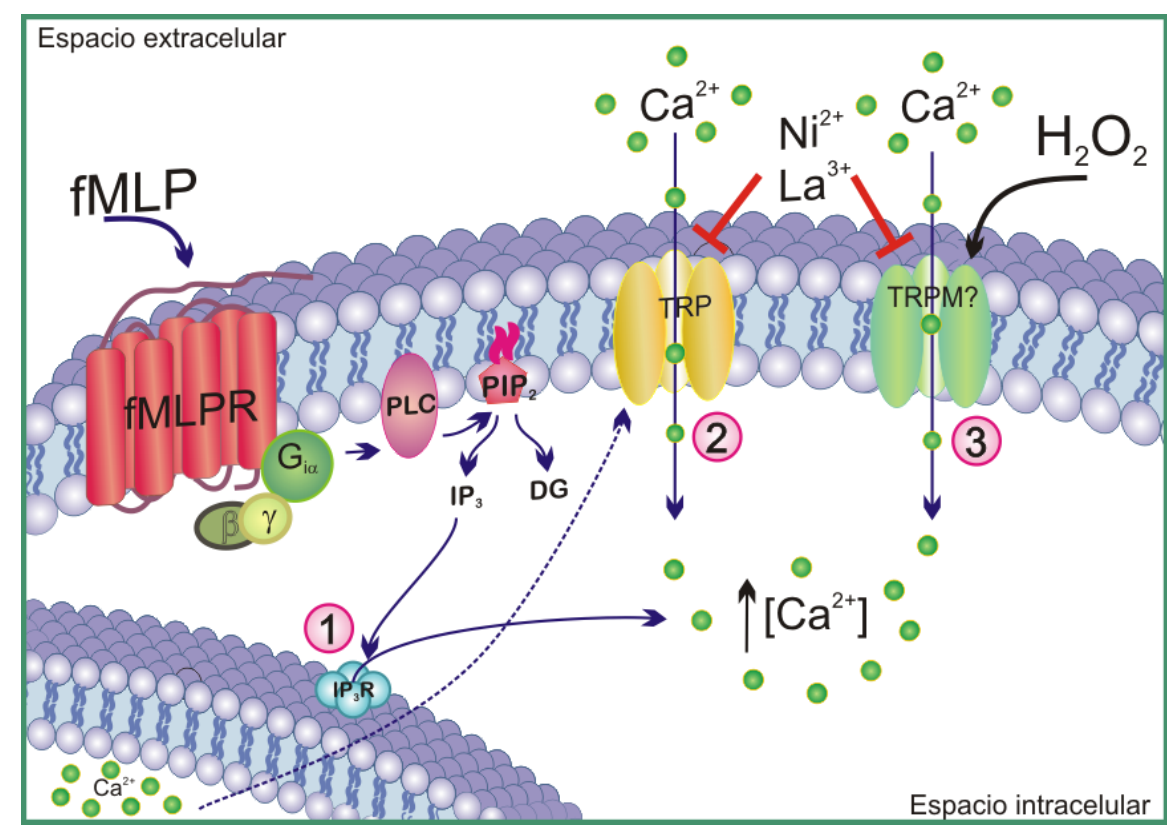

Figura III-4: Comparación de los mecanismos por los que el fMLP y $\mathrm{H}_{2} \mathrm{O}_{2}$ aumentan la concentración de calcio intracelular: 1: Liberación de depósitos intracelulares; 2: Entrada capacitativa de calcio; 3 : Entrada no capacitativa de calcio.

En nuestros estudios mostramos la existencia de un mecanismo dependiente de ROS, que regula y controla la entrada de calcio en neutrófilos circulantes, aunque su función fisiológica no es clara.

¿Son las concentraciones utilizadas fisiológicamente relevantes? Se ha calculado que la cantidad de ROS producidos luego de la estimulación con agentes quimiotácticos en neutrófilos en suspensión a una densidad celular similar a la de la sangre llevaría su concentración a $15 \mu \mathrm{M}$ (Liu y Zweier, 2001). Sin embargo, la concentración de $\mathrm{H}_{2} \mathrm{O}_{2}$ in vivo en el reducido entorno de las células sería mucho más alta, en niveles compatibles con la que hemos utilizado en nuestros experimentos.

¿La secreción de $\mathrm{H}_{2} \mathrm{O}_{2}$ por neutrófilos activados, podría actuar como un regulador autocrino/paracrino de las funciones de los neutrófilos a través de la activación de la entrada de calcio? Fue descripto previamente que el $\mathrm{H}_{2} \mathrm{O}_{2}$ exógeno aumenta la quimiotaxis en neutrófilos peritoneales (Klyubin y col., 1996), las funciones fagocíticas en neutrófilos (Benjarano y col., 2007) y en células de la microglía (Takeda y col., 1998). La sensibilidad de los neutrófilos al $\mathrm{H}_{2} \mathrm{O}_{2}$ ha mostrado ser mucho menor que la de otras células. Rosado y col. (2004), reportaron una significativa elevación de la $\left[\mathrm{Ca}^{2+}\right]_{i}$ luego de la restauración del calcio extracelular en plaquetas pretratadas con $10 \mu \mathrm{M}$ de $\mathrm{H}_{2} \mathrm{O}_{2}$. Esta concentración fue tolerada por los neutrófilos en nuestras condiciones experimentales sin que ocurran cambios en la $\left[\mathrm{Ca}^{2+}\right]_{\mathrm{i}}$. La baja sensibilidad de los neutrófilos circulantes podría servir como un mecanismo para controlar su activación, que solo se desarrollaría para reforzar la actividad de los neutrófilos después de la transmigración hasta el foco de la infección.

Otra función fisiológica que podría tener la entrada de calcio activada por $\mathrm{H}_{2} \mathrm{O}_{2}$ sería la de dar una señal apoptótica cuando el nivel de agentes oxidantes en el ambiente alrededor de las células alcanza niveles peligrosos (Watson, 2002). 


\section{Capítulo IV}

FLUJOS IÓNICOS EN MEDIOS HIPERTÓNICOS 


\section{ANTECEDENTES}

El shock o choque circulatorio es un síndrome clínico complejo, producido por una insuficiencia circulatoria con reducción del aporte de oxígeno y nutrientes a los tejidos, lo que determina la lesión celular. Por su origen se distinguen el shock hipovolémico (hemorrágico, por fístulas o quemaduras graves), cardiogénico (por ineficiencia del corazón) y séptico (por redistribución de la volemia). Independientemente de la causa del shock, en todos los casos se requiere restaurar la volemia.

El tipo de fluidos que deben ser empleados para el tratamiento del shock continúa siendo un tema controvertido. Las soluciones cristaloides que se emplean habitualmente son la solución salina fisiológica ( $\mathrm{NaCl}$ 0,9\%) y el Ringer Lactato, que rápidamente difunden al espacio extravascular. En sujetos sanos adultos sólo una cuarta parte del volumen infundido permanece en el espacio intravascular al cabo de una hora. Por ello se requieren grandes volúmenes para conseguir una volemia adecuada, lo que provoca una disminución de la presión oncótica del plasma. Recientemente se ha empleado la solución salina hipertónica (HS) en el tratamiento del shock hipovolémico, con mejoría en los parámetros hemodinámicos y de oxigenación (Kreimeier y Messmer, 2002). Los volúmenes infundidos son mucho más pequeños que cuando se emplean soluciones isotónicas. La HS es una solución de $\mathrm{NaCl}$ al 7,5\% (2400 mOsm/L) a veces asociada a coloides (Dextrán 70 o hidroxietilalmidón).

$\mathrm{Si}$ bien estas soluciones se empezaron a usar porque mejoraban los parámetros hemodinámicos y de la microcirculación, luego se observó que reducían el riesgo de reacciones inflamatorias disfuncionales.
Debido a sus efectos inmunomodulatorios, las soluciones salinas hipertónicas podrían utilizarse en la resucitación de pacientes con shock séptico e hipovolémico, sepsis severa y otras patologías.

\subsection{Mecanismos Propuestos para la Inmunomodulación y para los Efectos Antiinflamatorios de la Hipertonicidad}

Las soluciones hipertónicas modulan la respuesta inmune y poseen efectos antiinflamatorios ya que inhiben la activación de neutrófilos y macrófagos (Pascual y col., 2003; Powers y col., 2005). La hiperosmolaridad atenúa varias funciones de los neutrófilos como la expresión de CD11b, liberación de elastasa, la producción de superóxido, la fagocitosis y la transmigración (Rizoli y col., 1999a; Rizoli y col., 1999b).

\subsubsection{Efecto sobre la Producción de Citoquinas}

En medios hipertónicos hay disminución de la actividad de NFkb que disminuye la expresión de citoquinas proinflamatorias como IL-1, IL-6, TNF $\alpha$ y aumenta la síntesis de mediadores antiinflamatorios como la IL-10 (Staudenmeyer y col., 2005).

\subsubsection{Modificación en las Cascadas de Señalización}

Podemos mencionar varios pasos en las vías de señalización que estarían mediando los efectos de las soluciones hipertónicas, entre ellos:

Fosforilación de p38 MAPK: la fosforilación de esta quinasa forma parte de la cascada de señalización de muchos estímulos que producen respuestas inflamatorias. La fosforilación de esta proteína se encuentra reducida en medios hipertónicos (Ciesla y col., 2000). 
Concentración Intracelular de $A M P C$ : se ha encontrado un aumento en la concentración intracelular de AMPc en neutrófilos incubados en medio hipertónico, lo cual se ha relacionado con la disminución de la actividad inflamatoria de estas células (Orlic y col., 2002).

Expresión de las HSP: las HSP (Heat shock proteins o proteínas de golpe térmico) estarían implicadas en la inmunomodulación por $\mathrm{NaCl}$ hipertónico. Se observó una reducción de la apoptosis y del daño en intestino de ratones con shock hemorrágico debido a la preservación de la expresión de HSP40 y HSP70 (Murao y col., 2003).

Vías de Señalización Mediadas por Calcio: la alteración de la señalización por calcio es un tema controvertido que discutiremos luego de presentar los resultados obtenidos en relación a este tema.

\section{RESULTADOS}

2.1. La citocalasina $B$ incrementa la producción de ROS, la movilización y la entrada de calcio y la entrada de manganeso inducida por el fMLP

Luego de la estimulación con fMLP se desencadena una producción explosiva de ROS. En un medio isotónico, la liberación de ROS fue $6.88 \pm 1.27$ veces mayor en las células pretratados con CitB que en las células no tratadas (Fig. IV-1A). Las células expuestas a la CitB exponen en su membrana una mayor cantidad de receptores para fMLP y representarían un estado de activación similar al que tienen los neutrófilos que migran hacia los tejidos.

El aumento de la $\left[\mathrm{Ca}^{2+}\right]_{i}$ medido en un medio con calcio $1 \mathrm{mM}$ mostró un aumento monofásico en el control y bifásico en células pretratadas con CitB. Este aumento de calcio bifásico, consta de un
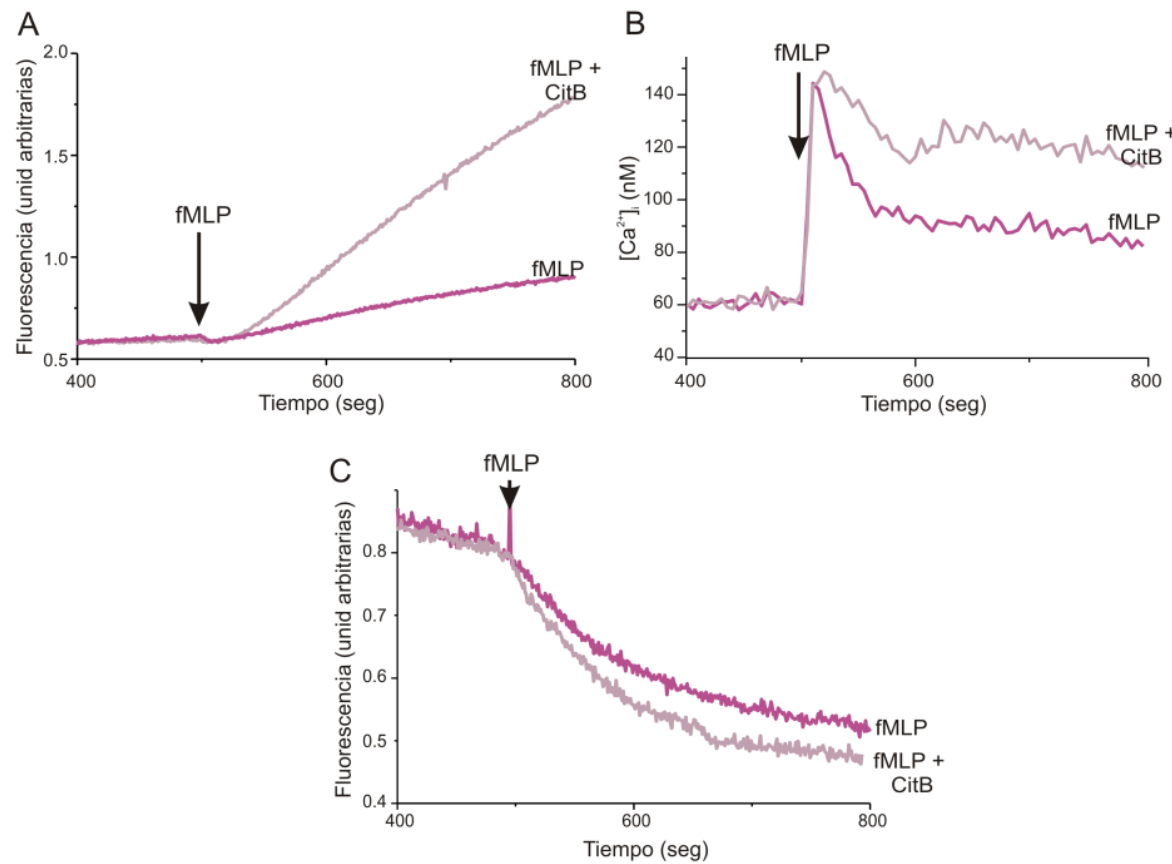

Figura IV-1: Efecto de la citocalasina B sobre la producción de ROS y el movimiento de iones bivalentes en neutrófilos aislados. Las figuras muestran una representación gráfica de los cambios de fluorescencia a lo largo del tiempo en una preparación representativa. Los neutrófilos se incubaron en HBS con el agregado de $5 \mathrm{mg} / \mathrm{ml}$ de CitB (línea lila) o sin él (línea rosa) y fueron estimulados con fMLP $0.1 \mu \mathrm{M}$ en el momento indicado por la flecha. En el panel A se muestra los cambios de fluorescencia del Oxyburst a lo largo del tiempo; en $B$ los cambios de concentración intracelular de calcio; en $C$ el apagado de la fluorescencia del FURA 2 que indica mayor la entrada de $\mathrm{Mn}^{2+}$ en presencia de CitB.

primer aumento en la $\left[\mathrm{Ca}^{2+}\right]_{i}$ similar al control, seguida de un segundo aumento de la $\left[\mathrm{Ca}^{2+}\right]_{\mathrm{i}}$ que se produce tardíamente. El área bajo la curva 5 minutos después del agregado del fMLP fue $174 \pm 18 \%$ mayor en los neutrófilos tratados con CitB que en los no tratados (Fig. IV-1B). 
En presencia de manganeso $\left(\mathrm{Mn}^{2+}\right)$, la estimulación de los neutrófilos con fMLP resultó en una disminución de la fluorescencia reflejando una velocidad de entrada de cationes bivalentes mayor en células pretratadas con Cit B (Fig. IV-1C).

2.2. La hiperosmolaridad reduce la producción de ROS inducida por distintos agonistas

La Fig. IV-2 muestra el efecto de la hipertonicidad sobre la producción de ROS en neutrófilos con o sin CitB.

Se observó un efecto depresor de la hipertonicidad sobre la producción de ROS inducida por fMLP tanto en neutrófilos tratados como en los no tratados con CitB, al mismo nivel independientemente del tratamiento previo $(15 \% \pm 4 \%$ de la liberación de ROS en el control isotónico).

Cuando se utilizó PMA se produjo un mayor incremento en la producción de ROS que con el fMLP y aunque la respuesta al fMLP fue reducida cuando las células fueron incubadas en medio hipertónico, la respuesta al PMA sufrió variaciones menos importantes (Fig. IV-2) en ausencia de CitB. EI PMA es un activador de PKC que no tiene efecto sobre la concentración de calcio intracelular; el escaso efecto de la hipertónicidad sobre la producción de ROS inducida por PMA descartó una posible vía de acción "downstream" PKC e independiente de la señal de calcio.

La producción de ROS inducida por PMA se incrementó significativamente en neutrófilos pre-tratados con CitB y se redujo a un $72 \% \pm 7 \%$ del control isotónico cuando se aumentó la osmolaridad del medio (Fig. IV-2B). Estos resultados evidencian que el efecto inhibitorio de las soluciones hipertónicas sobre la producción de ROS ocurre principalmente a nivel de la membrana y es "upstream" PKC.

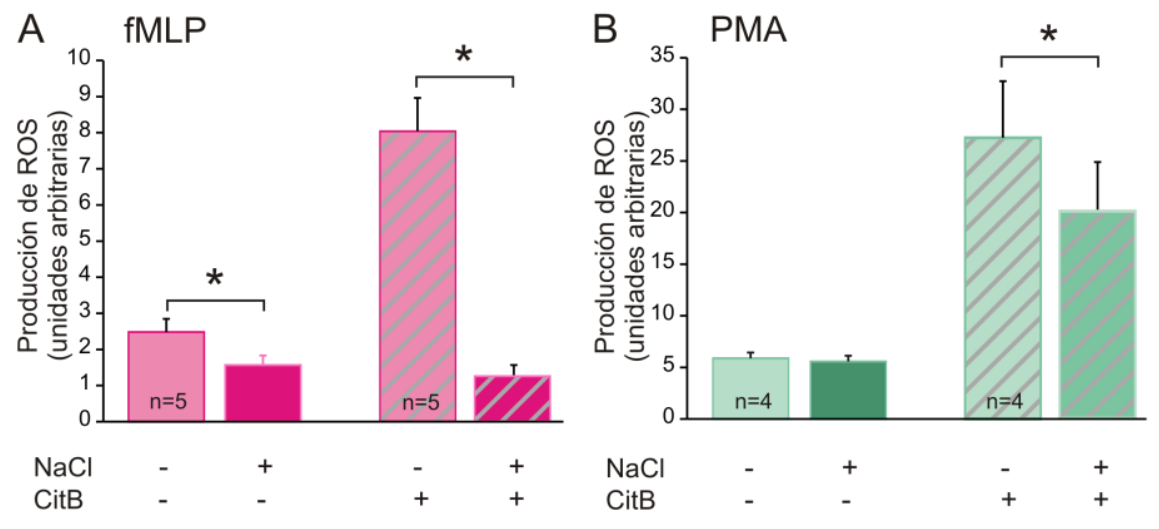

Figura IV-2: Efecto del NaCl sobre la producción de ROS en neutrófilos estimulados con fMLP o PMA. En el panel A las columnas representan en términos porcentuales la producción de ROS inducida por $\mathrm{AMLP} 0.1 \mu \mathrm{M}$ en neutrófilos suspendidos en HBS isotónico o en presencia de $200 \mathrm{mOsmoles/l} \mathrm{adicionales} \mathrm{de} \mathrm{NaCl;} \mathrm{El} \mathrm{panel} \mathrm{B} \mathrm{muestra} \mathrm{la}$ respuesta inducida por PMA $0.1 \mu \mathrm{M}$. Las barras rayadas corresponden a neutrófilos tratados con CitB 5 min antes del estímulo. Cada columna indica la media y error estándar de la media. El número de preparaciones apareadas se indica en la columna que representa al control isotónico. El asterisco indica $P<0.05$.

2.3. La disrupción del citoesqueleto no altera el efecto inhibitorio de la hiperosmolaridad

Dado que la producción de ROS inducida por el fMLP resultó ser muy pobre en medio isotónico como para caracterizar el efecto de la hiperosmolaridad sobre esta respuesta, en los experimentos subsiguientes sólo se estudió la respuesta en neutrófilos tratados con CitB.

La importancia de la secuencia CitB/Hiperosmolaridad/fMLP vs. Hiperosmolaridad/CitB/fMLP en la producción de ROS se estudió utilizando el agregado de diversas de cantidades de $\mathrm{NaCl}(25-100 \mathrm{mM})$. 


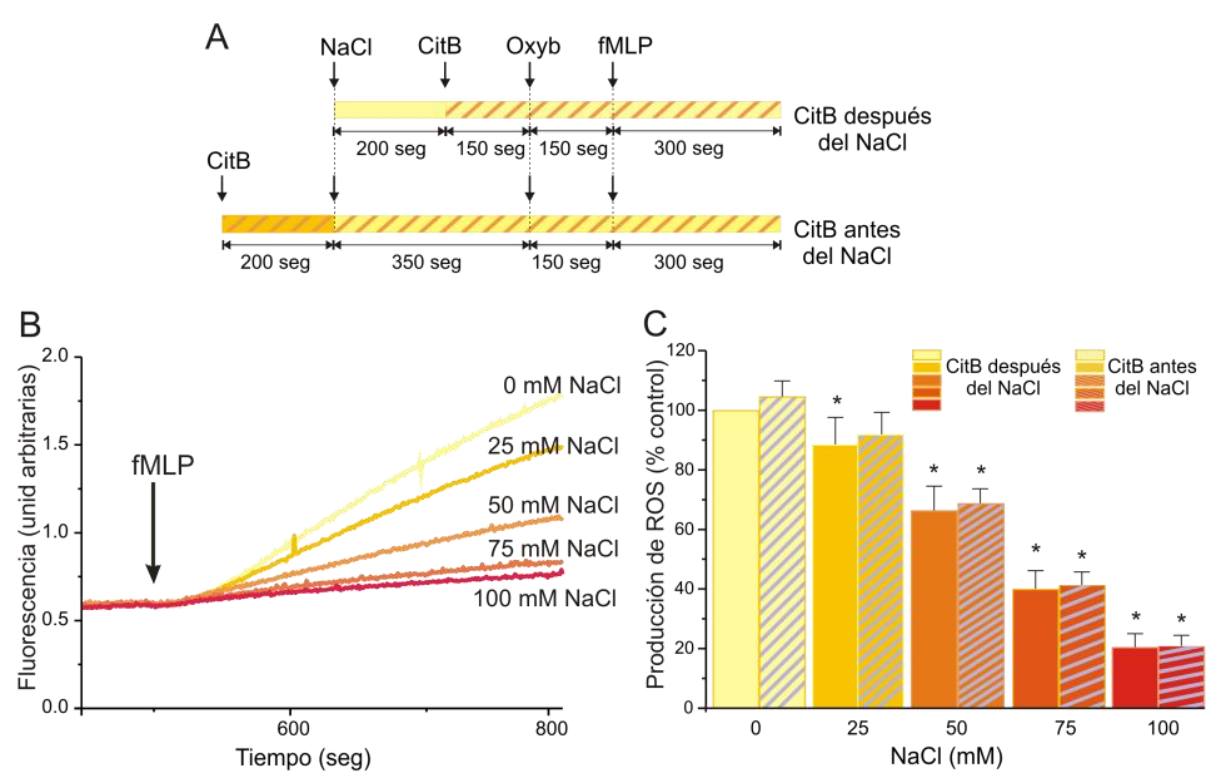

Figura IV-3: Efecto de la disrupción del citoesqueleto sobre la producción de ROS. En el panel A se muestran las secuencias de los protocolos seguidos donde la CitB se agregó previo o posterior al agregado del $\mathrm{NaCl}$; en $\mathrm{B}$ se muestra un experimento típico en neutrófilos tratados con CitB 200 segundos después del agregado $\mathrm{NaCl}$ a distintas concentraciones; en $C$ las columnas corresponden a los valores medios $\pm S E M$. El asterisco indica $P<0.05$ respecto al grupo isotónico tratado con CitB después del agregado del $\mathrm{NaCl}(n=4)$.

Se realizaron dos grupos de experimentos en los cuales los neutrófilos eran tratados con CitB 200 segundos antes o después del agregado de distintas concentraciones de $\mathrm{NaCl}$ (Fig. IV-3). En ambos casos la reducción en la producción de ROS fue similar, por lo cual se concluyó que la CitB no es capaz de revertir ni prevenir el efecto inhibitorio de la hiperosmolaridad sobre esta respuesta.

\subsection{El efecto inhibitorio de la hiperosmolaridad es reversible}

Para dilucidar si los neutrófilos guardaban algún tipo de memoria del tratamiento al que habían sido expuestos aun cuando el $\mathrm{NaCl}$ en exceso era removido del medio se estudió la reversibilidad del efecto inhibitorio de la hiperosmolaridad sobre la producción de ROS. Los neutrófilos fueron expuestos a soluciones adicionadas con $100 \mathrm{mM}$ de $\mathrm{NaCl}$ por 10 minutos y luego se retornó al nivel de isotonicidad por el agregado de una solución hipoosmótica. Los neutrófilos permanecieron por 100 segundos en esta solución isoosmótica antes de la estimulación con fMLP. Se observó una reversión parcial del efecto de la hipertonicidad sobre la producción de ROS $(72.5 \pm 2.24 \%$ del control isotónico) 100 segundos después de haber retornado a la isotonicidad (Fig. IV-4).

\subsection{La hiperosmolaridad tardía tiene un efecto paradojal}

La Fig. IV-5 muestra experimentos en los que se estudió el cambio en la producción de ROS cuando la osmolaridad del medio aumentó tardíamente, para determinar el efecto de la hiperosmolaridad posterior a la activación. Se determinó la producción de ROS inducida por el agregado del fMLP, 150 segundos después del comienzo de la activación se agregó $\mathrm{NaCl} 100 \mathrm{mM}$. Paradójicamente, el aumento de la osmolaridad del medio produjo un aumento significativo de la producción de ROS $(86.8 \% \pm 6.4 \%$ en medio isotónico vs. $115.5 \% \pm$ $9 \%$ en medio hiperosmótico).

\subsection{El efecto inhibitorio es independiente del osmolito utilizado}

La Fig. IV-6 muestra el efecto de las soluciones hipertónicas compuestas por diversos osmolitos estudiada en neutrófilos pretratados con Cit B. Se observó que el efecto inhibitorio de la 

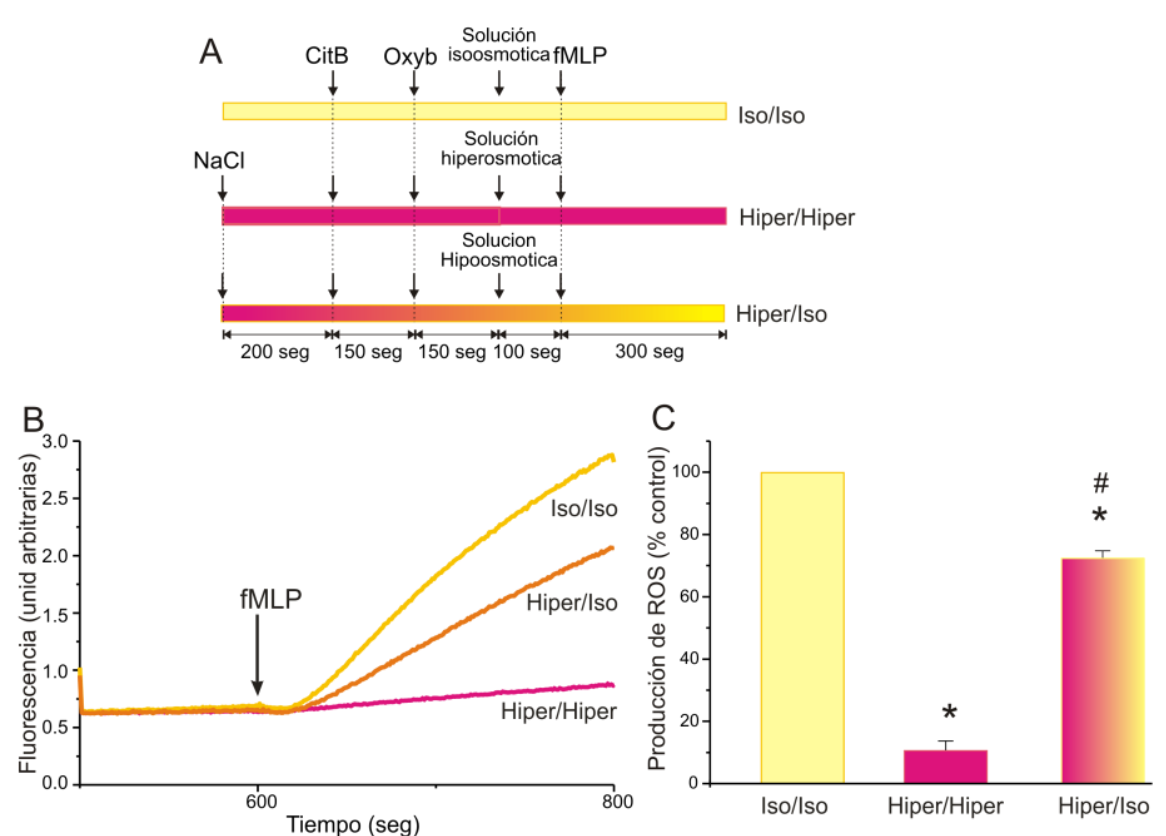

Figura IV-4: Reversibilidad del efecto inhibitorio de la hiperosmolaridad. El panel A muestra las secuencias de los protocolos seguidos; $B$ se muestra un experimento típico, con neutrófilos tratados con CitB y preincubados en medio isotónico (Iso/Iso) o hipertónico (Hiper/Hiper) antes de ser estimulados con $\mathrm{fMLP}$, o incubados en medio hipertónico y cambiado a isotónico100 segundos antes de estimularlos (Hiper/lso); en C las barras corresponden a los valores medios \pm SEM. $E I{ }^{*}$ indica $P<0.05$ respecto al grupo Iso/lso y el \# con respecto al Hper/Hiper ( $n=3$ ).

hiperosmolaridad sobre la producción de ROS medido en soluciones con el agregado de $\mathrm{NaCl}$ pudo ser reproducido cuando los neutrófilos fueron incubados en soluciones hipertónicas por el agregado de cloruro de N-metilglucamina (NMG-Cl) o sacarosa (13.3 $\pm 2.4 \%$ en $\mathrm{NaCl}, 20.2$
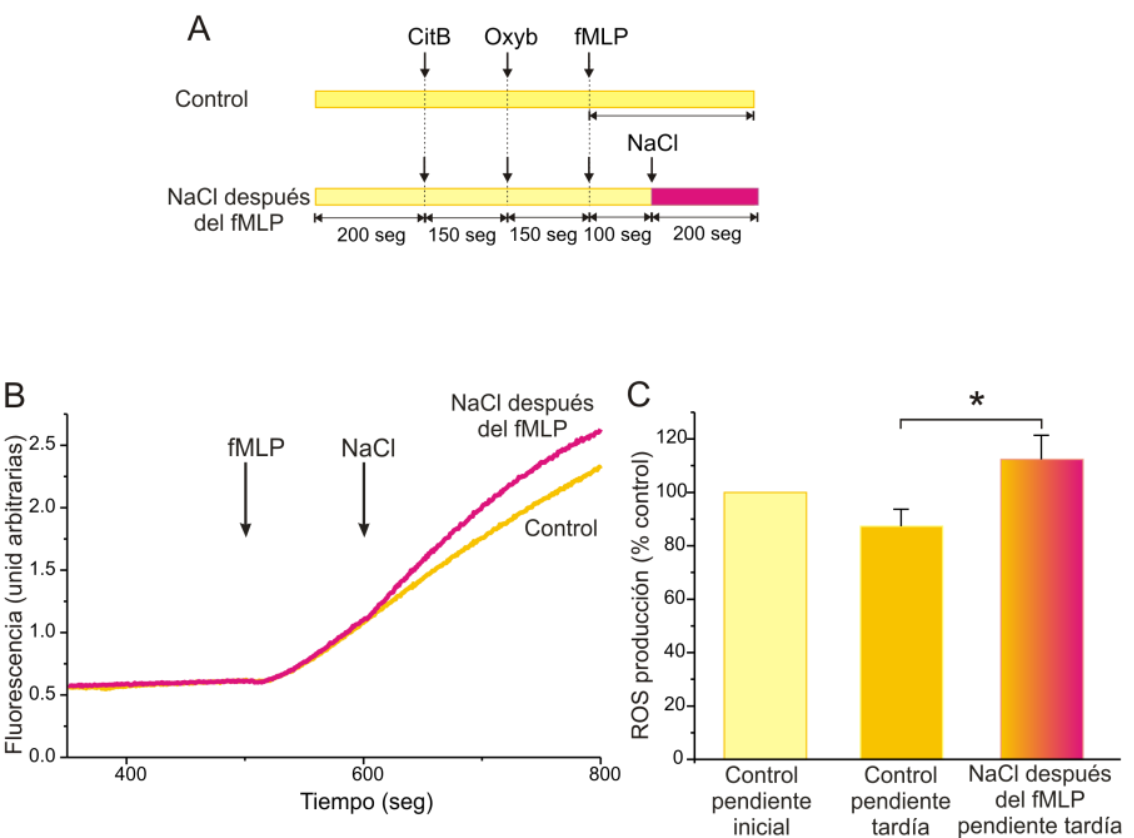

Figura IV-5: Efecto del aumento tardío de la osmolaridad. En el panel A se muestra la secuencia de los protocolos seguidos; en $B$ un experimento típico (aumento de osmolaridad previo: línea amarilla, o posterior a la estimulación con fMLP: línea rosa); y en $C$ las columnas corresponden a los valores medios \pm SEM de la pendiente máxima antes y después del cambio de osmolaridad expresadas como porcentaje del experimento apareado en HBS. El * indica $P<0.05$ test de " $t$ " para muestras apareadas. $(n=4)$.

$\pm 4.3 \%$ en NMG-Cl y $10 \pm 4 \%$ en solución de sacarosa), mostrando que este efecto era independiente del osmolito utilizado. Sin embargo las soluciones de manitol mostraron un efecto inhibitorio mucho menor (72.2 $\pm 6 \%$ del control isotónico). 

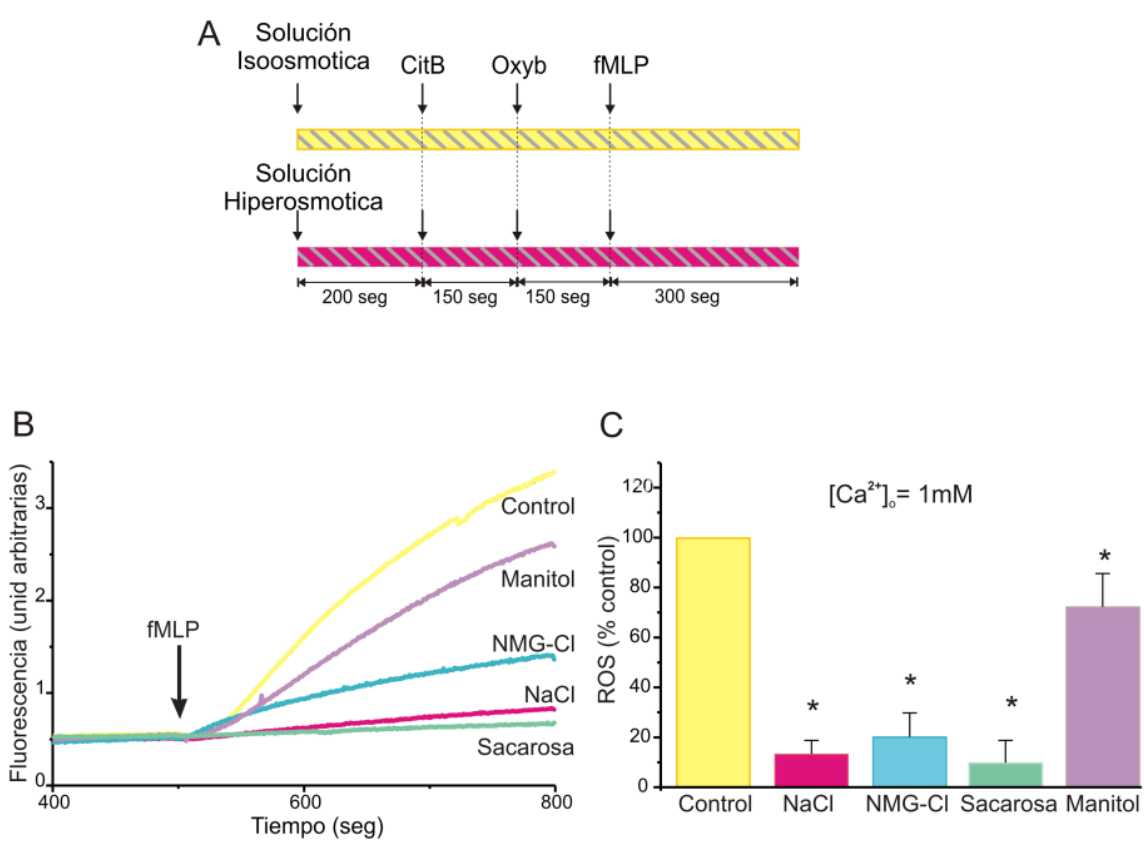

Figura IV-6: Efecto de soluciones hipertónicas de distintos osmolitos sobre la producción de ROS. En el panel A se muestra la secuencia de los protocolos seguidos; B muestra un experimento típico con diversos osmolitos; en $C$ las columnas corresponden a los valores medios $\pm S E M$ de la pendiente máxima expresados como porcentaje del experimento apareado en HBS. EI * indica $P<0.05$ ANOVA para muestras repetidas. $(n=4)$.

\subsection{La restitución del calcio extracelular no afecta la producción de} ROS

Se estudió el efecto de la hiperosmolaridad sobre la producción de ROS en ausencia de calcio extracelular. En soluciones isotónicas, la producción de ROS inducida por fMLP se redujo en ausencia de calcio extracelular en $\left[\mathrm{Ca}^{2+}\right]_{0}=0 \mathrm{mM}$ a $67 \%$ de la respuesta en $\left[\mathrm{Ca}^{2+}\right]_{0}=1 \mathrm{mM}$.
A Solución
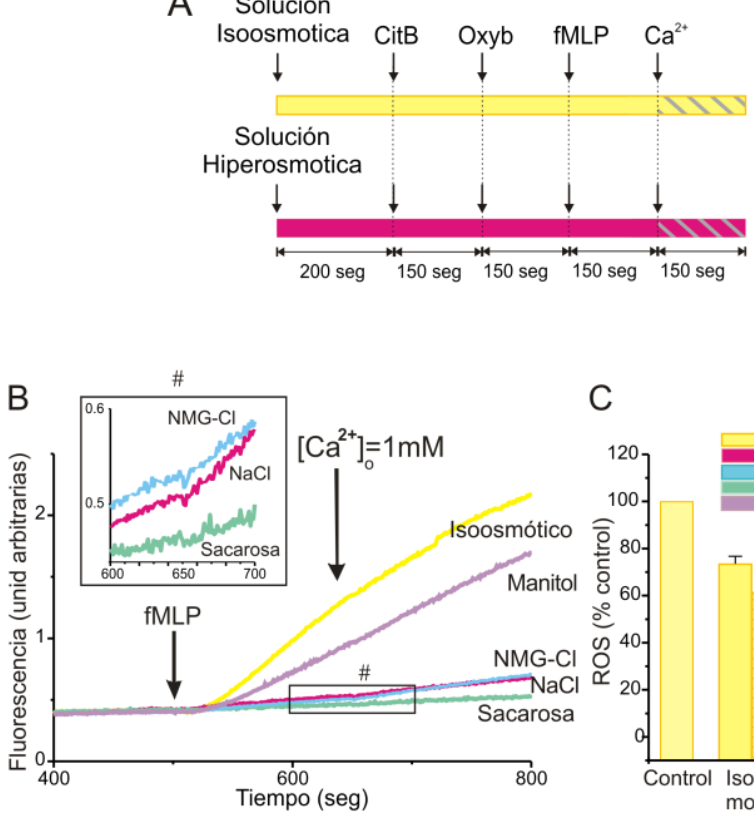

C

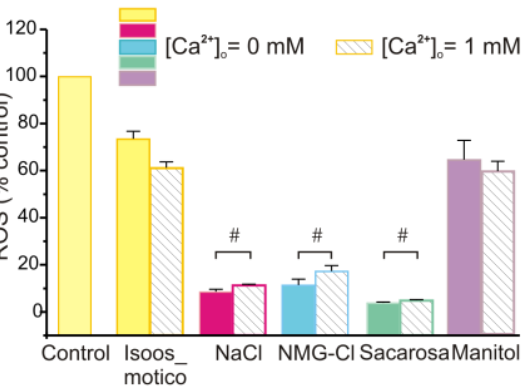

Figura IV-7: Efecto de soluciones hipertónicas de distintos osmolitos sobre la producción de ROS en medios libres de calcio. En el panel A se muestran la secuencia de los protocolos seguidos; en $B$ se muestran los trazos de un experimento típico en $\mathrm{HBS} / \mathrm{sCa}$, con restitución del calcio extracelular a $1 \mathrm{mM}$ posterior a la estimulación con $\mathrm{fMLP}$. En medio isotónico (línea amarilla) o con agregado de 200 mosmoles/l de diferentes osmolitos. En C las columnas corresponden a los valores medios \pm SEM de la pendiente máxima antes (lisas) y después (rayadas) de la restitución del calcio expresados como porcentaje del experimento apareado en el control isotónico en HBS. El asterisco indica $P<0.05$ test de "t" para muestras apareadas. $(n=5)$.

extracelular en $\left[\mathrm{Ca}^{2+}\right]_{0}=0 \mathrm{mM}$ a $67 \%$ de la respuesta en $\left[\mathrm{Ca}^{2+}\right]_{0}=1 \mathrm{mM}$. El agregado de calcio 150 segundos después de la estimulación no produjo cambios en la tasa de producción de ROS en medio isotónico pero si se produjo un aumento significativo cuando los neutrófilos habían sido incubados en un medio al cual se le había adicionado 
$\mathrm{NaCl}, \mathrm{NMG}-\mathrm{Cl}$ o sacarosa $(7.88 \%$ a $10.4 \%$ en $\mathrm{NaCl}, 10.2 \%$ a $15.5 \%$ en NMG-Cl y $3.4 \%$ a $4.5 \%$ en sacarosa, expresado en $\%$ del control isotónico) (Fig. IV-7).

2.8. La hiperosmolaridad reduce el aumento en la concentración de calcio intracelular inducida por $\mathrm{FMLP}$

En la Figura IV-8 se muestra en un experimento típico el aumento de $\left[\mathrm{Ca}^{2+}\right]_{i}$ producida por el fMLP en neutrófilos incubados en solución con $\left[\mathrm{Ca}^{2+}\right]_{\mathrm{e}}=1 \mathrm{mM}$ en medio isotónico o hipertónico. Este aumento de la $\left[\mathrm{Ca}^{2+}\right]_{i}$ fue debido tanto a su liberación desde los depósitos intracelulares como a su entrada desde el medio extracelular. Tanto el pico como la duración del aumento de la $\left[\mathrm{Ca}^{2+}\right]_{i}$ se incrementaron en los neutrófilos tratados con CitB. La hipertonicidad no provocó cambios significativos en la $\left[\mathrm{Ca}^{2+}\right]$ basal, mientras que el pico y la duración del cambio de $\left[\mathrm{Ca}^{2+}\right]_{i}$ disminuyeron significativamente, llegando a valores similares en los neutrófilos tratados con CitB y en los no tratados.

2.9. La hipertonicidad reduce la movilización de calcio desde los depósitos intracelulares

Para poder dilucidar si el efecto inhibitorio de las soluciones hipertónicas, se debía a una disminución en la liberación o a una menor entrada de calcio desde el medio extracelular o a ambos, los neutrófilos se incubaron en soluciones libres de calcio, isotónicas 0 hipertónicas. En ausencia del fMLP el agregado de calcio extracelular produce un pequeño artefacto que no es afectado por el cambio en la osmolaridad del medio (Fig. IV-9). La hipertonicidad produjo una reducción significativa de la movilización de calcio desde los depósitos, y secundariamente una reducción de su entrada a través de la membrana en neutrófilos tratados y no tratados con CitB.

También se estudió la dependencia con la concentración de $\mathrm{NaCl}$ del efecto inhibitorio que poseen las soluciones hipertónicas sobre los aumentos en la $\left[\mathrm{Ca}^{2+}\right]_{i}$ inducido por el fMLP. Los neutrófilos aislados fueron incubados 600 segundos en medios libres de $\mathrm{Ca}^{2+}$ con el agregado de $\mathrm{NaCl}$ 0, 25, 50, 75 y 100mM y luego fueron estimulados con fMLP. La movilización de calcio desde los depósitos intracelulares mostró ser dependiente de la concentración de $\mathrm{NaCl}$ y se observó que pequeños aumentos en la concentración de $\mathrm{NaCl}$ eran suficientes para lograr una reducción significativa de la $\left[\mathrm{Ca}^{2+}\right]_{i}(\mathrm{Fig}$. IV-10).

\subsection{El efecto inhibitorio de la hiperosmolaridad sobre el aumento en la $\left[\mathrm{Ca}^{2+}\right]_{i}$ es reversible}

Para poder dilucidar si los neutrófilos guardaban algún tipo de memoria del tratamiento al que habían sido expuestos aun cuando el $\mathrm{NaCl}$ en exceso era removido del medio se estudio la reversibilidad del efecto inhibitorio de la hiperosmolaridad. Estos experimentos se realizaron con protocolos similares a los utilizados cuando se estudió este efecto sobre la producción de ROS. Los neutrófilos fueron expuestos a soluciones adicionadas con $100 \mathrm{mM}$ de $\mathrm{NaCl}$ en ausencia de calcio extracelular por 10 minutos y luego se retornó al nivel de isotonicidad por el agregado de una solución hipoosmótica. Los neutrófilos permanecieron por 100 segundos en esta solución isoosmòtica antes de la estimulación con fMLP. En estos experimentos se observó que la inhibición de la movilización de calcio fue parcialmente reversible en estas condiciones experimentales (Fig. IV11). 


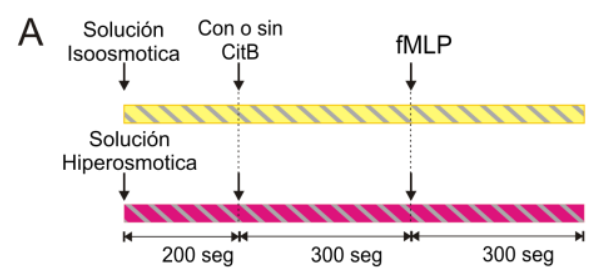

B

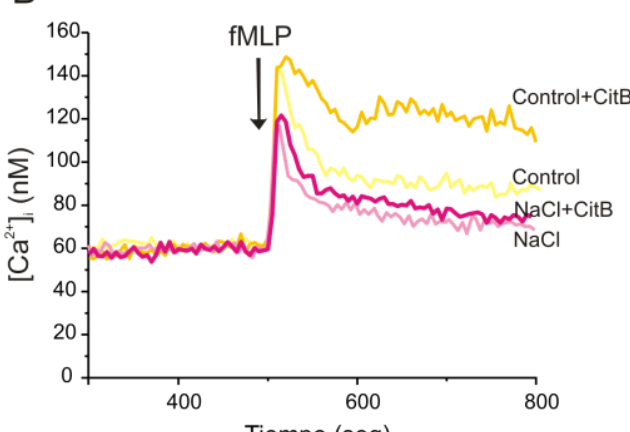

C

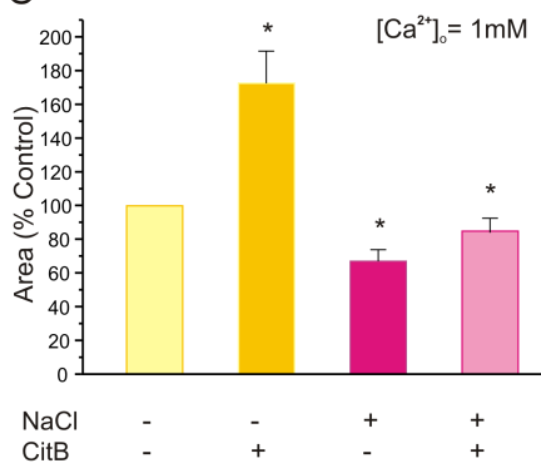

Figura IV-8: Efecto de la hiperosmolaridad sobre el aumento de la concentración de calcio intracelular inducida por el fMLP. En el panel A se muestra la secuencia de los protocolos seguidos; en $B$ se muestra el cambio de la concentración intracelular de calcio en un experimento típico con neutrófilos suspendidos en HBS en ausencia o presencia de CitB y/o 200 Osmoles/l adicionales de NaCl; y en C las columnas corresponden a los valores medios \pm SEM del área bajo la curva durante 5 minutos después de la estimulación con $f M L P$. Los valores fueron expresados como porcentaje del experimento apareado en HBS. El * indica $P<0.05$ ANOVA. $(n=4)$.

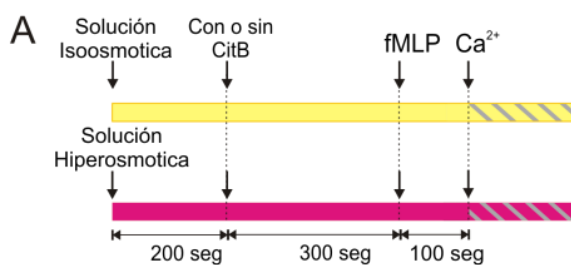

B
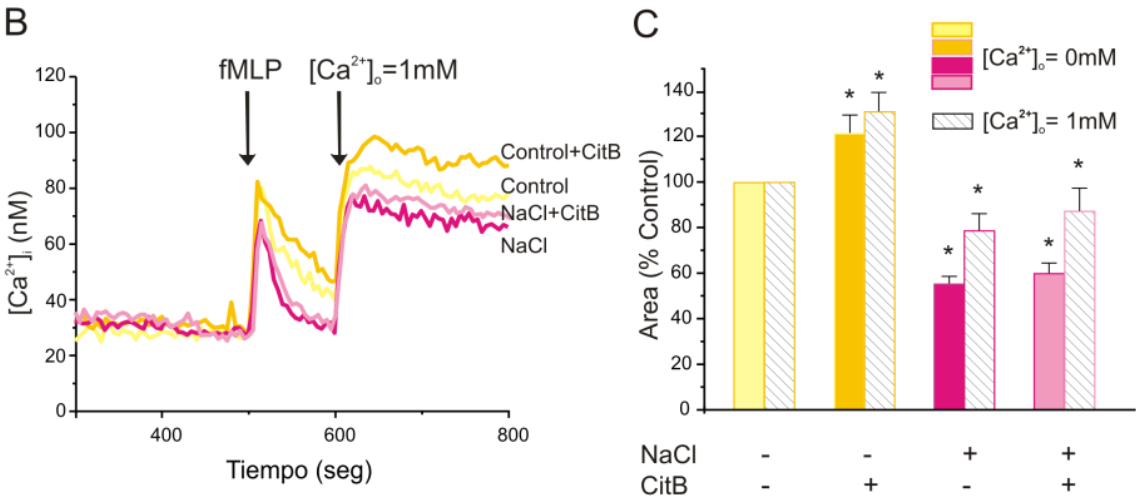

Figura IV-9: Efecto de la hiperosmolaridad sobre el aumento de la concentración de calcio intracelular en medios libres de calcio. El panel $A$ se muestra la secuencia de los protocolos seguidos; en $B$ se muestran los cambio en la concentración intracelular de calcio en un experimento típico con neutrófilos suspendidos en HBS/EGTA en ausencia o presencia de CitB y/o 200 Osmoles/l adicionales de NaCl; en C las columnas corresponden a los valores medios \pm SEM del área bajo la curva durante 100 segundos después del estimulo con fMLP o 200 segundos después de la restauración del calcio extracelular a $1 \mathrm{mM}$, expresadas como porcentaje del experimento apareado en HBS. EI * indica $P<0.05$ ANOVA. $(n=4)$. 

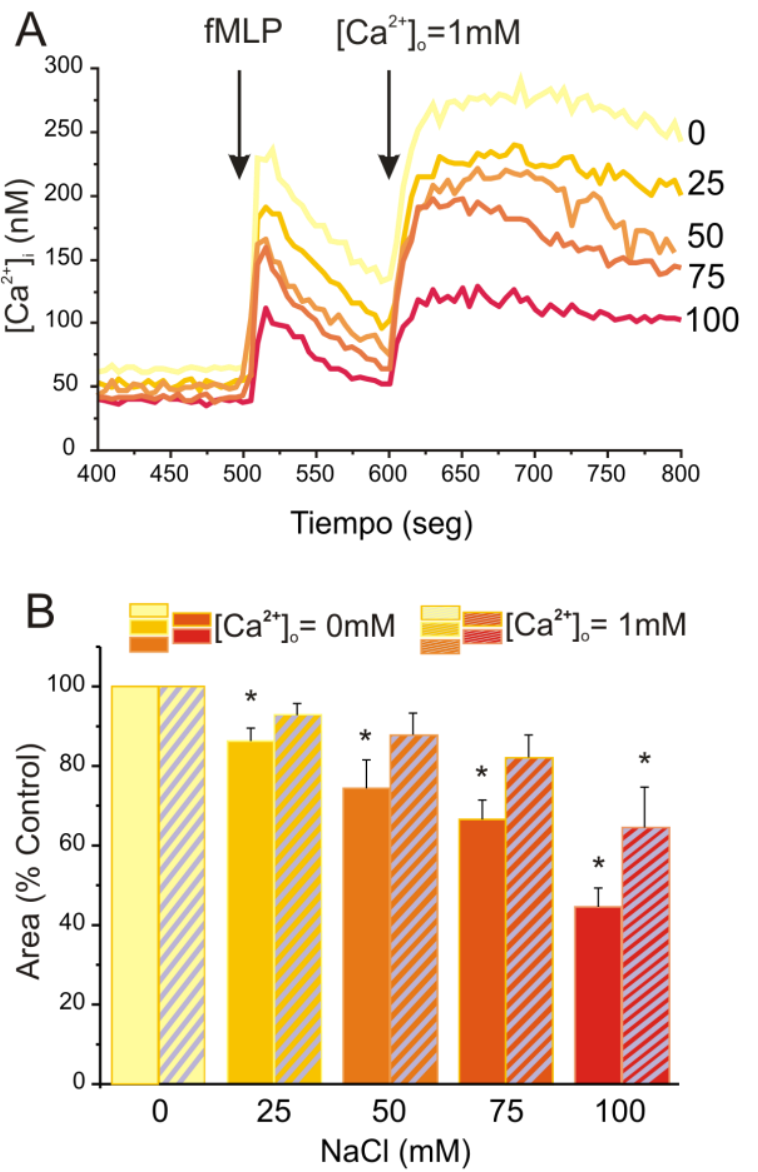

Figura IV-10: Efecto de distintos grados de hiperosmolaridad sobre el aumento de la concentración de calcio intracelular inducida por el fMLP. En el panel A se muestran los cambios en la concentración intracelular de calcio en un experimento típico con neutrófilos suspendidos en HBS/EGTA con diversas cantidades adicionales de $\mathrm{NaCl}$; en $B$ las columnas corresponden a los valores medios \pm SEM del área bajo la curva durante 100 segundos después del estímulo con fMLP o 200 segundos después de restaurar la concentración de calcio extracelular. Los valores fueron expresados como porcentaje del experimento apareado en HBS/EGTA isotónico. El asterisco indica $P<0.05$ ANOVA. $(n=7)$
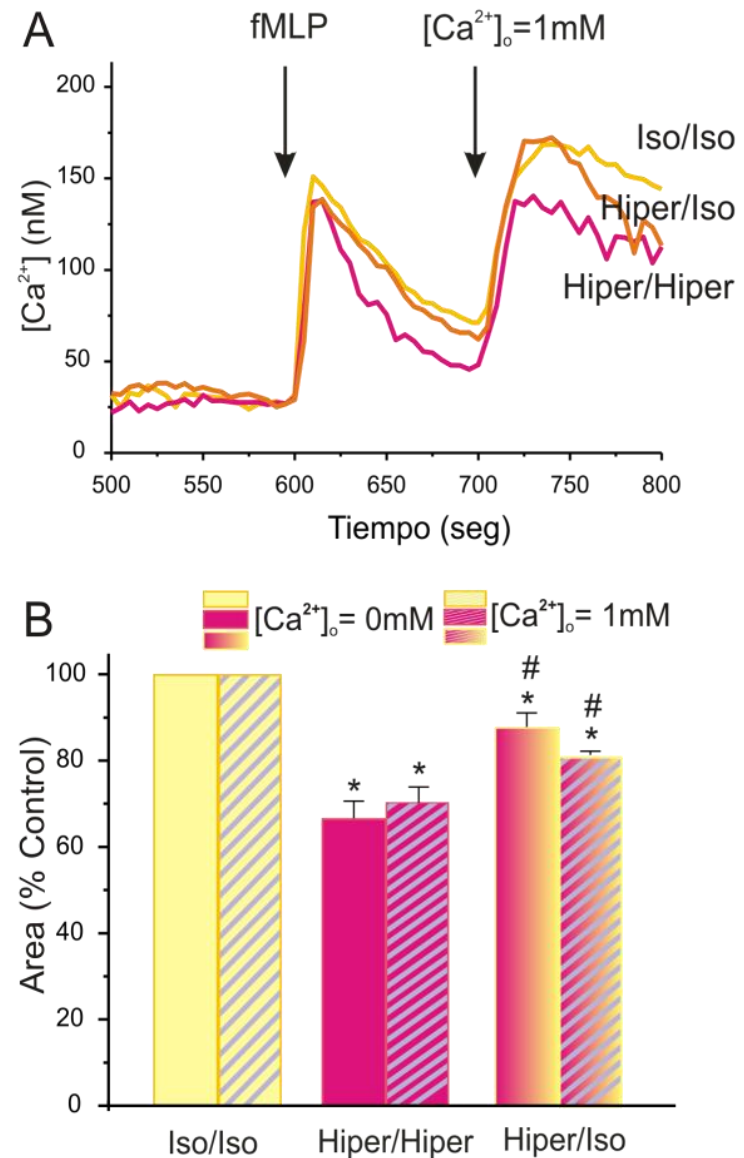

Figura IV-11: Reversibilidad del efecto inhibitorio de la hiperosmolaridad sobre la concentración de calcio intracelular. En el panel A se muestra un experimento típico de reversibilidad con neutrófilos suspendidos en HBS/EGTA (línea amarilla), en un medio con el agregado de 200 Osmoles/l adicionales de $\mathrm{NaCl}$ continuamente (línea rosa) o solo los primeros 500 segundos (línea naranja); en B las columnas corresponden a los valores medios \pm SEM del área bajo las curvas 100 segundos después del agregado del fMLP y 180 segundos después del agregado de $\mathrm{CaCl}_{2}$, expresadas como porcentaje del experimento apareado en HBS. EI * indica $P<0.05$ ANOVA. ( $n=7)$. 
2.11. El efecto inhibitorio de la hiperosmolaridad sobre la $\left[\mathrm{Ca}^{2+}\right]_{i}$ es independiente del osmolito utilizado

En la Tabla IV-1 se muestran los resultados obtenidos cuando se determinó el efecto de las soluciones hipertónicas de distinta composición. Los neutrófilos fueron incubados durante 10 minutos en un medio hiperosmótico donde se reemplazaron los $100 \mathrm{mM}$ de $\mathrm{NaCl}$ por $100 \mathrm{mM}$ de NMG-Cl, por $200 \mathrm{mM}$ de sacarosa o por $200 \mathrm{mM}$ de manitol, previo a la estimulación con fMLP. Las soluciones hipertónicas por el agregado de NMG-Cl, o sacarosa mostraron una depresión similar de la respuesta al fMLP que la que se observó cuando se utilizaba $\mathrm{NaCl}$, indicando que este efecto era debido al cambio de osmolaridad y no a la composición del medio. Sin embargo soluciones hipertónicas compuestas por manitol produjeron un efecto inhibitorio mucho menor de la señal de calcio (Tabla IV-1)

Cuando se estudió por separado la movilización desde los depósitos intracelulares y la entrada de calcio se observó que el manitol sólo afecta la entrada de calcio mientras que los demás osmolitos afectan la movilización y secundariamente se reduce la entrada.

2.12. El efecto inhibitorio de las soluciones hipertónicas no es mediado por la alcalinización

En neutrófilos se ha demostrado la presencia del NHE-1, la isoforma de mantenimiento homeostático ("housekeping") del intercambiador $\mathrm{Na}^{+} / \mathrm{H}^{+}$. En estado basal el intercambiador está casi
Tabla IV-1: Efecto de distintos osmolitos sobre la señal de calcio

\begin{tabular}{cccccc}
\hline Osmolito & \multicolumn{3}{c}{$\left[\mathrm{Ca}^{2+}\right]_{0}=1 \mathrm{mM}$} & \multicolumn{3}{c}{$\left[\mathrm{Ca}^{2+}\right]_{0}=0 \mathrm{mM}$} \\
\cline { 2 - 6 } & $\mathrm{N}$ & $\begin{array}{c}\text { Respuesta } \\
\text { Total }\end{array}$ & $\mathrm{N}$ & Movilización & Entrada \\
$\mathrm{NaCl}$ & 10 & $75 \pm 3^{*}$ & 14 & $57 \pm 3^{*}$ & $82 \pm 4^{*}$ \\
$\mathrm{NMG-Cl}$ & 6 & $72 \pm 7^{*}$ & 10 & $66 \pm 4^{*}$ & $85 \pm 3^{*}$ \\
Sacarosa & 6 & $60 \pm 8^{*}$ & 6 & $49 \pm 6^{*}$ & $73 \pm 12^{\mathrm{ns}}$ \\
Manitol & 8 & $81 \pm 7^{*}$ & 6 & $91 \pm 7^{\mathrm{ns}}$ & $66 \pm 10^{*}$ \\
\hline
\end{tabular}

La señal de calcio se expresó como porcentaje del área debajo de la curva realizada en medio isotónico o HBS.

inactivo ya que el $\mathrm{pH}$ intracelular $\left(\mathrm{pH}_{\mathrm{i}}\right)$ está en su punto de ajuste (set point). Cuando se aplica una carga ácida, que reduce el $\mathrm{pH}_{\mathrm{i}}$ y lo aleja del "set point", el intercambiador aumenta la velocidad de expulsión de $\mathrm{H}^{+}$tratando de que el $\mathrm{pH}_{\mathrm{i}}$ retorne el valor del "set point". Tanto el PMA como el fMLP producen una carga ácida inicial que aleja el $\mathrm{pH}_{\mathrm{i}}$ del "set point" y hacen que el intercambiador expulse $\mathrm{H}^{+}$. En el caso de la estimulación con PMA la recuperación tiende a alcanzar el valor basal mientras que en la estimulación con fMLP produce una elevación del "set point" que hace que el $\mathrm{pH}_{\mathrm{i}}$ alcance un estado estacionario a un valor más alto. 
La Fig. IV-12 muestra que si antes de la estimulación con fMLP se eleva el $\mathrm{pH}_{\mathrm{i}}$ con trimetilamina (TMA), una amina permeable, el "set point" alcanzado finalmente es siempre el mismo ( $\mathrm{pH}:$ 7.45) independientemente del valor del que se parta. La recuperación es más veloz cuando se parte del $\mathrm{pH}_{\mathrm{i}}$ del control $(\mathrm{pH}:$ 7.22) que cuando se parte de valores mas alcalinos $(\mathrm{pH}$ : 7.30 y 7.33 para 1 y $10 \mathrm{mM}$ de TMA, respectivamente). En cambio la producción de ROS disminuye cuando el medio está previamente alcalinizado con TMA (Fig. IV-12B).

El hecho de que la alcalinización intracelular por TMA, provoque una reducción de la producción de ROS plantea el problema de que la inhibición de la producción de ROS por hiperosmolaridad podría ser mediada por su efecto alcalinizante ya que la adición de $\mathrm{NaCl} 100$ mM lleva el pH de 7.2 a 7.4 (Fig. IV-13) por activación del intercambiador $\mathrm{Na}^{+} / \mathrm{H}^{+}$.

Sin embargo vemos que EIPA, que impide el cambio de $\mathrm{pHi}$ que provoca la hiperosmolaridad, no altera su efecto inhibitorio sobre la producción de ROS. Existe una pequeña diferencia entre la producción de ROS en medio hipertónico con y sin EIPA, pero esta diferencia también se ve en medio isotónico, y es atribuible a un efecto inespecífico de la droga estimulando la producción de ROS. Las diferencias desaparecen cuando se usa cariporide, un inhibidor más específico de NHE1.

El uso de otras alternativas para reducir la actividad del intercambiador como el reemplazo del sodio extracelular por NMG, no se pudieron usar porque el reemplazo reduce la producción de ROS aun en medio isotónico.
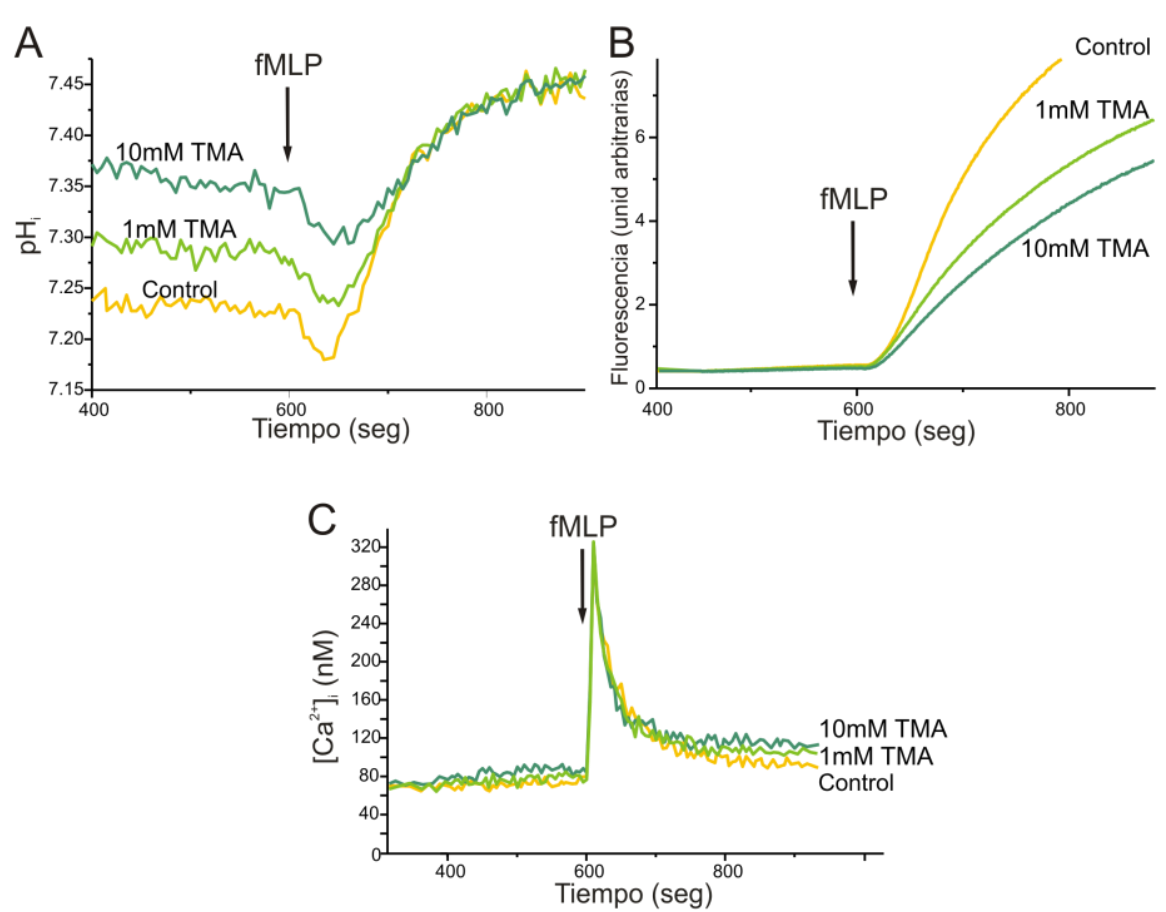

Figura IV-12. Experimentos típicos mostrando el efecto del agregado de TMA sobre el $\mathrm{pH}$ intracelular (A), la producción de ROS (B) y el aumento en el calcio intracelular (C).

El hecho de que el pHi alcanzado finalmente (entre los $1000 \mathrm{y}$ $1200 \mathrm{seg}$ ) luego de la estimulación con fMLP sea distinto en medio isotónico e hipertónico sugieren que el mecanismo alcalinizante del fMLP y de la hiperosmolaridad actúa por distintas vías. 


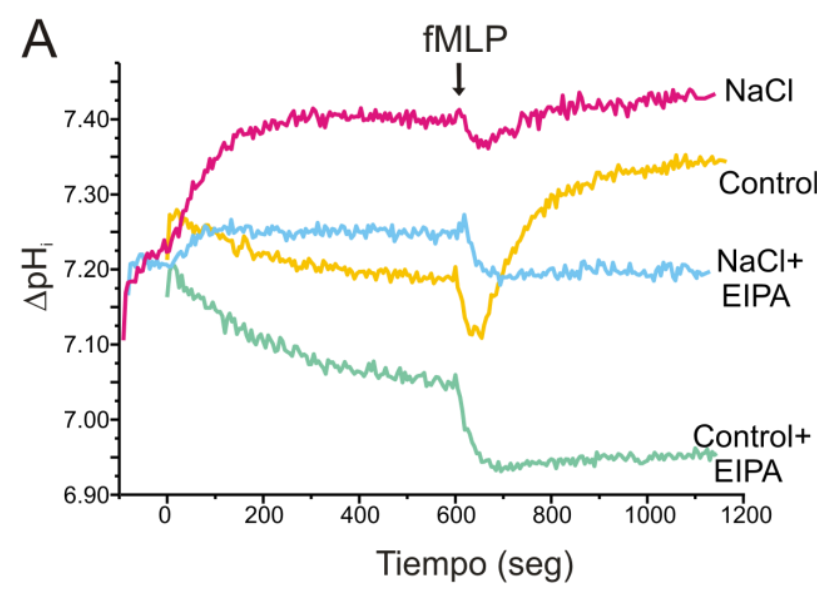

B

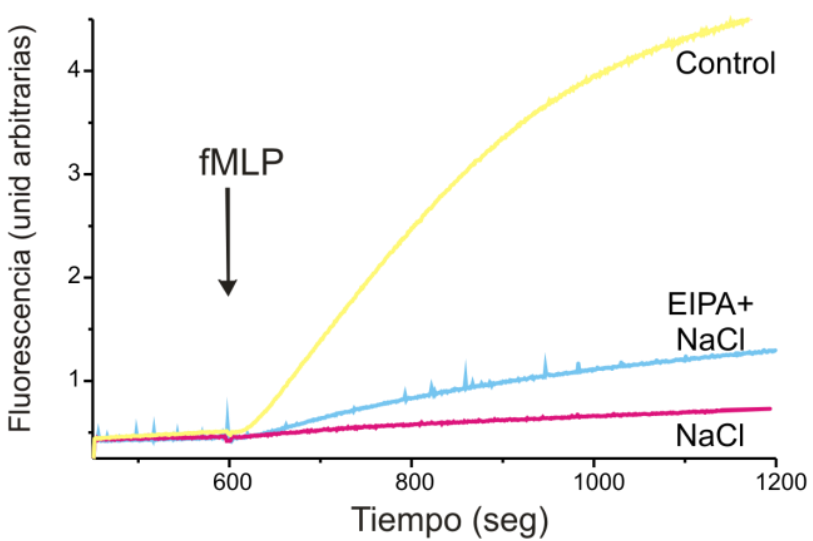

Figura IV-13. Efecto de la hiperosmolaridad en presencia de un inhibidor del intercambiador $\mathrm{Na}^{+} / \mathrm{H}^{+}$. En A se muestra un experimentos típico donde el EIPA (línea celeste) bloqueó el efecto alcalinizante de la hiperosmolaridad (línea rosa); sin embargo se mantuvo el efecto depresor de la hiperosmolaridad sobre la producción de ROS (B).

\section{DISCUSIÓN}

¿Cuál es el efecto de la hipertonicidad sobre la producción de ROS y la movilización de calcio promovida por fMLP? Los resultados experimentales obtenidos muestran que la hiperosmolaridad tiene una fuerte acción inhibitoria sobre la producción de ROS y sobre la vía de señalización iniciada por el fMLP.

Previamente fue descripto un efecto inhibitorio de las soluciones hipertónicas, compuestas por $\mathrm{NaCl}$ o de cloruro de colina, sobre el aumento en la $\left[\mathrm{Ca}^{2+}\right]_{i}$ inducida por fMLP en presencia (Kazilek y col., 1988) o ausencia de CitB (Chandler y Kazilek, 1987). Sin embargo, se postuló que niveles bajos de hiperosmolaridad sólo suprimían la activación de neutrófilos sin provocar cambios en la señal de calcio (Junger y col., 1998). En cambio nuestros resultados muestran que la adición de $25 \mathrm{mM}$ de $\mathrm{NaCl}$ ya producía una reducción estadísticamente significativa en la movilización de calcio desde los depósitos intracelulares, que se correlacionaba con el efecto supresor sobre la producción de ROS y tenía una dependencia similar con la concentración del osmolito.

¿Son las concentraciones utilizadas comparables a las alcanzadas en situaciones clínicas? ¿Son comparables a las utilizadas por otros investigadores? En la resucitación del shock hemorrágico se emplean dosis de $4 \mathrm{ml} / \mathrm{kg}$ de peso por vía endovenosa de $\mathrm{NaCl}$. Se distribuye en el líquido extracelular cuya expansión se genera a expensas del líquido intracelular con un gradiente de $25 \mathrm{mOsm} / \mathrm{L}$. Las concentraciones que utilizamos in vitro son más altas, como ocurre en la mayoría de los trabajos experimentales. Siempre se debe ser prudente al extrapolar resultados de las células aisladas a la situación clínica. 
En nuestras condiciones experimentales pudimos estimar que la producción de ROS inducida por el fMLP en neutrófilos tratados con CitB fue reducida en un $50 \%$ cuando se les agregó $64 \mathrm{mM}$ de $\mathrm{NaCl}$. Este valor fue mayor al reportado previamente para la inhibición provocada por la hiperosmolaridad sobre la formación intracelular de superóxido. La inhibición del $50 \%$ de la producción de ROS, determinada mediante el ensayo de reducción del citocromo, se obtuvo con un incremento en el $\mathrm{NaCl}$ de aproximadamente $20 \mathrm{mM}$ y alcanzó un $100 \%$ con la adición de $80 \mathrm{mM}$ de $\mathrm{NaCl}$ en neutrófilos no tratados con CitB (Orlic y col., 2002). El agregado de $40 \mathrm{mM}$ de $\mathrm{NaCl}$ durante 5 minutos llevó la producción de superóxido inducida por fMLP a un 45\% del control isoosmótico (Ciesla y col., 2001a).

¿A qué nivel de la cascada de señalización ejerce su efecto inhibitorio la hipertonicidad? Los resultados presentados en nuestro trabajo mostraron que la respuesta obtenida en neutrófilos tratados con CitB es inhibida por la hiperosmolaridad en un paso cercano al receptor. Sin embargo, esto no descarta la posibilidad de que la hiperosmolaridad estuviese provocando cambios en otros pasos que están más allá del aumento en la $\left[\mathrm{Ca}^{2+}\right]_{i}$ y que estarían participando en su efecto inhibitorio.

¿Un aumento transitorio en la osmolaridad sería suficiente para causar una supresión prolongada de la activación de los neutrófilos? Junger y col. (1998), reportaron que la formación de superóxido fue suprimida por más de 3 horas cuando las células fueron expuestas durante 2 minutos a niveles de hiperosmolaridad de $50 \mathrm{mM}$, sugiriendo que la hiperosmolaridad obstruye las vías de señalización activadas por el fMLP bloqueando las vías de la p38 MAPK y Ras/Raf/MAPK/quinasa regulada por señales extracelulares. Sin embargo, otros autores encontraron que el retorno a la condición isoosmótica luego del tratamiento con soluciones hipertónicas restauraba esta respuesta (Ciesla y col., 2001b). En nuestros experimentos, la reducción en la producción de ROS en neutrófilos tratados con CitB mostró una reversibilidad casi completa. Esto se correlacionó con una reversión de los efectos inhibitorios de la hiperosmolaridad sobre en aumento en la $\left[\mathrm{Ca}^{2+}\right]_{i}$ inducida por el fMLP.

¿La estimulación del intercambiador $\mathrm{Na}^{+} / \mathrm{H}^{+}$y la consiguiente alcalinización provocada por la hiperosmolaridad podrían explicar la inhibición de las respuestas? Si bien la alcalinización es capaz de inhibir la producción de ROS, la inhibición del intercambiador $\mathrm{Na}^{+} / \mathrm{H}^{+}$no afecta el efecto inhibitorio de la hiperosmolaridad.

¿Existe alguna relación entre el mecanismo de acción de la hiperosmolaridad y el citoesqueleto? La CitB bloquea la adición de nuevos monómeros de actina en el extremo barbado terminal de los filamentos, desplazando el equilibrio hacia su despolimerización. De esta manera se inhibe la asociación de los receptores de fMLP al citoesqueleto y se prolonga el tiempo durante el cual el complejo ligando-receptor induce la producción de segundos mensajeros (Särndahl y col., 1989). La CitB aumentó la producción de ROS, aunque la despolimerización de actina no fue capaz de revertir los cambios producidos por las soluciones hipertónicas, las cuales redujeron la producción de ROS al mismo nivel en células tratadas y no tratadas con CitB. La CitB potenció la liberación de ROS inducida por PMA, pero esta respuesta fue escasamente reducida por las soluciones hipertónicas, sugiriendo que el principal efecto de la hipertonicidad está en un paso previo a la activación de PKC. La 65 


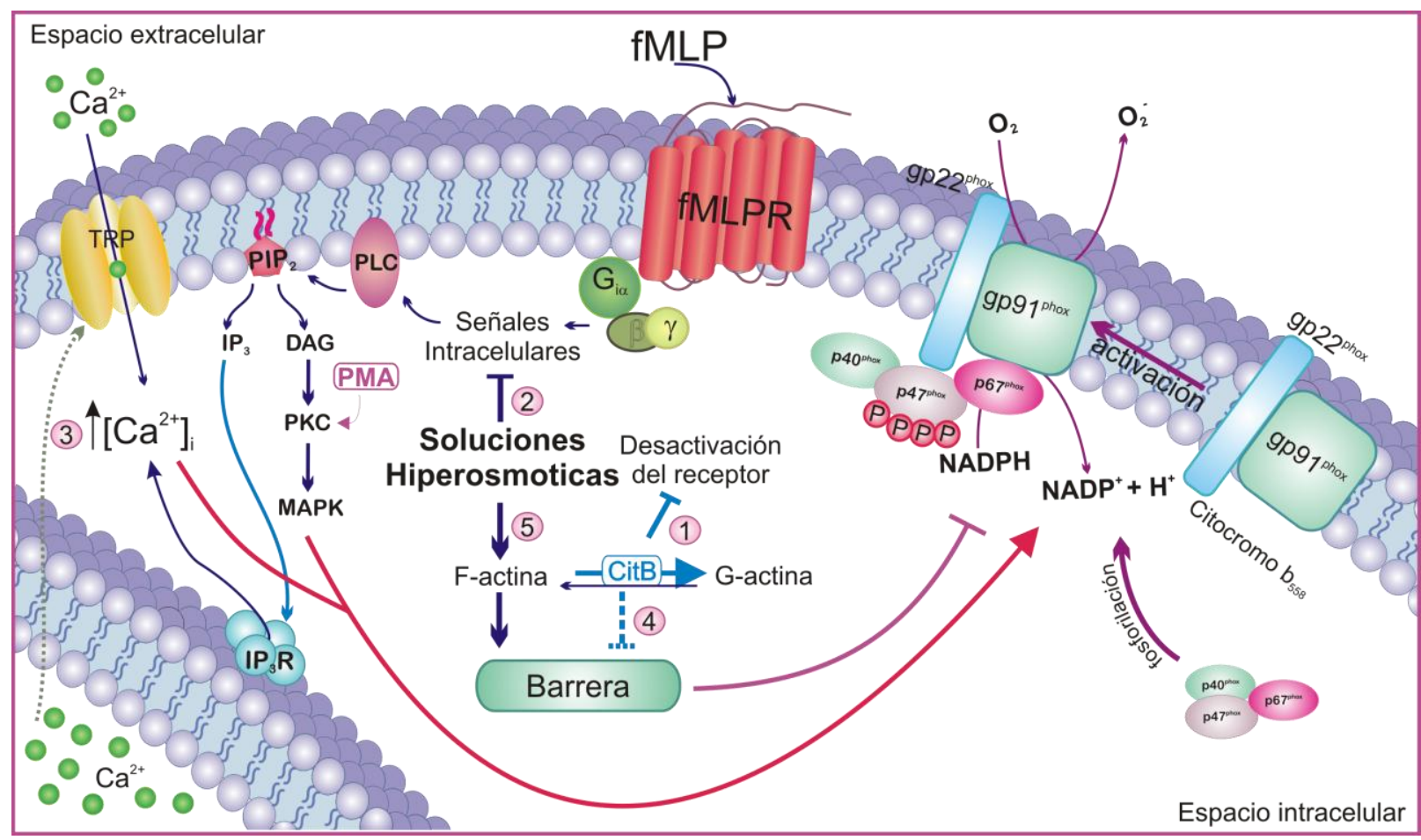

Figura IV-15. Esquema que muestra la relación entre la producción de ROS y la señal de calcio en neutrófilos tratados con CitB. La despolimerización de la F-actina impide el acoplamiento de los receptores de $F M L P$ al citoesqueleto, manteniéndolos activos (1). La hiperosmolaridad ejerce un fuerte efecto depresor sobre las señales intracelulares producidas por la activación del fMLPR (2). Lo que deprime la liberación de calcio de los depósitos y secundariamente su entrada del medio extracelular (3). Además, la CitB inhibe la formación de la barrera (4) creada por la hiperosmolaridad (5) limitando la producción de ROS por PMA.

la activación de PKC, podría explicarse por la eliminación de la barrera formada por el sistema de filamentos de actina permitiendo una rápida traslocación de los gránulos. Los gránulos están rodeados por una red de filamentos de actina la cual es disgregada por la CitB, facilitando el movimiento de los gránulos hacia la membrana. Los gránulos específicos contienen los componentes principales de la NADPH oxidasa, por lo cual una mayor fusión de estos gránulos con la membrana plasmática debido a CitB lleva a una mayor expresión de la NADPH oxidasa, causando una producción de ROS incrementada y prolongada en el tiempo.
¿El tratamiento con CitB puede revertir o prevenir el efecto inhibitorio de la hiperosmolaridad? Cielsa y col. (2001a), encontraron que la disrupción del citoesqueleto con CitB prevenía la atenuación de la activación de la p38 MAPK mediada por receptor cuando se incubaban los neutrófilos en un medio hiperosmotico. Sin embargo, nuestros resultados muestran que el efecto inhibitorio ocurre de igual manera cuando la osmolaridad del medio aumenta antes o después del agregado de CitB. La diferencia puede ser debida al menor nivel de hipertonicidad utilizado por estos autores. 
¿El efecto inhibitorio de las soluciones hipertónicas varia con el osmolito utilizado? Se encontró que la producción de ROS fue reducida en igual magnitud cuando se utilizaban soluciones hipertónicas compuestas por $\mathrm{NaCl}, \mathrm{NMG}-\mathrm{Cl}$ o sacarosa. De acuerdo con estos resultados, otros autores han demostrado que la formación de superóxido fue inhibida de manera similar por soluciones hipertónicas de cloruro de colina, $\mathrm{NaCl}, \mathrm{KCl}$ y sacarosa (Junger y col., 1998).

Se estudió el efecto del manitol porque es el agente osmótico de elección para tratar el aumento de la presión intracraneal, para el cual las soluciones salinas hipertónicas han evolucionado como un tratamiento alternativo. En nuestros experimentos, el manitol fue el osmolito con el menor efecto inhibitorio sobre la movilización de calcio desde los depósitos intracelulares, lo que podría explicar su menor efecto inhibitorio sobre la liberación de ROS. Este resultado concuerda con otro estudio donde se muestra que la adición de $100 \mathrm{mM}$ de manitol no provocó una disminución significativa de la producción de superóxido inducida por fMLP (Verghese y Boucher, 1998). La eficacia de las soluciones hipertónicas de manitol disminuye debido a su tendencia a causar un efecto de rebote sobre el incremento en volumen celular. Las soluciones hipertónicas salinas pueden, a largo plazo, causar una disminución del volumen del tejido superior a la provocada por el manitol ya que carecen de este efecto de rebote (Holbeck y col., 2002).

¿Qué sucede si la osmolaridad del medio aumenta luego de la activación celular? Previamente, se describió que cuando la osmolaridad del medio aumentaba luego de la activación se producía un aumento en la expresión de integrina $\beta_{2}$, de la degranulación (Chen y col., 2006) y de la liberación de elastasa (Ciesla y col., 2001a; Chen y col., 2006). Se encontró que no se reducía la formación de $\mathrm{H}_{2} \mathrm{O}_{2}$ y que aumentaba la producción de superóxido (Ciesla y col., 2001a). De acuerdo con esto, en nuestros experimentos, la adición de $\mathrm{NaCl} 100$ segundos después de la estimulación con fMLP produjo un incremento paradójico en la liberación extracelular de ROS. Estos resultados sugieren que la hiperosmolaridad no bloquea la vía citotóxica una vez que la señal producida desde el receptor de fMLP ha alcanzado su sitio de acción. Es evidente que la rapidez del tratamiento sería muy importante si los resultados son extrapolables a situaciones clínicas. 


\section{CAPÍTULO V}

FLUJOS IÓNICOS EN MEDIOS CON GLICINA 


\section{ANTECEDENTES}

La glicina (Gli) tiene un papel protector en tejidos y en animales enteros ante situaciones agresivas tales como hipoxia, isquemia/reperfusión (I/R) (Lee y col., 2001; Ascher y col., 2001; Kim y col., 2003; Yin y col., 2002), transplante (Schemmer y col., 1999; Gohrbandt y col., 2006), shock hemorrágico (Wang y col., 2004), daños por endotoxinas y drogas citotóxicas (Ikejima y col., 1996, Wheeler y col., 2000a). Los efectos anti-inflamatorios, inmuno-moduladores y citoprotectores de la glicina producen reducción en la mortalidad, en la disfunción de los órganos, en la injuria al parénquima y en la apoptosis celular. Para explicar estos efectos citoprotectores se han propuesto diversos mecanismos.

\subsection{Reducción de la Producción de Citoquinas}

Las células de Kupffer del hígado constituyen el $80 \%$ de los macrófagos residentes en el organismo. Cuando se activan liberan potentes mediadores inflamatorios tales como citoquinas $y$ eicosanoides (Laskin, 1990) los cuales desempeñan un importante papel en la respuesta inflamatoria progresiva (Goris y col., 1985; Carrico y col., 1986). Se ha demostrado que los macrófagos son activados por endotoxinas, por la hipotensión sistémica y por procesos de I/R (Bouwens, 1988; Jaeschke y Farhood, 1991).

Se ha encontrado en animales de experimentación después de la isquemia hepática selectiva que hay una mayor supervivencia en presencia de glicina lo que se ha atribuido a la reducción del efecto adverso del TNF- $\alpha$ (Zhong y col., 1999).

En el transplante hepático, la capacidad de regeneración del órgano y la viabilidad son preservadas en presencia de glicina, lo que se relaciona con el aumento de la supervivencia de las células transplantadas. Este resultado parece depender de una reducción en la formación de citoquinas proinflamatorias. La reducción por glicina de la injuria por $\mathrm{I} / \mathrm{R}$ del transplante se ha atribuído a la inhibición de la producción de TNF- $\alpha$ y IL-1 en las células de Kupffer y la represión de la expresión de NF-kb y CD14 (Peng y col., 2005).

Las endotoxinas liberadas en el intestino tras la isquemia producida por el shock hemorrágico estimulan la producción del TNF- $\alpha$, una citoquina pro-inflamatoria que es liberada por monocitos y macrófagos activados, y tiene un papel crítico en los procesos inflamatorios sistémicos (Carrico y col, 1986). Además, la lesión de la mucosa intestinal causada por la hipoperfusión/reperfusión conduce a la traslocación bacteriana y aumento de endotoxinas que son potentes activadores de macrófagos.

El corazón aislado de rata también es capaz de sintetizar y liberar TNF- $\alpha$, en respuesta a I/R. El deterioro mecánico y la necrosis celular se correlacionan con la producción de esta citoquina (Gurevitch y col., 1997). Paradojicamente, Lacerda y col. (2006) reportaron que TNF- $\alpha$ mimetiza el pre-condicionamiento isquémico en el corazón o en mioblastos. Esta citoprotección requiere la producción de radicales libres por la mitocondria de los miotúbulos.

El tejido adiposo es capaz de producir citoquinas proinflammatorias (IL-6, resistina, TNF- $\alpha$ ) y anti-inflamatorias (adiponectina) (Ahima y Flier, 2000). IL-6 contribuye a la resistencia del tejido muscular y adiposo a la insulina. Sus principales productores son el tejido adiposo y los fibroblastos. Las citoquinas pro-inflamatorias están aumentadas en diabetes tipo 2 (Hotamisligil y col., 1997; Xu y col., 2002; Pickup, 2004; Trujillo y Scherer, 2006), mientras que mRNA y la expresión de adiponectina están reducidas en obesos insulino-resistentes tanto humanos (Cruz y col., 2004), monos (Hotta y col., 2001) o ratones 
(Yamauchi y col., 2001). Estudios recientes en células adiposas 3T3-L1 muestran que en presencia de glicina la expresión del mRNA de las citoquinas proinflamatorias (IL-6, resistina, y TNF- $\alpha$ ) está disminuída y el gen de adiponectina sobre regulado. La sobre-expresión de adiponectina que produce glicina, reduce el aumento de IL-6 inducido por LPS atenuando la activación de NF-kb (Ajuwon y Spurlock, 2005). De esta forma glicina modifica la expresión del mRNA de citoquinas.

\subsection{Participación de Canales de Cloruro}

Entre las hipótesis que se han evaluado para explicar el mecanismo de acción de glicina a nivel molecular se destacan las que han postulado la participación de un receptor de glicina de tipo neuronal clásico, capaz de activarse formando un canal que permite el ingreso de cloruro.

Pfeiffer y Betz (1981) caracterizaron un receptor de glicina (GliR) y lo purificaron de una fracción rica en membranas de médula espinal de rata. Este receptor es un pentámero compuesto de tres polipéptidos: dos glucoproteínas de 48 y 58 kDa (subunidades $\alpha$ y $\beta$ ) y una proteína citoplasmática de anclaje de $93 \mathrm{kDa}$ (gefirina). El receptor de glicina es ionofórico, al unirse el ligando se abre un canal selectivo para cloruro. Hay diversas evidencias de que GliR tiene también expresión extrasináptica.

El GliR se encuentra distribuído en una amplia variedad de células, además de las neuronas. Se ha encontrado en células involucradas en la inflamación y en la respuesta inmune tales como macrófagos, monocitos, neutrófilos, células de Jurkat, células linfoblasticas humanas inmortalizadas y linfocitos T (Ikejima y col. 1996; Li y col., 2001; Wheeler y col., 2000a; Wheeler y col., 2000b; Stachlewitz y col., 2000).
La existencia de GliR en células no neuronales fue evidenciada primero por técnicas farmacológicas y fue confirmado más recientemente por estudios que utilizan técnicas de biología molecular. Utilizando RT-PCR se identificó la subunidad $\beta$ del GliR en macrófagos esplénicos y células del endotelio vascular. En células corticales y en los túbulos proximales de riñón de conejo se identificó a la subunidad $\beta$ del receptor y a gefirina, pero no a la subunidad $\alpha$ (Miller $y$ Schnellmann, 1994).

El análisis por Western blot permitió identificar la subunidad $\alpha$ en membranas aisladas de células de Kupffer, neutrófilos peritoneales y en macrófagos esplénicos y alveolares. Sin embargo, la isoforma presente varía de una célula a otra (Froh y col, 2002).

Cuando glicina se une a el GliR se abre un canal que permite el flujo de cloruro $\left(\mathrm{Cl}^{-}\right)$desplazando el potencial de membrana hacia el potencial de equilibrio del cloruro. Dependiendo de las concentraciones extra e intracelular, el flujo de $\mathrm{Cl}^{-}$puede causar hiperpolarización o despolarización (Lynch, 2004). En las sinapsis neuronales, glicina actúa como neurotransmisor inhibitorio porque permite el ingreso de cloruro, hiperpolarizando la membrana y reduciendo la posibilidad de descargar potenciales de acción en el axón (Lynch, 2004). En cambio, en células con elevada concentración intracelular de $\mathrm{Cl}^{-}$, como ocurre en neuronas embrionarias, el resultado de la apertura del canal sería la salida de $\mathrm{Cl}^{-}$y la despolarización (Kneussel y Betz, 2000).

El modelo neuronal inhibitorio fue aplicado a macrófagos, células de Kupffer y neutrófilos. Se propuso que la hiperpolarización producida por glicina podría prevenir la entrada de calcio a través de canales activados por agonistas. Este modelo permitiría explicar el hallazgo experimental de una reducción de la entrada de calcio provocada por agonistas en presencia de glicina y la anulación de esta 
inhibición con bajas concentraciones de estricnina, un antagonista farmacológico del GliR (Froh y col., 2002).

Esta hipótesis supone la presencia de canales de calcio operados por voltaje, cuya existencia fue postulada en células de Kupffer (Hijioka y col., 1992) y en células hepáticas (Oide y Thurman, 1994), basándose en la inhibición del aumento del $\left[\mathrm{Ca}^{2+}\right]_{i}$ por nitrendipina y su estimulación por BAY8644. En las células de Kupffer, PAF produce una entrada de calcio inhibible con gadolinio, un bloqueante de canales activados por estiramiento (Roland y col., 1999), y la I/R hepática produce una entrada de calcio inhibible por bloqueantes de canales operados por vaciamiento del depósito (SOC).

\subsection{Participación de los Flujos de Calcio}

En las células de Kupffer, glicina produce hiperpolarización y previene la despolarización causada por $25 \mathrm{mM} \mathrm{K}^{+}$y reduce la magnitud de los cambios transitorios de calcio inducidos por LPS, efecto que es sensible a estricnina (Ikejima y col., 1997).

En macrófagos alveolares, el pico de $\left[\mathrm{Ca}^{2+}\right]_{i}$ producido por LPS se reduce a la mitad en presencia de glicina 10 uM, esta concentración también inhibe en un $50 \%$ la liberación de TNF- $\alpha$ (Wheeler y col., 2000b).

En células del parénquima hepático estimuladas con prostaglandina $\mathrm{E}$ o fenilefrina, glicina bloquea el aumento de $\left[\mathrm{Ca}^{2+}\right]_{i}$ producido por estos agonistas. El efecto inhibitorio es menor en presencia de estricnina (Qu y col., 2002).

Los miocitos sometidos a hipoxia/reoxigenación se cargan de calcio. Glicina inhibe este aumento (Qi y col., 2007). Un fenómeno similar ocurre en los neutrófilos estimulados con LPS (Wheeler y col, 2000a).
El aumento de $\left[\mathrm{Ca}^{2+}\right]_{i}$ producido por Concavalina $\mathrm{A}$ en células de Jurkat es inhibido por glicina. Este aumento depende del $\mathrm{Cl}^{-}$ extracelular y es revertido por estricnina. Además, se encontró que glicina reduce significativamente el aumento de $\left[\mathrm{Ca}^{2+}\right]_{i}$ en linfocitos estimulados con anticuerpos anti C3 o IL-2 (Stachlewitz y col., 2000).

Wheeler y col. (2000a) mostraron que glicina amortigua los aumentos de $\left[\mathrm{Ca}^{2+}\right]_{i}$ en neutrófilos adherentes, tanto en medios con calcio, como en medios carentes de él. Es decir que no sólo afecta el ingreso de calcio sino que también previene su liberación de los depósitos intracelulares. Este efecto fue revertido por estricnina que restaura la señal de calcio a valores cercanos al control. Como veremos más adelante, nuestros experimentos muestran, por el contrario, que la entrada de calcio estimulada por fMLP aumenta en presencia de glicina y que esta potenciación no es sensible a la presencia de estricnina.

\section{RESULTADOS}

\subsection{Glicina reduce la producción de ROS}

Para estudiar el efecto de bajas concentraciones de glicina sobre la producción de ROS se utilizaron neutrófilos pretratados con CitB. Fueron activados con fMLP o PMA con el fin de comparar el efecto de la glicina sobre la activación de neutrófilos mediada por receptor (fMLP) o independiente de este mecanismo (PMA).

Los neutrófilos fueron incubados 10 minutos a $37{ }^{\circ} \mathrm{C}$ en soluciones con diversas concentraciones de glicina, luego se estimuló la producción de ROS con fMLP $0.1 \mu \mathrm{M}$ ó PMA $0.1 \mu \mathrm{M}$. Se asumió que la tasa de aumento de la fluorescencia era proporcional a la cantidad de ROS producidos. 

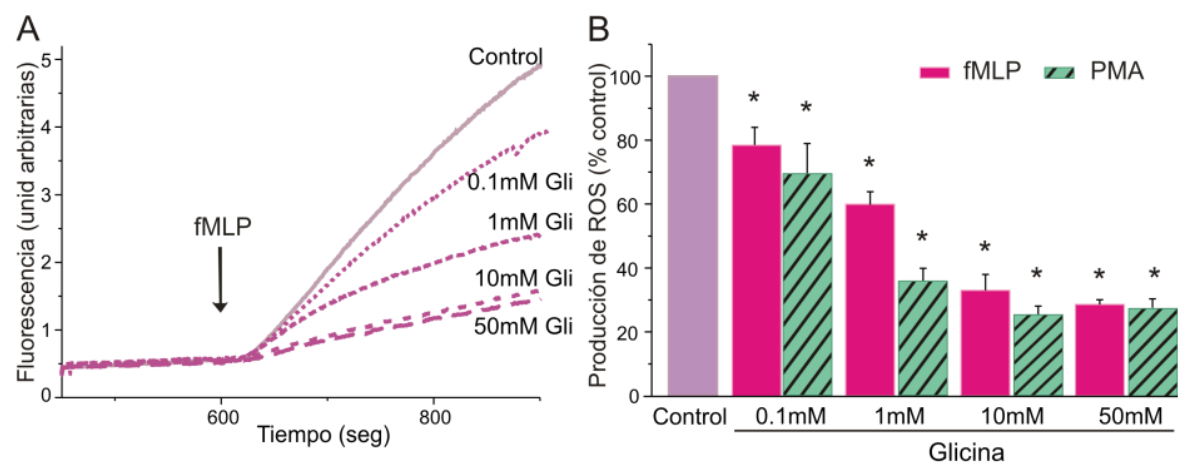

C

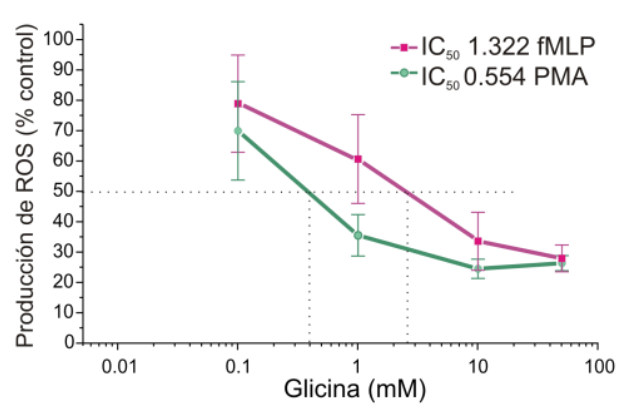

Figura V-1. Efecto de concentraciones crecientes de glicina sobre la producción de ROS El panel A muestra el efecto inhibitorio de glicina sobre la producción de ROS inducida por $f M L P$ en una preparación representativa. Los neutrófilos pretratados con CitB fueron incubados $10 \mathrm{~min}$ en HBS, con distintas concentraciones de glicina (0.1-50 mM). La flecha indica el agregado del $f M L P$. En el panel $B$ se muestran los valores medios alcanzados cuando la producción de ROS fue inducida por fMLP ( $n=7)$ o PMA ( $n=4)$, a distintas concentraciones de glicina. Cada columna indica la media y error estándar de la media. Los * indican una diferencia significativa con respecto al control (P<0.05). En C se muestran las curvas concentración-respuesta.

Se observó una pequeña producción basal de ROS previa a la estimulación de los neutrófilos, que aumentó explosivamente luego del agregado del fMLP o PMA. El grado de inhibición de la liberación de
ROS dependió de la concentración de glicina utilizada, tanto en neutrófilos estimulados con $\mathrm{fMLP}\left(\mathrm{IC}_{50}=1.322 \mathrm{mM}\right)$ como en los estimulados con PMA $\left(\mathrm{IC}_{50}=0.554 \mathrm{mM}\right)($ Fig. V-1)

2.2. Glicina previene y revierte la producción de ROS inducida por agonistas

Glicina fue capaz de inhibir la respuesta iniciada a nivel del receptor de membrana ( $\mathrm{fMLP}$ ) o en un paso posterior de la cadena de señalización (PMA), lo que sugirió que la modulación de la liberación de ROS en neutrófilos inducida por glicina ocurría principalmente en un nivel "downstream" PKC.

Para determinar si glicina $1 \mathrm{mM}$ es capaz de prevenir o revertir la activación de la NADPH oxidasa, se estudió la producción de ROS en cuatro grupos experimentales que fueron estimulados con fMLP o PMA después de $10 \mathrm{~min}$ de incubación. Al grupo control no se le agregó glicina, mientras que a los grupos t:0, t:590 y t:700 se les agregó al comienzo del experimento, 10 segundos antes o 100 segundos después de la activación respectivamente. Se observó que glicina producía una rápida inhibición de la producción de ROS, independientemente del estimulo o del momento en el que se agregaba (Fig. V-2).

Estos resultados sugieren que la glicina reduce la producción de ROS aún cuando la NADPH oxidasa ya está ensamblada en la membrana.

\subsection{El efecto inhibitorio de glicina es insensible a estricnina}

La glicina es un neurotransmisor inhibitorio que hiperpolariza las neuronas activando canales de cloruro en la membrana postsinápticas. El efecto inhibitorio de la glicina sobre la producción de ROS podría deberse a su acción sobre canales de cloruro similares a 

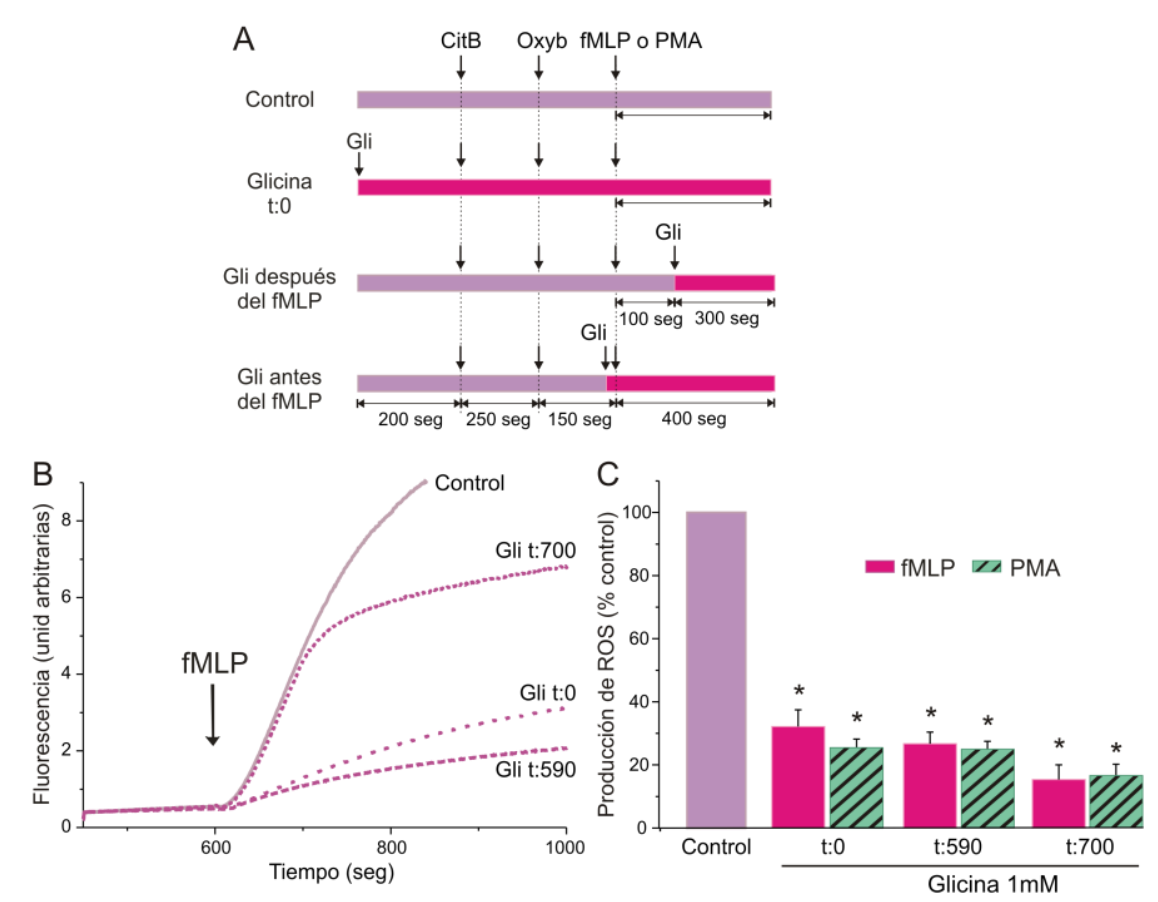

Figura V-2. Efecto del agregado de glicina a distintos tiempos sobre la producción de ROS. En el panel A se muestran los protocolos seguidos. En el panel B se muestra en un experimento típico los cambios en la producción de ROS inducida por fMLP cuando los neutrófilos son incubados con glicina $1 \mathrm{mM}$ al comienzo del experimento (t:0), 10 segundos antes de activar a los neutrófilos (t:590) o después de la activación (t:700). En $C$ se muestran los valores medios alcanzados cuando la producción de ROS fue inducida por fMLP (n=7) o PMA ( $n=4)$. Cada columna indica la media y SEM. Los *indican una diferencia significativa con respecto al control sin glicina $(P<0.05)$.

los neuronales que también fueron descriptos en neutrófilos. Para evaluar esta posibilidad los neutrófilos fueron incubados en presencia de estricnina $1 \mu \mathrm{M}$ y/o glicina $1 \mathrm{mM}$, y activados con fMLP. La estricnina, un bloqueante de los canales de cloruro gatillados por glicina, no
A
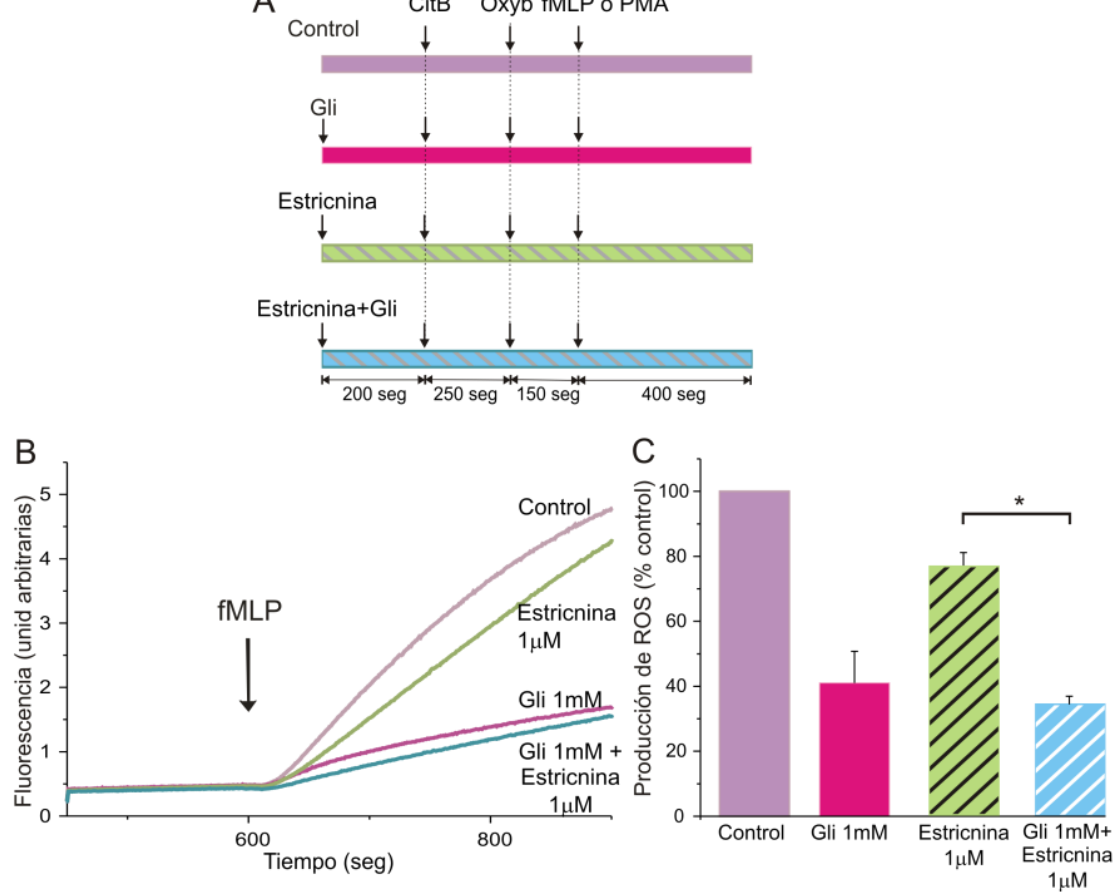

Figura V-3. Efecto de la estricnina sobre la reducción en la producción de ROS inducida por glicina. En el panel A se muestran los protocolos seguidos. En el panel B se muestra un experimento típico con neutrófilos incubados en presencia o ausencia de glicina 1 $\mathrm{mM}, y / 0$ estricnina $1 \mu \mathrm{M}$. En $\mathrm{C}$ se muestran los valores medios alcanzados cuando la producción de ROS inducida por fMLP fue reducida por glicina en ausencia o presencia de estricnina. Cada columna indica la media y SEM. Los valores fueron expresados como porcentaje del control. Como indica el * el efecto de glicina se mantiene aun en presencia de estricnina $(P, 0.05)(n=3)$.

revirtió el efecto inhibitorio de glicina sobre la producción de ROS, lo cual descartó la posibilidad de que el efecto de la glicina fuese mediado por este mecanismo (Fig. V-3). 


\subsection{El efecto de glicina no está acoplado al transporte de sodio}

Muchos aminoácidos, incluyendo la glicina, ingresan a la célula por un transporte acoplado a la entrada de sodio; para estudiar si la glicina necesitaba entrar en la célula para inhibir la producción de ROS, los neutrófilos fueron incubados en un medio libre de $\mathrm{Na}^{+}$. Cuando se reemplazó el $\mathrm{Na}^{+}$extracelular por $\mathrm{Li}^{+}$, la producción de ROS se redujo a un $88 \pm 20 \%$ del control con $\mathrm{Na}^{+}$, pero el efecto inhibitorio de glicina $1 \mathrm{mM}$ fue similar $\left(40 \pm 10 \%\right.$ en un medio con $\mathrm{Na}^{+}$y $42 \pm 9 \%$ en un medio con $\mathrm{Li}^{+}$).

Estos resultados indican que glicina podría ejercer su efecto inhibitorio sobre la producción de ROS sin entrar en la célula, o que la entrada no está acoplada al transporte de sodio.

\subsection{Glicina reduce la carga ácida producida por la NADPH oxidasa}

La NADPH oxidasa es un complejo multienzimatico que transporta electrones desde el NADPH citoplasmático al oxígeno molecular para generar radicales superóxido. Este transporte electrogénico de electrones a través de la membrana está asociada con el flujo de iones hidrógeno. Como un "test" indirecto para medir el efecto inhibitorio de glicina sobre la sobrecarga ácida producida por la NADPH oxidasa, se estudió el efecto de glicina sobre los cambios en el $\mathrm{pH}_{\mathrm{i}}$ inducido por fMLP o PMA en células cargadas con BCECF.

La estimulación de los neutrófilos produce una acidificación transitoria seguida de una recuperación inicial; esta última fase se anula cuando se utilizan inhibidores del intercambiador $\mathrm{Na}^{+} / \mathrm{H}^{+}$(NHE). En los neutrófilos cargados con BCECF y estimulados con PMA, se observó una acidificación tardía debida a la activación de la NADPH oxidasa. Esta carga ácida fue anulada cuando la enzima fue inhibida con DPI. La acidificación tardía también fue reducida
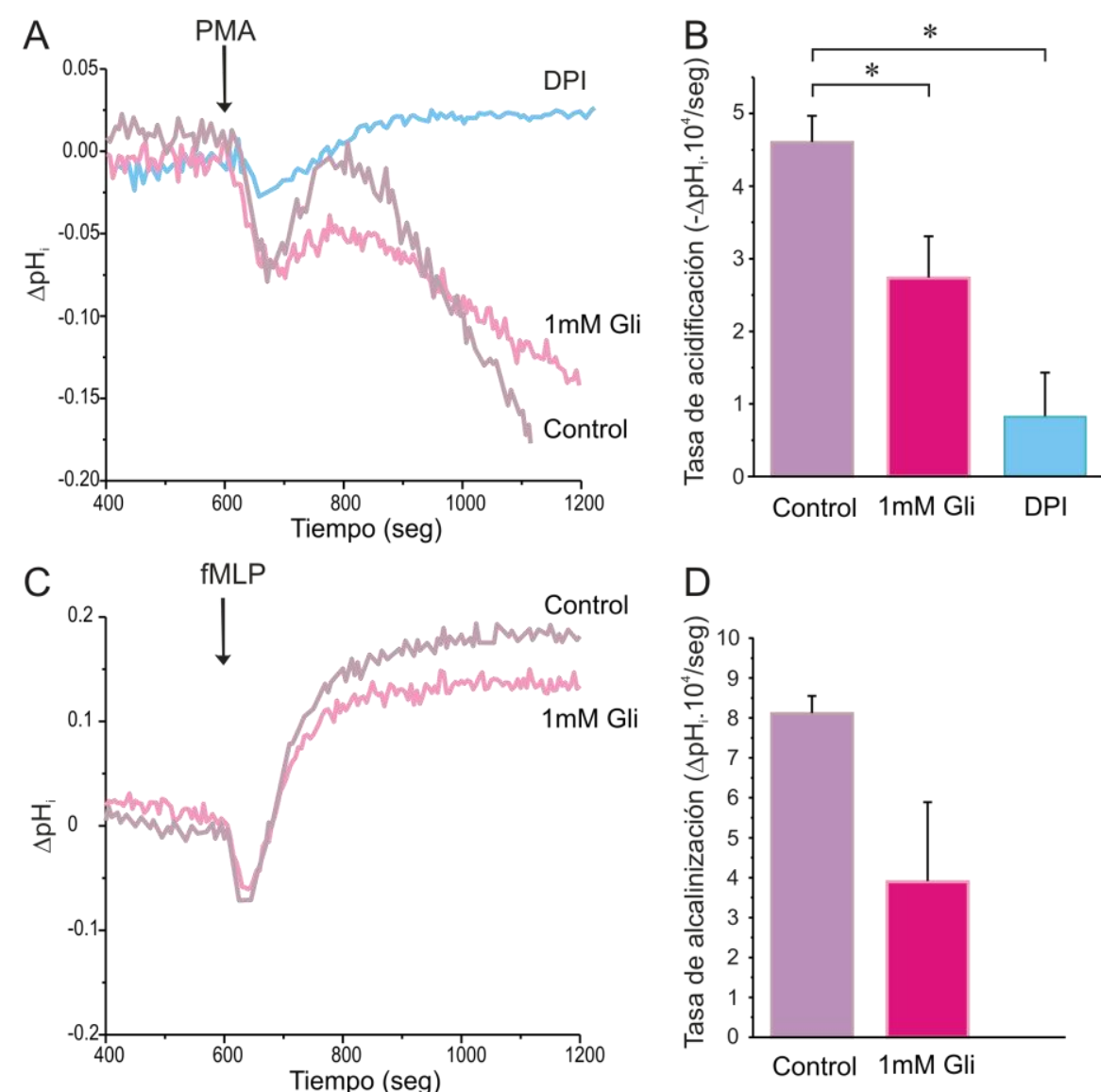

Figura V-4. Efecto de glicina sobre los cambios en el $\mathrm{pH}$ intracelular inducido por $f M L P$ o $P M A$. Los paneles A y C: muestran los cambios en el pH intracelular inducidos por el agregado de fMLP o PMA, en presencia o ausencia de glicina $1 \mathrm{mM}$ en experimentos típicos. En A se muestra además el trazado de un experimento donde la NADPH oxidasa fue inhibida con $2.5 \mu M$ de DPI (línea celeste). Paneles $B$ y D: Las barras indican la media y SEM de las pendientes tardías (de 900 a 1100 segundo). Los * indican una diferencia significativa $(P<0.05)$ respecto al control $(n=3)$. 
significativamente cuando los neutrófilos se incubaron en presencia de glicina $1 \mathrm{mM}$. La tasa de la sobrecarga ácida (en $\Delta \mathrm{pH} / \mathrm{seg} .10^{4}$ ) fue 4.61 \pm 0.36 en el control, $0.83 \pm 0.60$ cuando la NADPH oxidasa fue inhibida por DPI $10 \mu \mathrm{M}$, y $2.74 \pm 0.56$ en presencia de glicina $1 \mathrm{mM}$ (Fig. V-4A).

Cuando los neutrófilos fueron estimulados con fMLP, el cambio del "set point" superó la sobrecarga ácida debida a la activación de la NADPH oxidasa (Fig. 4D). Los cambios en el $\mathrm{pH}_{\mathrm{i}}$ producidos por presencia de glicina no se diferenciaron significativamente de los producidos en el grupo control. Estos resultados indican que el efecto inhibitorio de la glicina sobre la producción de ROS en respuesta al fMLP no era debido a cambios producidos en el $\mathrm{pH}$ intracelular.

\subsection{Glicina aumenta la entrada de calcio inducida por el $f M L P$}

Neutrófilos pretratados con CitB incubados en HBS $\left(\left[\mathrm{Ca}^{2+}\right]_{\mathrm{e}}=1\right.$ $\mathrm{mM}$ ) con glicina $0,1 \mathrm{mM}, 10 \mathrm{mM}$ y $50 \mathrm{mM}$, fueron activados con fMLP. En el grupo sin glicina la estimulación produjo un aumento de la $\left[\mathrm{Ca}^{2+}\right]_{i}$ que fue seguida por una disminución progresiva, sin volver a los valores de calcio intracelular previos a la estimulación. En los neutrófilos incubados con distintas concentraciones de glicina la activación produce una respuesta bifásica, donde se observa un primer aumento en la $\left[\mathrm{Ca}^{2+}\right]_{i}$ similar al control, seguida de un segundo aumento de la $\left[\mathrm{Ca}^{2+}\right]_{\mathrm{i}}$ que se produce tardíamente. El área bajo la curva en cada preparación aumentó en presencia de glicina $1 \mathrm{mM}, 10 \mathrm{mM}$ y $50 \mathrm{mM}$ en $126 \pm 8 \%, 142.7 \pm 12 \%$ y $147.3 \pm 10 \%$ del control respectivamente (Fig. V-5).

Para poder dilucidar si el aumento de la $\left[\mathrm{Ca}^{2+}\right]_{i}$ inducido por glicina, se debía a un aumento en la liberación de calcio desde los depósitos intracelulares o a una mayor entrada desde el medio extracelular o a ambos, se incubaron los neutrófilos en soluciones sin calcio (HBS/EGTA). Luego del agregado del fMLP se produce un primer aumento de la $\left[\mathrm{Ca}^{2+}\right]_{i}$ debido a la liberación de este catión desde los depósitos intracelulares. Cuando 100 segundos después se restableció la concentración extracelular de calcio, por el agregado de $\mathrm{CaCl}_{2}$ se produjo un segundo aumento de la $\left[\mathrm{Ca}^{2+}\right]_{i}$ que fue debido a su entrada desde el medio extracelular.

En los neutrófilos incubados con glicina no se produjo un cambio en la liberación de calcio desde los depósitos intracelulares, pero sí un aumento significativo en su entrada desde el medio extracelular. EI área bajo la curva durante la entrada de calcio en presencia de glicina $1 \mathrm{mM}, 10 \mathrm{mM}$ y $50 \mathrm{mM}$ aumento en $122.5 \pm 8 \%, 120.6 \pm 4 \%$ y $122.5 \pm$ $9 \%$ del control, respectivamente (Fig. V-6). 

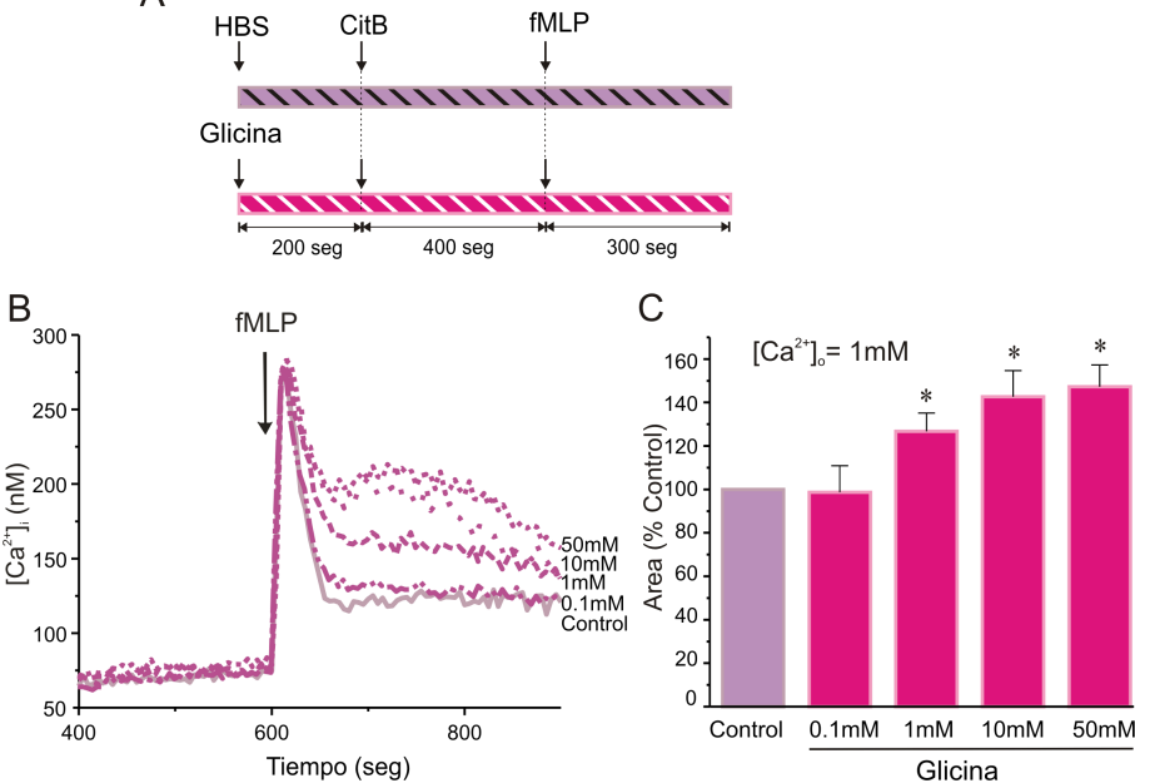

Figura V-5. El aumento en la $\left[\mathrm{Ca}^{2+}\right]_{i}$ inducido por el fMLP es potenciado por glicina. En el panel $A$ se muestran los protocolos seguidos. En el panel $B$ se muestra un experimento típico donde se pueden observar los cambios en la $\left[\mathrm{Ca}^{2+}\right]_{i}$ en neutrófilos incubados 10 minutos en HBS antes de ser estimulados con $\mathrm{AMLP}$, con el agregado de distintas concentraciones de glicina (50-0.1mM). En el panel $C$ las columnas corresponden a los valores medios \pm SEM del área bajo la curva durante 5 minutos después de la estimulación con $\mathrm{fMLP}$. Los valores fueron expresados como porcentaje del experimento apareado en HBS. EI * indica $P<0.05$ ANOVA. $(n=6)$.

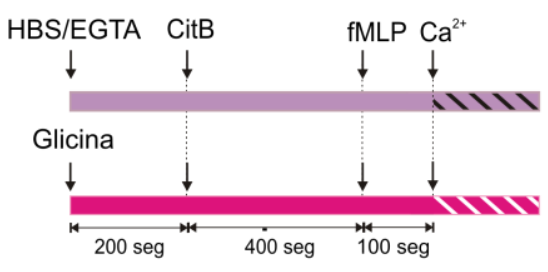

B
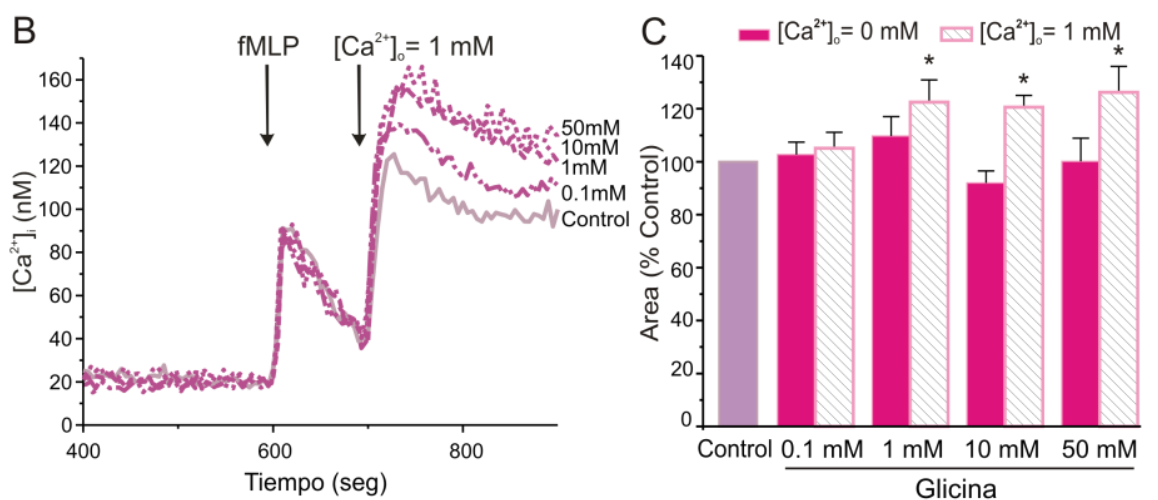

Figura V-6. Glicina aumenta la entrada de calcio inducida por el fMLP. En el Panel A se muestran los protocolos seguidos. En el panel $B$ muestra un experimento típico donde se puede observar los cambios en la $\left[\mathrm{Ca}^{2+}\right]_{i}$ en neutrófilos incubados 10 minutos en HBS/EGTA con el agregado de distintas concentraciones de glicina (50-0.1mM). La estimulación con fMLP (primer flecha) provocó un aumento en la $\left[\mathrm{Ca}^{2+}\right]_{i}$ debido al vaciamiento de los depósitos intracelulares (barras lisas). 100 segundos después se repuso la concentración de calcio extracelular por el agregado de $\mathrm{CaCl}_{2}$ (segunda flecha), lo cual indujo la entrada de calcio a la célula (barras rayadas). En el panel C las columnas corresponden a los valores medios \pm SEM del área bajo la curva durante 100 segundos después de la estimulación con fMLP (barra lisa) y 180 segundos después del agregado del $\mathrm{CaCl}_{2}$ (barra rayada). Los valores fueron expresados como porcentaje del experimento apareado sin glicina. El * indica $P<0.05$. ANOVA. $(n=6)$. 


\section{DISCUSIÓN}

Para estudiar el efecto de la glicina sobre la producción de ROS se utilizaron neutrófilos humanos previamente tratados con CitB para lograr su máxima activación (Giambelluca y Gende, 2008). Este enfoque descartó un posible efecto de la glicina sobre la traslocación de los receptores de fMLP.

¿Cómo se ha explicado el mecanismo de acción de la glicina utilizando el modelo neuronal? La glicina es un neurotransmisor inhibitorio que activa un canal de cloruro que se expresa en las membranas postsinápticas (Hall, 1998). La activación del canal permite la entrada de cloruro a la célula y da como resultado la hiperpolarización de la membrana celular. Algunas evidencias experimentales sugieren la existencia del canal de cloruro en otras células además del tejido neuronal. La presencia de una subunidad inmunológicamente homóloga a la del canal neuronal fue descripta en neutrófilos peritoneales de rata (Froh y col., 2002), donde glicina estimuló la entrada de cloruro radioactivo (Wheeler y col., 2000a).

La estricnina, un conocido antagonista de los canales de cloruro gatillados por glicina, suministró pruebas farmacológicas adicionales para corroborar la presencia de un canal de cloruro en neutrófilos ya que $1 \mu \mathrm{M}$ de estricnina revirtió el efecto inhibitorio de la glicina, restituyendo el aumento en la $\left[\mathrm{Ca}^{2+}\right]_{\mathrm{i}}$ a valores cercanos al control (Ikejima y col., 1997)

Según este modelo, glicina activaría el canal de cloruro y permitiría su entrada a la célula, a partir de lo cual la membrana se hiperpolariza impidiendo así la entrada del calcio a través de canales operados por voltaje. De esta forma se reduciría la acumulación de este catión en la célula. De acuerdo con esta idea, Wheeler y col. (2000a), mostró que glicina $1 \mathrm{mM}$ bloqueaba el aumento en la $\left[\mathrm{Ca}^{2+}\right]_{\mathrm{i}}$ inducido por el fMLP con un $\mathrm{IC}_{50}: 0.3 \mathrm{mM}$. Un hallazgo inesperado fue que glicina prevenía el aumento de la concentración de calcio intracelular en presencia o ausencia de calcio extracelular por lo cual ellos concluyeron que glicina no sólo afectaba la entrada de calcio desde el medio extracelular, sino que también impedía su liberación desde los depósitos intracelulares. Basado en estos hallazgos Wheeler y col. (2000a), sugirieron que glicina debía inhibir secundariamente procesos que son dependientes de los aumentos en $\left[\mathrm{Ca}^{2+}\right]_{\mathrm{i}}$, como la activación de la NADPH oxidasa y la producción de ROS. De acuerdo con esto, ellos mostraron que glicina inhibía parcialmente la producción de ROS.

¿Cuál es el efecto de glicina sobre la producción de ROS inducida por el fMLP en nuestras condiciones experimentales? Nuestros resultados muestran que la liberación de ROS al medio extracelular fue reducido por glicina por un efecto independiente del canal de cloruro ya que la estricnina no fue capaz de revertir el efecto inhibitorio de la glicina.

¿Cómo podemos explicar el efecto de la glicina sobre la $\left[\mathrm{Ca}^{2+}\right]_{i}$ ? El aumento en $\left[\mathrm{Ca}^{2+}\right]_{i}$ producido en neutrófilos preincubados con glicina, podría ser explicado como un efecto secundario de la inhibición de la NADPH oxidasa. La entrada de calcio a través de canales catiónicos depende de la existencia de una diferencia de potencial electroquímico o fuerza impulsora. La activación de la NADPH oxidasa provoca una despolarización de la membrana plasmática que reduce la fuerza impulsora para la entrada de calcio. Por consiguiente, la inhibición de la NADPH oxidasa incrementa la fuerza impulsora y facilita la entrada de calcio (Tintinger y Anderson, 2004). 


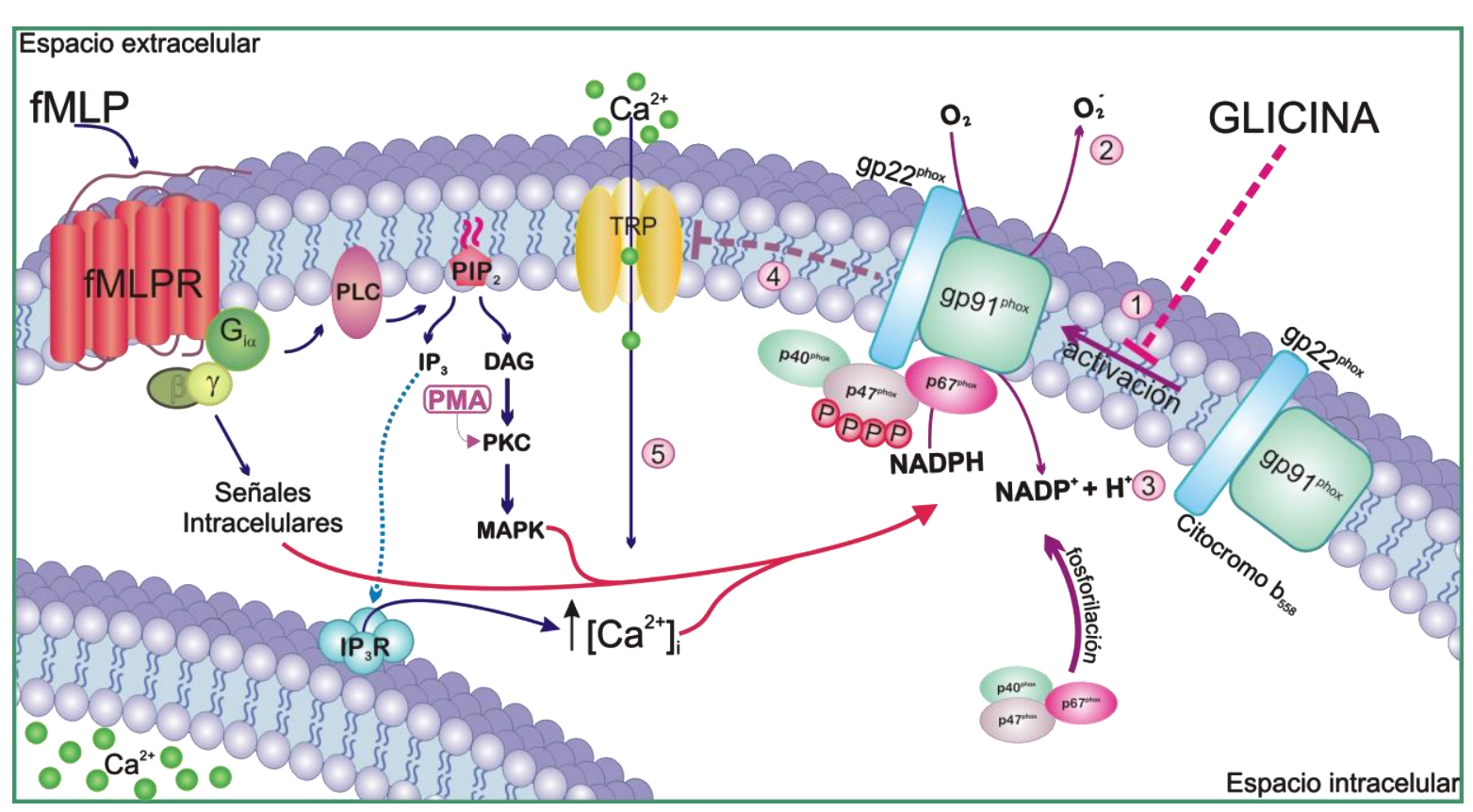

Figura V-7: Mecanismo de acción propuesto para glicina. Glicina inhibe la activación de la NADPH oxidasa (1), impidiendo la producción de superóxido (2), así como la acidificación del citoplasma celular (3) y la despolarización de la membrana (4), manteniendo la fuerza impulsora para la entrada de calcio, lo que permite una mayor entrada de este catión a través de la membrana (5).

No podemos establecer la causa de la diferencia entre nuestros resultados y los descriptos por Wheeler y col (2000a). Descartamos que se deba a la diferencia de especies, ya que la glicina facilitó la entrada de calcio en neutrófilos peritoneales. La única diferencia experimental obvia fue la utilización de células adherentes mientras nosotros las estudiamos en suspensión.

¿Afecta la glicina la activación de la NADPH oxidasa por un mecanismo no mediado por receptor e independiente de la $\left[\mathrm{Ca}^{2+}\right]_{i}$ ? Para estudiar esto utilizamos neutrófilos estimulados con PMA (Lopez y col., 1999). La producción de ROS inducida por el PMA fue reducida significativamente cuando los neutrófilos fueron incubados en presencia de glicina. Confirmando este efecto inhibitorio sobre NADPH oxidasa, el pHi muestra una disminución de la carga ácida que provoca la actividad de la enzima. Esta disminución no aparecería si la glicina actuara solo como "scavenger" de los ROS

¿Cuál es el mecanismo de acción de la glicina? Para determinar si era necesario que la glicina entrara a la célula para ejercer su efecto, se realizaron experimentos donde la glicina $1 \mathrm{mM}$ se añadió 10 segundos antes o 150 segundos después de estimular las células con fMLP o PMA. El efecto de glicina sobre la liberación de ROS fue similar y comparable con el efecto de inhibitorio obtenido en neutrófilos pre-incubados 600 segundos con glicina $1 \mathrm{mM}$. Estos resultados indican que glicina estaría inhibiendo la producción de ROS aun cuando la NADPH oxidasa ya se encontraría ensamblada y funcionando en la membrana.

Recientemente, se sugirió (Carini y col., 2007) que el 
mecanismo de protección utilizado por glicina en hepatocitos sería un aumento en la hidratación de la célula como consecuencia de la entrada de aminoácidos dependiente de $\mathrm{Na}^{+}$. Otro mecanismo propuesto sugiere que glicina interferiría, a través de una vía p38MAPK-dependiente, con la actividad del intercambiador $\mathrm{Na}^{+} / \mathrm{H}^{+}$, reduciendo la entrada de sodio en respuesta a la estimulación de la célula. En nuestros experimentos con neutrófilos la sustitución del sodio por litio no modificó el efecto inhibitorio de la glicina.

La glicina tiene un grupo amino (pK: 9.6) y un grupo carboxilo (pK: 2.3) ionizables. Por ello estudiamos si la entrada de la glicina a la célula podía provocar cambios en el pHi y modificar la respuesta al fMLP. Los experimentos mostrados en Fig. V-4 descartaron esta posibilidad.
En conclusión proponemos que la glicina actúa por un mecanismo distal, independiente del canal de cloruro, inhibiendo la NADPH oxidasa, reduciendo la despolarización que ella produce y que secundariamente al mantener la fuerza impulsora favorece la entrada de calcio (Fig. V-7).

Nuestros resultados confirman informes previos sobre el potencial anti-inflamatorio de las soluciones suplementadas con glicina. Aunque debemos ser cautelosos al momento de extrapolar estas conclusiones a una situación clínica, el alto efecto citoprotector de bajas concentraciones de glicina indica que la adición de glicina para las soluciones de resucitación podría ser útil para reducir reacciones inflamatorias disfuncionales. 


\section{Capítulo VI}

DISCUSIÓN GENERAL 


\section{Modelo Elegido}

En nuestros experimentos se utilizaron neutrófilos periféricos humanos; sin embargo ¿Es este el mejor modelo para estudiar el comportamiento de los neutrófilos en los procesos inflamatorios?

Sin duda existen marcadas diferencias entre el neutrófilo circulante y el que se encuentra en los tejido donde se ha orquestado una respuesta inflamatoria. Este último ha sufrido procesos de interacción con el endotelio, transmigración, "priming" por citoquinas y otros procesos que alteran su capacidad de respuesta y modifican los mecanismos de traducción de señales. Así por ejemplo en presencia de TNF $\alpha$, los neutrófilos responden al LPS mucho más activamente (Jersmann y col., 1998)

En algunos modelos se recurre a la adhesión en sustratos sólidos para estudiar la respuesta de los neutrófilos. Según el sustrato utilizado las respuestas varían, en general la interacción entre las moléculas de adhesión y el sustrato, amplifica la respuesta. Las funciones anti-infecciosas y pro-inflamatorias de los neutrófilos se desarrollan normalmente después de que los neutrófilos abandonan la circulación y se han adherido unos a otros, o a las plaquetas, al endotelio, a células del estroma, o a proteínas de la matriz extracelular. Esto motivó a muchos investigadores a explorar la función de los neutrófilos en modelos en los que se adherían a superficies activantes. Diferentes modelos usan la adhesión a plástico o a vidrio cubierto de plasma, suero, fibrinógeno, fibronectina, vitronectina, laminina o trombospondina (Dahinden y col., 1983; Hanlon y col., 1991; Kowanko y Ferrantes, 1991; Nathan, 1987, Nathan, 1989, Nathan y col., 1989; Wolpe y col., 1988). También se han usado como soporte cultivos confluentes de células endoteliales (Nathan, 1987) o miocitos (Entman y col., 1990).
El principal hallazgo de estos estudios fue que en neutrófilos adherentes TNF $\alpha$, GM-CSF, MIP-1, IL-8, C5a y fMLP actúan como potentes secretagogos, independientes de citocalasina, mientras que se comportan como agonistas débiles y dependientes de citocalasina cuando se los estimula en suspensión (Nathan, 1993).

La adherencia parece ser un pre-requisito para que estímulos fisiológicos produzcan el clivaje de CD43 que a su vez es necesario para la adhesión firme y la producción masiva de ROS (Nathan, 1993).

La obtención de células adherentes implica la incubación de las células durante periodos prolongados (24-48 hs) y la medición de flujos iónicos requiere equipos de epifluorescencia. Es posible que alguna de las diferencias entre nuestros resultados y los obtenidos con neutrófilos adheridos a soportes sólidos puedan atribuirse a estas diferentes condiciones experimentales.

Cuando se comparan los cambios de $\left[\mathrm{Ca}^{2+}\right]_{i}$ promovidos por fMLP en células adherentes y en suspensión se ha observado un mayor aumento, un retorno a los niveles basales mas lento y una menor dependencia del calcio extracelular en los neutrófilos adherentes. La magnitud de la producción de superóxido en respuesta al fMLP está aumentada comparada con lo obtenido en neutrófilos en suspensión. Esta respuesta debe relacionarse con el aumento en la movilización de calcio, el cual es un importante mediador de la preactivación para las respuestas inducidas por el fMLP (Ginis y Tauber, 1990).

Los flujos de calcio también se han medido por citometría de flujo en sangre entera (Desmeules y col., 2009), en neutrófilos aislados (Lee y col., 2005; Gilli y col., 2005; Rose y col., 2004; Chen y col., 2000; Burke y col. 1994; Zhang y col., 2009) o en neutrófilos periféricos no adheridos. Si bien esta técnica presenta algunas ventajas en 
comparación con la que nosotros utilizamos, se decidió utilizar técnicas fluorometricas en las cuales se tenía mucha experiencia y nos permitieron cumplir los objetivos planteados en el tiempo establecido.

\section{Agonistas Elegidos}

Estamos advertidos que el fMLP es un agonista que mimetiza la estimulación por productos bacterianos, mientras que las soluciones hipertónicas se han propuesto para limitar procesos inflamatorios no sépticos como el shock hemorrágico, y la principal promesa de la glicina es ser aplicable en transplantes hepáticos donde el riesgo es la sobreestimulación con TNF $\alpha$. Por lo tanto estos resultados deben ser tomados como estudios preliminares y su extrapolación a situaciones clínicas exigirá modelos más complejos. No obstante, creemos que nuestros estudios son importantes porque aportan nuevas evidencias sobre los posibles mecanismos de acción tanto de las soluciones hipertónicas como de glicina. Para poder dilucidar estos mecanismos se utilizaron tanto el fMLP como el PMA, que si bien no son los agonistas que fisiológicamente se encuentran relacionados con las reacciones inflamatorias disfuncionales que se desea evitar, nos han servido como herramientas para este fin.

Otro agonista utilizado ha sido el $\mathrm{H}_{2} \mathrm{O}_{2}$, que si bien no es un agonista tradicional, ha sido el que más nos ha acercado a una situación fisiológica, ya que está presente en el entorno de las células en el foco inflamatorio, y cuyo mecanismo de acción como inductor de señales intracelulares no había sido estudiado en neutrófilos anteriormente.

\section{Medios Salinos Utilizados}

En nuestros experimentos utilizamos soluciones amortiguadoras con HEPES, lo que elimina los mecanismos de transporte de bicarbonato, el principal amortiguador fisiológico en el organismo y reduce la capacidad amortiguadora intracelular. El neutrófilo tiene un intercambiador Cl/Bicarbinato (Simchowitz y Davis, 1990) estas circunstancias podrían alterar el "cross talk" entre pHi y ROS.

Los experimentos fueron realizados con soluciones ajustadas a $\mathrm{pH}:$ 7.4. Sin embargo es posible que en el mismo ambiente donde se desarrollan las reacciones inflamatorias el pH extracelular sea más bajo, un factor que contribuye a la activación del neutrófilo.

\section{Concentraciones Utilizadas}

¿Se pueden extrapolar estos resultados para su aplicación clínica? ¿Son las concentraciones de $\mathrm{H}_{2} \mathrm{O}_{2}$, glicina y $\mathrm{NaCl}$ utilizadas in vitro clínicamente relevantes? Sin duda se han elegido concentraciones tanto o más altas que las que se pueden alcanzar durante el tratamiento de un paciente, pero también es cierto que esto ocurre en la mayoría de los estudios in vitro donde lo que se intenta es dilucidar los posibles mecanismos que luego requieren una validación en modelos más complejos como por ejemplo animales enteros.

\section{Importancia del Calcio Intracelular en los Mecanismos de Señalización}

Históricamente se le ha atribuido una gran importancia a los mecanismos de señalización por calcio. Posteriormente el hallazgo de que muchos procesos de activación se señalizaban aun en ausencia de cambios en la concentración de calcio intracelular, tendió a desvalorizar el papel de este ion.

Sin embargo, recientemente se ha insistido en que el control del calcio es una alternativa esperanzadora en la modulación 
farmacológica de la respuesta inmune mediada por los neutrófilos (Tintinger y col., 2005). Alguna de las distintas estrategias propuestas se resumen en la Tabla VI-1.

\section{6. "CrossTalk" entre la NADPH Oxidasa y la Entrada de Calcio}

La estimulación de la NADPH oxidasa produce una marcada despolarización de la membrana que reduce la fuerza impulsora para la entrada de calcio. Esta correlación entre la inhibición de la actividad de la NADPH oxidasa y la mayor entrada de calcio justifica los resultados descriptos en el capítulo de glicina.

Sin embargo, en el capítulo III describimos un efecto facilitador de los ROS sobre la entrada de calcio, similar al que se ha descripto en otros tejidos.

Esta aparente contradicción puede ser explicada por un efecto bifásico de los ROS: en ausencia de agonista despolarizante se hace evidente el efecto facilitador de los ROS. Dado que la estimulación de la entrada de calcio en los neutrófilos tiene un umbral más alto que el encontrado en otros tejidos, este umbral más alto permitiría mantener inactivos a los neutrófilos circulantes y durante la transmigración mientras que reforzaría la actividad solo en el foco inflamatorio. Otra posibilidad es que cuando los ROS superan un cierto umbral se produzca la entrada de calcio para desatar señales apoptoticas que limiten el daño a las células vecinas.

Otra aparente contradicción podría ser el efecto de las soluciones hipertónicas, donde se produce la inhibición de la actividad de la NADPH oxidasa y una reducción en la concentración de calcio intracelular. Las soluciones hipertónicas provocan una reducción de la liberación de calcio desde los depósitos intracelulares, y como consecuencia se produce una reducción de la entrada capacitativa. Sin embargo, la entrada no disminuye significativamente a pesar de que la liberación de calcio desde los depósitos disminuye, esto podría

Tabla VI-1: Estrategias propuestas para la modulación farmacológica de la respuesta inmune mediada por los neutrófilos

\begin{tabular}{|c|c|c|c|}
\hline $\begin{array}{c}\text { Objetivo } \\
\text { farmacologico }\end{array}$ & Función & Estrategia farmacológica & $\begin{array}{l}\text { Ejemplos de drogas } \\
\text { antiinflamatorias }\end{array}$ \\
\hline Fosfolipasa C & $\begin{array}{l}\text { Movilización de } \\
\mathrm{Ca}^{2+}\end{array}$ & Inhibir: reducir la movilización de $\mathrm{Ca}$ & U73122 \\
\hline $\begin{array}{c}\mathrm{Ca}^{2+} \text {-ATPasa } \\
\text { membrana } \\
\text { plasmatica }\end{array}$ & $\begin{array}{l}\text { Clearence de } \\
\qquad \mathrm{Ca}^{2+}\end{array}$ & $\begin{array}{l}\text { Potenciar: modular negativamente las } \\
\text { actividades proinflamatorias }\end{array}$ & $\begin{array}{l}\text { Ácidos grasos } \\
\text { poliinsaturados }\end{array}$ \\
\hline $\begin{array}{l}\text { NADPH } \\
\text { oxidasa }\end{array}$ & $\begin{array}{l}\text { Exclusión de } \mathrm{Ca}^{2+} \\
\quad \text { extracelular }\end{array}$ & $\begin{array}{l}\text { Potenciar: prevenir el llenado del } \\
\text { depósito y la reactivación de las células }\end{array}$ & Clofazimine \\
\hline $\begin{array}{c}\mathrm{Ca}^{2+} \text {-ATPasa } \\
\text { endo- } \\
\text { membrana }\end{array}$ & $\begin{array}{l}\text { Clearence de } \\
\qquad \mathrm{Ca}^{2+}\end{array}$ & $\begin{array}{l}\text { Potenciar: modular negativamente las } \\
\text { actividades proinflamatorias }\end{array}$ & $\begin{array}{l}\text { Agonistas del } \\
\text { receptor b- } \\
\text { adrenergico y del } \\
\text { receptor de } \\
\text { adenosina }\end{array}$ \\
\hline $\begin{array}{l}\text { IIntercambiador } \\
\qquad \mathrm{Na}^{+} / \mathrm{Ca}^{2+}\end{array}$ & $\begin{array}{l}\text { Facilita la entrada } \\
\qquad \text { de } \mathrm{Ca}^{2+}\end{array}$ & $\begin{array}{l}\text { Inhibir: prevenir el llenado del depósito } \\
\text { y la reactivación de las células }\end{array}$ & $\begin{array}{l}\text { KB-R7943, } \\
\text { SEA0400 }\end{array}$ \\
\hline $\begin{array}{l}\text { Canales de } \\
\mathrm{Ca}^{2+} \text { operados } \\
\text { por deposito }\end{array}$ & $\begin{array}{l}\text { Media la entrada } \\
\text { de calcio. }\end{array}$ & $\begin{array}{l}\text { Bloquear: prevenir el llenado del } \\
\text { depósito y la reactivación de las } \\
\text { células. }\end{array}$ & Itraconazole \\
\hline
\end{tabular}

deberse a que la entrada de calcio esta favorecida por la persistencia de la fuerza impulsora, que compensaría la menor apertura de los canales operados por reservorio. 


\section{Conclusiones}

En estos trabajos hemos analizado la posibilidad de que la producción de especies reactivas del oxigeno por los neutrófilos activados actué como regulador autocrino/paracrino de la función o supervivencia de los neutrófilos a través de la activación de la entrada de calcio.

Describimos la reducción de la movilización de calcio en medios hipertónicos como resultado de acciones a diverso nivel en la vía de señalización, "upstream" de la activación de NADPH oxidasa.

Concluimos que la glicina actúa por un mecanismo distal, independiente del canal de cloruro, inhibiendo la NADPH oxidasa, reduciendo la despolarización que ella produce y que secundariamente al mantener la fuerza impulsora favorece la entrada de calcio. 
CAPÍTULO VII

\author{
REFERENCIAS
}


Abraham E, Carmody A, Shenkar R, Arcaroli J. (2000) Neutrophils as early immunologic effectors in hemorrhage- or endotoxemia-induced acute lung injury. Am. J. Physiol. Lung Cell Mol. Physiol. 279:L1137-45.

Ahima RS, Flier JS. (2000) Adipose tissue as an endocrine organ. Trends Endocrinol. Metab. 11: 327-32.

Ahluwalia J, Tinker A, Clapp LH, y col. (2004) The large-conductance $\mathrm{Ca}^{2+}$-activated $\mathrm{K}^{+}$ channel is essential for innate immunity. Nature 427(6977): 853-8.

Ajuwon KM, Spurlock ME. (2005) Adiponectin inhibits LPS-induced NF-kappa B activation and IL-6 production and increases PPARy2 expression in adipocytes. Am. J. Physiol. Regul. Integr. Comp. Physiol. 288: R1220-5.

Ali H, Richardson RM, Haribabu B, Snyderman R. (1999) Chemoattractant receptor cross-desensitization. J. Biol. Chem. 274(10): 6027-30.

Araki A, Inoue T, Cragoe E, Sendo F. (1991) $\mathrm{Na}^{+} / \mathrm{H}^{+}$exchange modulates rat neutrophil mediated tumor cytotoxicity. Cancer Research 51: 3212-6.

Araki H, Katayama N, Yamashita Y, y col. (2004) Reprogramming of human postmitotic neutrophils into macrophages by growth factors. Blood 103(8): 2973-80.

Ascher E, Hanson JN, Cheng W, Hingorani A, Scheinman M. (2001) Glycine preserves function and decreases necrosis in skeletal muscle undergoing ischemia and reperfusion injury. Surgery 129: 231-5.

Babior BM, Lambeth JD, Nauseef W. (2002) The neutrophil NADPH oxidase. Arch. Biochem. Biophys. 397(2): 342-4

Babior BM. (1982) The enzymatic basis for O-.2 production by human neutrophils.

Baggiolini M. (1972) The enzymes of the granules of polymorphonuclear leukocytes and their functions. Enzyme 13(1): 132-60.

Bahra PS, Rainger GE, Wautier JL, Nash GB. (2001) Effects of pentoxifylline on the different steps during adhesion and transendothelial migration of flowing neutrophils. Cell Biochem. Funct. 19: 249-57.

Bainton DF, Miller LJ, Kishimoto TK, Springer TA. (1987) Leukocyte adhesion receptors are stored in peroxidase-negative granules of human neutrophils. J. Exp. Med. 166: 1641-53
Bakowski B, Tschesche H. (1992) Migration of polymorphonuclear leukocytes through human amnion membrane: A scanning electron microscopic study. Biol. Chem. Hoppe Seyler 373: 529-46.

Bedard K, Krause KH. (2007) The NOX family of ROS-generating NADPH oxidases: physiology and pathophysiology. Physiol. Rev. 87(1): 245-313

Ben-Amor N, Redondo PC, Bartegi A, y col. (2006) A role for 5,6-epoxyeicosatrienoic acid in calcium entry by de novo conformational coupling in human platelets. J. Physiol. 570: 309-23.

Benjarano I, Terrón MP, Paredes SD, y col. (2007) Hydrogen peroxide increases the phagocytic function of human neutrophils by calcium mobilisation. Mol. Cell Biochem. 296: 77-84.

Berkow R, Dodson R. (1987) Functional analysis of the marginating pool of human polymorphonuclear leukocytes. Am. J. Hematol. 24(1): 47-54.

Berridge MJ, Lipp P, Bootman MD. (2000) The versatility and universality of calcium signalling. Nat. Rev. Mol. Cell Biol. 1(1): 11-21.

Berridge MJ. (1995) Capacitative calcium entry. Biochem. J. 312: 1-11.

Berridge MJ. (1993) Inositol trisphosphate and calcium signalling. Nature 361(6410): 315-25.

Berthier S, Paclet MH, Lerouge S, y col. (2003) Changing the conformation state of cytochrome b558 initiates NADPH oxidase activation: MRP8/MRP14 regulation. J. Biol. Chem. 278(28): 25499-508.

Bianchi ME. (2007) DAMPs, PAMPs and alarmins: all we need to know about danger. J. Leukoc. Biol. 81(1): 1-5.

Borregaard N. (1997) Development of neutrophil granule diversity. Ann. NY Acad. Sci. 832: 62-8.

Borregaard N, Kjeldsen L, Sengeløv H, y col. (1994) Changes in the subcellular localization and surface expression of L-selectin, alkaline phosphatase, and Mac-1 in human neutrophils during stimulation with inflammatory mediators. J. Leukoc. Biol. 56: 80-87.

Borregaard N, Schwartz JH, Tauber Al. (1984) Proton secretion by stimulated neutrophils. Significance of hexose monophosphate shunt activity as source of electrons and protons for the respiratory burst. J. Clin. Invest. 74(2): 455-9. 
Borregaard N, Heiple JM, Simons ER, Clark RA. (1983) Subcellular localization of the b-cytochrome component of the human neutrophil microbicidal oxidase: Translocation during activation. J. Cell Biol. 97: 52-61.

Bouwens L. (1988) Structural and functional aspects of Kupffer cells. Revis. Biol. Celular 16: 69-94.

Boxio R, Bossenmeyer-Pourié C, Steinckwich N, Dournon C, Nüsse O. (2004) Mouse bone marrow contains large numbers of functionally competent neutrophils. J. Leukoc Biol. 75(4): 604-11.

Brandtzaeg P, Gabrielsen TO, Dale I, Müller F, Steinbakk M, Fagerhol MK. (1995) The leucocyte protein L1 (calprotectin): a putative nonspecific defence factor at epithelial surfaces. Adv. Exp. Med. Biol. 371A: 201-6.

Brinkmann V, Reichard U, Goosmann C, y col. (2004) Neutrophil extracellular traps kill bacteria. Science 303(5663): 1532-5.

Brown KA, Brain SD, Pearson JD, Edgeworth JD, Lewis SM, Treacher DF. (2006) Neutrophils in development of multiple organ failure in sepsis. Lancet 368(9530): 157-69.

Burg ND, Pillinger MH. (2001) The neutrophil: function and regulation in innate and humoral immunity. Clin. Immunol. 99(1): 7-17.

Burke PA, Canning CM, Chartier S, y col. (1994) Alterations in Ca2+ signal transduction in critically ill surgical patients. Surgery 116(2): 378-86

Bylund J, Björstad A, Granfeldt D, Karlsson A, Woschnagg C, Dahlgren C. (2003) Reactivation of formyl peptide receptors triggers the neutrophil NADPH-oxidase but not transient rise in intracellular calcium. J. Biol. Chem. 278: 30578-86.

Cao D, Boxer LA, Petty HR. (1993) Deposition of reactive oxygen metabolites onto and within living tumor cells during neutrophil-mediated antibody-dependent cellular cytotoxicity. J. Cell Physiol. 156(2): 428-36.

Carini R, Alchera E, Baldanzi G, y col. (2007) Role of p38 map kinase in glycineinduced hepatocyte resistance to hypoxic injury. J. Hepatol. 46:692-9.

Carlier MF. (1998) Control of actin dynamics. Curr. Opin. Cell Biol. 10(1): 45-51.

Carrico CJ, Meakins JL, Marshall JC, Fry D, Maier RV. (1986) Multiple-organ failure syndrome. Arch. Surg. 121: 196-208.

Chandler DE, Kazilek CJ. (1987) Calcium signals in neutrophils can be divided into three distinct phases. Biochim. Biophys. Acta 931: 175-9.
Chaplin DD. (2006) Overview of human immune response. J. Allergy Clin. Immunol. 117:S430-5.

Chen LW, Huang HL, Lee IT, Hsu CM, Lu PJ. (2006) Thermal injury-induced priming effect of neutrophil is TNF-[alpha] and p38 dependent. Shock 26(1): 69-76

Chen X, Yang D, Shen W, Dong HF, Wang JM, Oppenheim JJ, Howard MZ. (2000) Characterization of chenodeoxycholic acid as an endogenous antagonist of the Gcoupled formyl peptide receptors. Inflamm. Res. 49 (12): 744-55.

Chen Y, Hashiguchi N, Yip L, Junger WG. (2006) Hypertonic saline enhances neutrophil elastase release through activation of $\mathrm{P} 2$ and $\mathrm{A} 3$ receptors. Am. J. Physiol. Cell Physiol. 290: C1051-9.

Ciesla DJ, Moore EE, Musters RJ, Biffl WL, Silliman CC. (2001a) Hypertonic saline alteration of the PMN cytoskeleton: Implications for signal transduction and the cytotoxic response. J. Trauma 50: 206-12.

Ciesla DJ, Moore EE, Biffl WL, Gonzalez RJ, Silliman CC. (2001b) Hypertonic saline attenuation of the neutrophil cytotoxic response is reversed upon restoration of normotonicity and reestablished by repeated hypertonic challenge. Surgery 129: 567-75.

Ciesla DJ, Moore EE, Gonzalez RJ, Biffl WL, Silliman CC. (2000) Hypertonic saline inhibits neutrophil (PMN) priming via attenuation of p38 MAPK signaling. Shock 14:265-9 Clapham DE. (2003) TRP channelsas cellular sensors. Nature 426: 517-24.

Clark RA. (1990) The human neutrophil respiratory burst oxidase. J. Infect. Dis. 161(6) 1140-7.

Cohn ZA, Hirsch JG. (1960) The isolation and properties of the specific cytoplasmic granules of rabbit polymorphonuclear leukocytes. J. Exp. Med. 112: 983-1004.

Crockett-Torabi E, Fantone JC. (1995) The selectins: Insights into selectin-induced intracellular signaling in leukocytes. Immunol. Res. 14: 237-51.

Cruz M, García-Macedo R, García-Valerio Y, y col. (2004) Low adiponectin levels predict type 2 diabetes in Mexican children. Diabetes Care 27: 1451-3.

Dahinden CA, Fehr J, Hugli TE. (1983) Role of cell surface contact in the kinetics of superoxide production by granulocytes. J. Clin. Invest. 72:113-21.

Damann N, Owsianik G, Li S, Poll C, Nilius B. (2009) The calcium-conducting ion channel transient receptor potential canonical 6 is involved in macrophage inflammatory protein-2-induced migration of mouse neutrophils. Acta Physiol. 195: 3-11. 
Dancey JT, Deubelbeiss KA, Harker LA, Finch CA. (1976) Neutrophil kinetics in man. J. Clin. Invest. 58(3): 705-15.

De Garavilla L, Greco MN, Sukumar N, y col. (2005) A novel, potent dual inhibitor of the leukocyte proteases cathepsin $G$ and chymase: molecular mechanisms and antiinflammatory activity in vivo. J. Biol. Chem. 280(18): 18001-7.

De Vito P. (2006) The sodium/hydrogen exchanger: a possible mediator of immunity. Cell Immunol. 240(2): 69-85.

Delclaux C, Delacourt C, d'Ortho MP, Boyer V, Lafuma C, Harf A. (1996) Role of gelatinase $\mathrm{B}$ and elastase in human polymorphonuclear neutrophil migration across basement membrane. Am. J. Respir. Cell Mol. Biol. 14: 288-95.

Demaurex N, Downey GP, Waddell TK, Grinstein S. (1996) Intracellular pH regulation during spreading of human neutrophils. J. Cell Biol. 133: 1391-402.

Den Dekker E, Molin DG, Breikers G, y col. (2001) Expression of transient receptor potential mRNA isoforms and $\mathrm{Ca}^{2+}$ influx in differentiating human stem cells and platelets. Biochim. Biophys. Acta 1539: 243-55.

Desmeules P, Dufour M, Fernandes MJ. (2009) A rapid flow cytometry assay for the assessment of calcium mobilization in human neutrophils in a small volume of lysed whole-blood. J. Immunol. Methods 340(2):154-7.

Dewald B, Bretz U, Baggiolini M. (1982) Release of gelatinase from a nover secretory compartment of human neutrophils. J. Clin. Invest. 70: 518-25.

Doan TN, Gentry DL, Taylor AA, Elliott SJ. (1994) Hydrogen peroxide activates agonist-sensitive $\mathrm{Ca}(2+)$-flux pathways in canine venous endothelial cells. Biochem. J. 297: 209-15.

Doerfler ME, Danner RL, Shelhamer JH, Parrillo JE. (1989) Bacterial lipopolysaccharides prime human neutrophils for enhanced production of leukotriene B4. J. Clin. Invest. 83: 970-7.

Doerfler ME, Weiss J, Clark JD, Elsbach P. (1994) Bacterial lipopolysaccharide primes human neutrophils for enhanced release of arachidonic acid and causes phosphorylation of an 85-kD cytosolic phospholipase A2. J. Clin. Invest. 93: 1583-91.

Donato R. (2001) S100: a multigenic family of calcium-modulated proteins of the EFhand type with intracellular and extracellular functional roles. Int. J. Biochem. Cell Biol. 33(7): 637-68
Edwards SW, Hallett MB. (1997) Seeing the wood for the trees: the forgotten role of neutrophils in rheumatoid arthritis. Immunol. Today 18: 320-4.

El-Benna J, Dang PM, Gougerot-Pocidalo MA. (2008) Priming of the neutrophil NADPH oxidase activation: role of p47phox phosphorylation and NOX2 mobilization to the plasma membrane. Semin. Immunopathol. 30(3):279-89.

Entman ML, Youker K, Shappell SB, y col. (1990) Neutrophil adherence to isolated adult canine myocytes. Evidence for a CD18-dependent mechanism. J. Clin. Invest. 85:1497-506.

Faurschou M, Borregaard N. (2003) Neutrophil granules and secretory vesicles in inflammation. Microbes Infect. 5(14): 1317-27.

Fein A, Calalang-Colucci M. (2000) Acute lung injury and acute respiratory distress syndrome in sepsis and septic shock. Crit. Care. Clin. 16(2):289-317.

Ferretti M, Spisani S, Pareschi M, y col. (1994) Two new formylated peptides able to activate chemotaxis and respiratory burst selectively as tools for studying human neutrophil responses. Cell Signal. 6(1): 91-101.

Fittschen C, Sandhaus RA, Worthen GS, Henson PM. (1988) Bacterial lipopolysaccharide enhances chemoattractant-induced elastase secretion by human neutrophils. J. Leukocyte Biol. 43: 547-56

Friedman AD. (2002) Transcriptional regulation of myelopoiesis. Int. J. Hematol. 75(5):466-72

Froh M, Thurman RG, Wheeler MD. (2002) Molecular evidence for a glycine-gated chloride channel in macrophages and leukocytes. Am. J. Physiol. Gastrointest. Liver Physiol. 283:G856-63.

Fu H, Bylund J, Karlsson A, Pellmé S, Dahlgren C. (2004) The mechanism for activation of the neutrophil NADPH-oxidase by the peptides formyl-Met-Leu-Phe and TrpLys-Tyr-Met-Val-Met differs from that for interleukin-8. Immunology 112(2): 201-10.

Fukushima T, Waddell TK, Grinstein S, Goss GG, Orlowski J, Downey GP. (1996) $\mathrm{Na}^{+} / \mathrm{H}^{+}$exchange activity during phagocytosis in human neutrophils: role of Fcgamma receptors and tyrosine kinases. J. Cell Biol. 132: 1037-52.

Gabig TG, Bearman SI, Babior BM. (1979) Effects of oxygen tension and pH on the respiratory burst of human neutrophils. Blood 53: 1133-39. 
Gallin, JI. Inflammation. En: Paul, WE. (Ed.) Fundamental Immunology. Raven Press, New York, 1989: 721-33.

Gallin, Jl; Goldstein, IM; Snyderman, R. Inflammation: Basic Principles and Clinical Correlates. Raven Press, New York, 1988.

Gallin Jl. (1984) Neutrophil specific granules: A fuse that ignites the inflammatory response. Clin. Res. 32:320-8.

Gasser O, Schifferli JA. (2004) Activated polymorphonuclear neutrophils disseminate anti-inflammatory microparticles by ectocytosis. Blood 104(8):2543-8.

Gasser O, Hess C, Miot S, Deon C, Sanchez JC, Schifferli JA. (2003) Characterisation and properties of ectosomes released by human polymorphonuclear neutrophils. Exp. Cell Res. 285: 243-57.

Gebska A, Olszanecki R, Korbut R. (2005) Endotoxaemia in rats: role of leukocyte sequestration in rapid pulmonary nitric oxide synthase-2 expression. J. Physiol Pharmacol. 56(2): 299-311.

Gee M, Albertine K. (1993) Neutrophil-endothelial cell interactions in the lung. Annu. Rev. Physiol. 55: 227-48.

Geffner J, Trevani A, Minucci F, Palermo M, Maugeri N, Isturiz M. (1993) Extracellular acidic $\mathrm{pH}$ modulates oxygen-dependent cytotoxic responses mediated by polymorphonuclear leucocytes and monocytes. Clin. Exp. Immunol. 91: 164-9.

Giambelluca MS, Gende OA. (2008) Inhibition of cytochalasin-primed neutrophils by hyperosmolarity. Shock 30:473-80.

Gilli UO, Schneider MK, Loetscher P, Seebach JD. (2005) Human polymorphonuclea neutrophils are recruited by porcine chemokines acting on CXC chemokine receptor 2 , and platelet-activating factor. Transplantation 79(10): 1324-31.

Ginis I, Tauber Al. (1990) Activation mechanisms of adherent human neutrophils. Blood 76(6): 1233-9.

Gohrbandt B, Fischer S, Warnecke G, y col. (2006) Glycine intravenous donor preconditioning is superior to glycine supplementation to low potassium dextran flush preservation and improves graft function in a large animal lung transplantation model after 24 hours of cold ischemia. J. Thorac. Cardiovasc. Surg. 131: 724-9.

Goris RJ, Te Boekhorst TP, Nuytinck JK, Gimbrere JS. (1985) Multiple-organ failure. Generalized autodestructive inflammation? Arch. Surg. 120: 1109-15.
Griffiths RD, Allen KD, Andrews FJ, Jones C. (2002) Infection, multiple organ failure, and survival in the intensive care unit: influence of glutamine-supplemented parenteral nutrition on acquired infection. Nutrition 18: 546-52.

Grinstein S, Furuya W, Biggar WD. (1986) Cytoplasmic pH regulation in normal and abnormal neutrophils. Role of superoxide generation and $\mathrm{Na}^{+} / \mathrm{H}^{+}$exchange. J. Biol. Chem. 261(2): 512-4

Grinstein S, Furuya W. (1986). Cytoplasmic pH regulation in phorbolester activated human neutrophiles. Am. J. Physiol. 251: C55-65.

Grinstein S, Vander Meulen J, Furuya W. (1982) Possible role of $\mathrm{H}^{+}$alkali cation countertransport in secretory granule swelling during exocytosis. FEBS Lett. 148(1): 1-4.

Grynkiewicz G, Poenie M, Tsien RY. (1985) A new generation of Ca2+ indicators with greatly improved fluorescence properties. J. Biol. Chem. 260: 3440-50.

Gullberg U, Bengtsson N, Bülow E, Garwicz D, Lindmark A, Olsson I. (1999) Processing and targeting of granule proteins in human neutrophils. J. Immunol. Methods 232(1-2):201-10.

Gurevitch J, Frolkis I, Yuhas Y, y col. (1997) Anti-tumor necrosis factor-alpha improves myocardial recovery after ischemia and reperfusion. J. Am. Coll. Cardiol. 30(6): 1554-61.

Guthrie LA, McPhail LC, Henson PM, Johnston Jr RB. (1984) Priming of neutrophils for enhanced release of oxygen metabolites: evidence for increased activity of the superoxide-producing enzyme. J. Exp. Med. 160: 1656-71.

Hall JC. (1998) Glycine. J. Par. Ent. Nutr. 2:393-8.

Han H y col. (2005) Calcium-sensing soluble adenylyl cyclase mediates TNF signal transduction in human neutrophils. J. Exp. Med. 202: 353-61.

Hanlon WA, Stolk J, Davies P, Humes JL, Mumford R, Bormey RJ. (1991) rTNFo facilitates human polymorphonuclear leukocyte adherence to fibrinogen matrices with mobilization of specific and tertiary but not azurophilic granule markers. J. Leukocyte Biol. 50:43-8.

Hara Y, Wakamori M, Ishii M, y col. (2002) LTRPC2 $\mathrm{Ca}^{2+}$-permeable channel activated by changes in redox status confers susceptibility to cell death. Mol. Cell 9(1): 163-73.

Hasenboehler E, Williams A, Leinhase I y col. (2006) Metabolic changes after polytrauma: an imperative for early nutritional support. World J. Emerg. Surg. 1: 29. 
Hawkins CL, Davies MJ. (2005) Inactivation of protease inhibitors and lysozyme by hypochlorous acid: role of side-chain oxidation and protein unfolding in loss of biological function. Chem. Res. Toxicol. 18(10):1600-10.

Hayashi H, Aharonovitz O, Alexander RT, y col. (2008) $\mathrm{Na}^{+} / \mathrm{H}^{+}$exchange and $\mathrm{pH}$ regulation in the control of neutrophil chemokinesis and chemotaxis. Am. J. Physiol. Cell Physiol. 294: C526-34.

Heiner I, Eisfeld J, Warnstedt M, Radukina N, Jüngling E, Lückhoff A. (2006) Endogenous ADP-ribose enables calcium-regulated cation currents through TRPM2 channels in neutrophil granulocytes. Biochem. J. 398:225-32

Heiner I, Eisfeld J, Lückhoff A. (2003) Role and regulation of TRP channels in neutrophil granulocytes. Cell Calcium 33(5-6): 533-40.

Heit B, Tavener S, Raharjo E, Kubes P. (2002) An intracellular signaling hierarchy determines direction of migration in opposing chemotactic gradients. J. Cell Biol. 159(1):

91-102.

Henderson LM, Chappell JB, Jones OT. (1987) The superoxide-generating NADPH oxidase of human neutrophils is electrogenic and associated with an $\mathrm{H}^{+}$channel. Biochem. J. 246: 325-9.

Hess C, Sadallah S, Hefti A, Landmann R, Schifferli JA. (1999) Ectosomes released by human neutrophils are specialized functional units. J. Immunol. 163: 4564-73.

Hibbs MS, Hasty KA, Seyer JM, Kang AH, Mainardi CL. (1985) Biochemical and immunological characterization of the secreted forms of human neutrophil gelatinase. J. Biol. Chem. 260: 2493-500.

Hijioka T, Rosenberg RL, Lemasters JJ, Thurman RG. (1992) Kupffer cells contain voltage-dependent calcium channels. Mol. Pharmacol. 41(3): 435-40.

Hofmann T, Obukhov AG, Schaefer M, Harteneck C, Gudermann T, Schultz G. (1999) Direct activation of human TRPC6 and TRPC3 channels by diacylglycerol. Nature 397(6716): 259-63.

Holbeck S, Bentzer P, Grände PO. (2002) Effects of hypertonic saline, mannitol, and urea with regard to absorption and rebound filtration in cat skeletal muscle. Crit. Care Med. 30: 212-7.
Hotamisligil GS, Arner P, Atkinson RL, Spiegelman BM. (1997) Differential regulation of the p80 tumor necrosis factor receptor in human obesity and insulin resistance. Diabetes 46: 451-5.

Hotta K, Funashi T, Bodkin NL, y col. (2001). Circulating concentrations of the adipocyte protein adiponectin are decreased in parallel with reduced insulin sensitivity during the progression to type 2 diabetes in rhesus monkeys. Diabetes 50: 1126-33.

Howard TH, Watts RG. (1994) Actin polymerization and leukocyte function. Curr. Opin. Hematol. 1(1): 61-8.

Ikejima K, Qu W, Stachlewitz RF, Thurman RG. (1997) Kupffer cells contain a glycinegated chloride channel. Am. J. Physiol. 272(6 Pt 1): G1581-6.

Ikejima K, limuro Y, Forman DT, Thurman RG. (1996) A diet containing glycine improves survival in endotoxin shock in the rat. Am. J. Physiol. Gastrointest. Liver Physiol. 271: G97-103.

Iking-Konert C, Ostendorf B, Sander $\mathbf{O}$ y col. (2005)Transdifferentiation of polymorphonuclear neutrophils to dendritic-like cells at the site of inflammation in rheumatoid arthritis: evidence for activation by T cells. Ann. Rheum. Dis. 64(10): 1436-42. Ipaktchi K, Mattar A, Niederbichler AD, y col. (2006) Topical p38 MAPK inhibition reduces dermal inflammation and epithelial apoptosis in burn wounds. Shock 26: 201-9.

Irving EA, Bamford M. (2002) Role of mitogen- and stress-activated kinases in ischemic injury. J. Cereb. Blood Flow Metab. 22(6): 631-47.

Irvine RF. (1990) 'Quantal' $\mathrm{Ca}^{2+}$ release and the control of $\mathrm{Ca}^{2+}$ entry by inositol phosphates a possible mechanism. FEBS Lett. 263(1): 5-9.

Itagaki K, Kannan KB, Singh BB, Hauser CJ. (2004) Cytoskeletal reorganization internalizes multiple transient receptor potential channels and blocks calcium entry into human neutrophils. J. Immunol. 172(1): 601-7.

Itagaki K, Hauser CJ. (2003) Sphingosine 1-phosphate, a diffusible calcium influx factor mediating store-operated calcium entry. J. Biol. Chem. 278: 27540-47.

Itagaki K, Kannan KB, Livingston DH, Deitch EA, Fekete Z, Hauser CJ. (2002) Storeoperated calcium entry in human neutrophils reflects multiple contributions from independently regulated pathways. J. Immunol. 168(8): 4063-9.

Jaeschke H, Farhood A. (1991) Neutrophil and Kupffer cell-induced oxidant stress and ischemia-reperfusion injury in rat liver. Am. J. Physiol. 260: 355-62. 
Jankowski A, Grinstein S (1999) A non-invasive fluorimetric procedure for measurement of membrane potential. Quantification of the NADPH oxidase-induced depolarization in activated neutrophils. J. Biol. Chem. 274: 26098-104.

Jeannin P, Delneste Y, Gosset P, y col. (1994) Histamine induces interleukin-8 secretion by endothelial cells. Blood 84: 2229-33.

Jersmann H, Rathjen DA, Ferrante A. (1998) Enhancement of lipopolysaccharideinduced neutrophil oxygen radical production by tumor necrosis factor alpha. Infect. Immun. 66(4): 1744-7.

Jesaitis A, Buescher ES, Harrison D, y col. (1990) Ultrastructural localization of cytochrome $\mathrm{b}$ in the membrane of resting and phagocytosing human granulocytes. J. Clin. Invest. 85:821-35.

Jesaitis AJ, Allen RA. (1988) Activation of the neutrophil respiratory burst by chemoattractants: regulation of the $\mathrm{N}$-formyl peptide recept or in the plasma membrane. J. Bioenerg. Biomembr. 20(6): 679-707.

Jesaitis AJ, Tolley JO, Allen RA. (1986) Receptor-cytoskeleton interactions and membrane traffic may regulate chemoattractant-induced superoxide production in human granulocytes. J. Biol. Chem. 261(29): 13662-9.

Joiner KA, Ganz T, Albert J, Rotrosen D. (1989) The opsonizing ligand on Salmonella typhimurium influences incorporation of specific, but not azurophil, granule constituents into neutrophil phagosomes. J. Cell. Biol. 109: 2771-82.

Junger WG, Hoyt DB, Davis RE, y col. (1998) Hypertonicity regulates the function of human neutrophils by modulating chemoattractant receptor signaling and activating mitogen-activated protein kinase p38. J. Clin. Invest. 101: 2768-79.

Kaneko S, Kawakami S, Hara Y, y col. (2006) A critical role of TRPM2 in neuronal cell death by hydrogen peroxide. J. Pharmacol. Sci. 101: 66-76.

Kazilek CJ, Merkle CJ, Chandler DE. (1988) Hyperosmotic inhibition of calcium signals and exocytosis in rabbit neutrophils. Am. J. Physiol. 254: C709-18.

Kerkhoff C, Sorg C, Tandon NN, Nacken W. (2001) Interaction of S100A8/S100A9 arachidonic acid complexes with the scavenger receptor CD36 may facilitate fatty acid uptake by endothelial cells. Biochemistry 40(1):241-8.
Kim JS, He L, Qian T, Lemasters JJ. (2003) Role of the mitochondrial permeability transition in apoptotic and necrotic death after ischemia/reperfusion injury to hepatocytes. Curr. Mol. Med. 3: 527-35

Kinnula VL, Fattman CL, Tan RJ, Oury TD. (2005) Oxidative stress in pulmonary fibrosis: a possible role for redox modulatory therapy. Am. J. Respir. Crit. Care Med. 172(4): 417-22

Kjeldsen L, Sengeløv H, Lollike K, Nielsen MH, Borregaard N. (1994) Isolation and characterization of gelatinase granules from human neutrophils. Blood 83: 1640-49.

Kloner RA, Przyklenk K, Wgittaker P. (1989) Deletorious effects of oxygen radicals in ischemia/reperfusion: resolved and unresolved issues. Circulation 80: 1115-27.

Klotz KN, Jesaitis AJ. (1994) Neutrophil chemoattractant receptors and the membrane skeleton. Bioessays 16: 193-8.

Klyubin IV, Kirpichnikova KM, Gamaley IA. (1996) Hydrogen peroxide-induced chemotaxis of mouse peritoneal neutrophils. Eur. J. Cell Biol. 70: 347-51.

Kneussel M, Betz H. (2000) Receptors, gephyrin and gephyrin-associated proteins: novel insights into the assembly of inhibitory postsynaptic membrane specializations. $J$. Physiol. 525: 1-9.

Kobayashi SD, Voyich JM, Somerville GA, y col. (2003) An apoptosis-differentiation program in human polymorphonuclear leukocytes facilitates resolution of inflammation. $J$. Leukoc. Biol. 74(3): 307-8.

Kohler R, Brakemeier S, Kuhn M, y col. (2001) Expression of ryanodine receptor type 3 and TRP channels in endothelial cells: comparison of in situ and cultured human endothelial cells. Cardiovasc. Res. 51: 160-8.

Korhonen R, Lahti A, Kankaanranta H, Moilanen E. (2005) Nitric oxide production and signaling in inflammation. Curr. Drug Targets Inflamm. Allergy 4(4): 471-9.

Kowanko IC, Ferrante A. (1991) Granulocyte-macrophage colonystimulating factor augments neutrophil-mediated cartilage degradation and neutrophil adherence. Arthritis Rheum. 34:1452-60.

Kraft R, Grimm C, Grosse K, y col. (2004) Hydrogen peroxide and ADP-ribose induce TRPM2-mediated calcium influx and cation currents in microglia. Am. J. Physiol. Cell Physiol. 286: C129-37. 
Krause KH, Demaurex N, Jaconi M, Lew DP. (1993) Ion channels and receptormediated $\mathrm{Ca}^{2+}$ influx in neutrophil granulocytes. Blood Cells 19(1): 165-73.

Kreimeier U, Messmer K. (2002) Small-volume resuscitation: from experimental evidence to clinical routine. Advantages and disadvantages of hypertonic solutions. Acta Anaesthesiol. Scand. 46: 625-38.

Kukreja RC, Hess ML. (1992) The oxygen free radical system: from equations through membrane-protein interactions to cardiovascular injury and protection. Cardiovasc. Res. 26: 641-65.

Lacerda L, Smith RM, Opie L, Lecour S. (2006) TNFalpha-induced cytoprotection requires the production of free radicals within mitochondria in $\mathrm{C} 2 \mathrm{C} 12$ myotubes. Life Sci. 79(23): 2194-201.

Lambeth JD. (2004) NOX enzymes and the biology of reactive oxygen. Nat. Rev. Immunol. 4(3): 181-9.

Lardner A. (2001) The effects of extracellular pH on immune function. J. Leukoc. Biol. 69: 522-30.

Laskin DL. (1990) Nonparenchymal cells and hepatotoxicity. Sem. Liver Dis. 10: 293304.

Lee C, Xu DZ, Feketeova E, y col. (2005) Store-operated calcium channel inhibition attenuates neutrophil function and postshock acute lung injury. J. Trauma 59 (1): 56-63.

Lee MA, McCauley RD, Kong SE, Hall JC. (2001) Pre-treatment with glycine reduces the severity of warm intestinal ischemic reperfusion injury in the rat. Ann. Plast. Surg. 45: $320-6$

Lee WL, Harrison RE, Grinstein S. (2003) Phagocytosis by neutrophils. Microbes Infect. 5(14): 1299-306

Lee WL, Downey GP. (2001) Neutrophil activation and acute lung injury. Curr. Opin. Crit. Care 7(1): 1-7.

Lemonier L, Trebak M, Putney JW Jr. (2008) Complex regulation of the TRPC3, 6 and 7 channel subfamily by diacylglycerol and phosphatidylinositol- 4,5-bisphosphate. Cell Calcium 43(5): 506-14.

Li YY, Perez HD, Zullner TM. (2006) Fatalities in natalizumab treatment a "no go" for leukocyte recirculation approaches. Expert Opin. Ther. Targets 10(4): 489-99.
Lindbom L, Werr J. (2002) Integrin-dependent neutrophil migration in extravascular tissue. Semin. Immunol.14(2): 115-21.

Liu X, Zweier JL. (2001) a real-time electrochemical technique for measurement of cellular hydrogen peroxide generation and consumption: evaluation in human polymorphonuclear leukocytes. Free Radic. Biol. Med. 3: 894-901.

Liu Y, Shaw SK, Ma S, Yang L, Luscinskas FW, Parkos CA. (2004) Regulation of leukocyte transmigration: cell surface interactions and signaling events. J. Immunol. 172(1): 7-13.

Lockwich TP, Singh BB, Liu X, Ambudkar IS. (2001) Stabilization of cortical actin induces internalization of Trp3-associated caveolar $\mathrm{Ca}^{2+}$ signaling complex and loss of $\mathrm{Ca}^{2+}$ influx without disruption of Trp3-IP ${ }_{3} \mathrm{R}$ association. J. Biol. Chem. 276(45): 42401-8.

Lockwich TP, Liu X, Singh BB, Jadlowiec J, Weiland S, Ambudkar IS. (2000) Assembly of Trp1 in a signaling complex associated with caveolin-scaffolding lipid raft domains. J. Biol. Chem. 275: 11934-42.

Lopes LR, Hoyal CR, Knaus UG, Babior BM. (1999) Activation of the leukocyte NADPH oxidase by protein kinase $\mathrm{C}$ in a partially recombinant cell-free system. J. Biol. Chem. 274:15533-7.

Luisetti M, Sturani C, Sella D, y col. (1996) MR889, a neutrophil elastase inhibitor, in patients with chronic obstructive pulmonary disease: a double-blind, randomized, placebo-controlled clinical trial. Eur. Respir. J. 9(7): 1482-6.

Lynch JW. (2004) Molecular structure and function of the glycine receptor chloride channel. Physiol. Rev. 84: 1051-95.

Mačičková T, Pečivová J, Nosál R, Holomáňová D. (2005) Influence of carvedilol on superoxide generation and enzime release from stimulated human neutrophils. Biomed Pap. Med. Fac. Univ. Palacky Olomouc Czech Repub. 149(2): 389-92.

Maher RJ, Cao D, Boxer LA, Petty HR. (1993) Simultaneous calcium-dependent delivery of neutrophil lactoferrin and reactive oxygen metabolites to erythrocyte targets: evidence supporting granule-dependent triggering of superoxide deposition. J. Cell Physiol. 156(2): 226-34.

Majander A, Wikström M. (1989) The plasma membrane potential of human neutrophils. Role of ion channels and the sodium/potassium pump. Biochim. Biophys. Acta 980(2): $139-45$ 
Male DK, Champion B, Cooke A, Owen M. Cell troffic and inflammation. En: Advance Immunology. $2^{\text {a }}$ ed. Ed Gower London-New York 1991.

Malle E, Marsche G, Arnhold J, Davies MJ. (2006) Modification of low-density lipoprotein by myeloperoxidase-derived oxidants and reagent hypochlorous acid Biochim. Biophys. Acta 1761(4): 392-415.

Marasco W, Phan S, Krutzsch H, y col. (1984) Purification and identification of formylmethionyl-leucyl-phenylalanine as the major peptide neutrophil chemotactic factor produced by Escherichia coli. J. Biol. Chem. 259(9): 5430-9.

Martin C, Burdon PC, Bridger G, Gutierrez-Ramos JC, Williams TJ, Rankin SM. (2003) Chemokines acting via CXCR2 and CXCR4 control the release of neutrophils from the bone marrow and their return following senescence. Immunity 19(4): 583-93.

Martinez D, Vermeulen M, Trevani A, y col. (2006) Extracellular acidosis induces neutrophil activation by a mechanism dependent on activation of phosphatidylinositol 3 Kinase/Akt and ERK pathways. J. Immunol. 176: 1163-71.

Maruyama K, Hartwig JH, Stossel TP. (1980) Cytochalasin B and the structure of actin gels. II. Further evidence for the splitting of F-actin by cytochalasin. Biochim. Biophys Acta. 626(2): 494-500

Mary JY. (1985) Normal human granulopoiesis revisited. II. Bone marrow data. Biomed Pharmacother 39: 66-77.

Mary JY. (1984) Normal human granulopoiesis revisited. I. Blood data. Biomed Pharmacother. 38(1): 33-43.

Massullo P, Sumoza-Toledo A, Bhagat H, Partida-Sánchez S. (2006) TRPM channels, calcium and redox sensors during innate immune responses. Semin. Cell Dev. Biol. 17(6): 654-66.

McHugh D, Flemming R, Xu SZ, y col. (2003) Critical intracellular Ca2+ dependence of transient receptor potential melastatin 2 (TRPM2) cation channel activation. J. Biol. Chem. 278: 11002-6

McMeekin SR, Dransfield I, Rossi AG, Haslett C, Walker TR. (2006) E-selectin permits communication between PAF receptors and TRPC channels in human neutrophils. Blood 107(12): 4938-45.

Mesri M, Altieri DC. (1998) Endothelial cell activation by leukocyte microparticles. J. Immunol. 161(8): 4382-7.
Mihelcic D, Schleiffenbaum B, Tedder TF, y col. (1994) Inhibition of leukocyte Lselectin function with a monoclonal antibody attenuates reperfusion injury to the rabbit ear. Blood 84: 2322-8.

Miller GW, Schnellmann RG. (1994) A putative cytoprotective receptor in the kidney: relation to the neuronal strychnine-sensitive glycine receptor. Life Sci 55: 27-34.

Montell C. (2005) Drosophila TRP channels. Pflugers Arch. 451(1): 19-28.

Moore AR, Willoughby DA. (1995) The role of cAMP regulation in controlling inflammation. Clin Exp Immunol. 101(3): 387-9.

Moraes TJ, Zurawska JH, Downey GP. (2006) Neutrophil granule contents in the pathogenesis of lung injury. Curr. Opin. Hematol.13(1): 21-7.

Morales S, Camello PJ, Rosado JA, Mawe GM, Pozo MJ. (2005) Disruption of the filamentous actin cytoskeleton is necessary for the activation of capacitative calcium entry in naive smooth muscle cells. Cell Signal 17(5): 635-45.

Morita K, Saida M, Morioka N, Kitayama T, Akagawa Y, Dohi T. (2008) Cyclic ADPribose mediates formyl methionyl leucyl phenylalanine (fMLP)-induced intracellular $\mathrm{Ca}^{2+}$ rise and migration of human neutrophils. J. Pharmacol. Sci. 106: 492-504.

Murao Y, Hata M, Ohnishi K, y col. (2003) Hypertonic saline resuscitation reduces apoptosis and tissue damage of the small intestine in a mouse model of hemorrhagic shock. Shock 20:23-8.

Murphy G, Ward R, Hembry RM, Reynolds JJ, Kühn K, Tryggvason K. (1989) Characterization of gelatinase from pig polymorphonuclear leucocytes. A metalloproteinase resembling tumor type IV collagenase. Biochem. J. 258: 463-72.

Murphy G, Reynolds JJ, Bretz U, Baggiolini M. (1982) Partial purification of collagenase and gelatinase from human polymorphonuclear leucocytes. Biochem. J. 203: 209-21.

Nacken W, Roth J, Sorg C, Kerkhoff C. (2003) S100A9/S100A8: Myeloid representatives of the $\mathrm{S} 100$ protein family as prominent players in innate immunity. Microsc. Res. Tech. 60(6): 569-80.

Nanda A, Gukovskaya A, Tseng J, Grinstein S. (1992) Activation of vacuolar-type proton pumps by protein kinase C. Role in neutrophil pH regulation. J. Biol. Chem. 267(32): 22740-6. 
Nanda A, Grinstein S. (1991) Protein kinase $\mathrm{C}$ activates an $\mathrm{H}^{+}$(equivalent) conductance in the plasma membrane of human neutrophils. Proc. Natl. Acad. Sci. USA. 88(23): 10816-20.

Natarajan V, Taher MM, Roehm B, y col. (1993) Activation of endothelial cell phospholipase $\mathrm{D}$ by hydrogen peroxide and fatty acid hydroperoxide. J. Biol. Chem. 268(2): 930-7.

Nathan C. (2002) Points of control in inflammation. Nature 420(6917): 846-52.

Nathan C, Xie Q, Halbwachs-Mecarelli L, Jin W. (1993) Albumin inhibits neutrophil spreading and hydrogen peroxide release by blocking the shedding of CD43 (Sialophofin, Leukosialin). J. Cell Biol. 122(1): 243-56

Nathan C. (1989) Respiratory burst in adherent human neutrophils: Triggering y colonystimulating factors CSF-GM and CSF-G. Blood 73: 301-6.

Nathan C, Srimal S, Farber C, y col. (1989) Cytokine-induced respiratory burst of human neutrophils: dependence on extracellular matrix proteins and CDII/CD18 integrins. J. Cell Biol. 109: 1341-9.

Nathan C. (1987) Neutrophil activation on biological surfaces. Massive secretion of hydrogen peroxide in response to product of macrophages and lymphocytes. J. Clin. Invest. 80: 1550-60.

Ni CN, Redmond HP. (2006) Cell response to surgery. Arch. Surg. 141: 1132-40.

Niggli V. (2003) Signaling to migration in neutrophils: importance of localized pathways. Int. J. Biochem. Cell Biol. 35(12): 1619-38.

Nilius B. (2007) TRP channels in disease. Biochim. Biophys. Acta 1772(8): 805-12.

Nilius B, Voets T. (2005) TRP channels: a TR(I)P through a world of multifunctional cation channels. Pflugers Arch. 451(1): 1-10.

Nilius B, Prenen J, Vennekens R, Hoenderop JG, Bindels RJ, Droogmans D. (2001) Pharmacological modulation of monovalent cation currents through the epithelial $\mathrm{Ca}^{2+}$ channel ECaC1. Br. J. Pharmacol. 134: 453-62.

Norman KE, Moore KL, McEver RP, Ley K. (1995) Leukocyte rolling in vivo is mediated by $\mathrm{p}$-selectin glycoprotein ligand-1. Blood 86: 4417-21.

Oberholzer A, Stahel P, Tschoke SK, Ertel W. (2006) Role of gene therapy in trauma and orthopedic surgery. Unfallchirurg 109: 521-7.
Oberholzer C, Oberholzer A, Bahjat FR, y col. (2001) Targeted adenovirus-induced expression of IL-10 decreases thymic apoptosis and improves survival in murine sepsis. Proc. Natl. Acad. Sci. USA 98: 11503-8.

Oide H, Thurman RG. (1994) Hepatic Ito cells contain calcium channels: increases with transforming growth factor beta 1. Hepatology 20: 1009-14.

Orlic T, Loomis WH, Shreve A, Namiki S, Junger WG. (2002) Hypertonicity increases CAMP in PMN and blocks oxidative burst by PKA-dependent and -independent mechanisms. Am. J. Physiol. Cell Physiol. 282: 1261-9.

Østby I, Benestad HB, Grøttum P. (2003) Mathematical modeling of human granulopoiesis: the possible importance of regulated apoptosis. Math. Biosci. 186(1): 127.

Owsianik G, D'hoedt D, Voets T, Nilius B. (2006) Structure-function relationship of the TRP channel superfamily. Rev. Physiol. Biochem. Pharmacol. 156:61-90.

Paclet MH, Davis C, Kotsonis P, Godovac-Zimmermann J, Segal AW, Dekker LV. (2004) Formyl peptide receptor subtypes in human neutrophils activate L-plastin phosphorylation through different signal transduction intermediates. Biochem. J. 377 (Pt 2): 469-77.

Parekh AB, Penner R. (1997) Store depletion and calcium influx. Physiol. Rev. 77: 901 30.

Partida-Sánchez S, Cockayne DA, Monard S, y col. (2001) Cyclic ADP-ribose production by $\mathrm{CD} 38$ regulates intracellular calcium release, extracellular calcium influx and chemotaxis in neutrophils and is required for bacterial clearance in vivo. Nat. Med. 7(11): 1209-16.

Pascual JL, Khwaja KA, Chaudhury P, Christou NV. (2003) Hypertonic saline and the microcirculation. J. Trauma 54 (5): S133-40.

Patat SA, Carnegie RB, Kingsbury C, Gross PS, Chapman R, Schey KL. (2004) Antimicrobial activity of histones from hemocytes of the pacific white shrimp. Eur. J. Biochem. 271(23-24): 4825-33.

Patel KD, Modur V, Zimmerman GA, Prescott SM, McIntyre TM. (1994) The necrotic venom of the brown recluse spider induces dysregulated endothelial cell-dependent neutrophil activation: Differential induction of GM-CSF, IL-8, and E- selectin expression. J. Clin. Invest. 94: 631-42. 
Patel KD, Zimmerman GA, Prescott SM, McEver RP, McIntyre TM. (1991) Oxygen radicals induce human endothelial cells to express GMP-140 and bind neutrophils. J. Cell Biol. 112(4): 749-59.

Pedersen SF, Owsianik G, Nilius B. (2005) TRP channels: an overview. Cell Calcium 38(3-4): 233-52.

Peng Y, Gong JP, Liu CA, Li SW, Gan L, Li SB. (2005) The effect of glycine on CD14 and NF-kappa $B$ in Kupffer cells from rat liver grafts after ischemia-reperfusion injury. Zhonghua Gan Zang Bing Za Zhi 13(3): 179-82.

Perez-Cornejo P, Arreola J, Law FY, Schultz JB, Knauf PA. (2004) Volume-sensitive chloride channels do not mediate activation-induced chloride efflux in human neutrophils. J. Immunol. 172(11): 6988-93.

Perraud AL, Fleig A, Dunn CA, y col. (2001) ADP-ribose gating of the calciumpermeable LTRPC2 channel revealed by Nudix motif homology. Nature 411(6837): 595-

Petrequin PR, Todd TF III, Devall LJ, Boxer LA, Curnutte JT. (1987) Association between gelatinase release and increased plasma membrane expression of the Mo1 glycoprotein. Blood 69: 606-10

Pfeiffer F, Betz H. (1981) Solubilization of the glycine receptor from the rat spinal cord. Brain Res. 226: 273-9.

Philipson KD, Nicoll DA. (2000) Sodium-calcium exchange: a molecular perspective. Annu. Rev. Physiol. 62: 111-3.

Pickup JC. (2004) Inflammation and activated innate immunity in the pathogenesis of type 2 diabetes. Diabetes Care. 27: 813-23.

Powers KA, Zurawska J, Szaszi K, Khdaroo RG, Kapus A, Rotstein OD. (2005) Hypertonic resuscitation of hemorrhagic shock prevents alveolar macrophage activation by preventing systemic oxidative stress due to gut ischemia/reperfusion. Surgery 137: 6674

Putney JW Jr. (2007) Recent breakthroughs in the molecular mechanism of capacitative calcium entry (with thoughts on how we got here). Cell Calcium 42(2): 103-10.

Qi R, Zhang J, Lu D, Wang H, Wang H, Li C. (2007) Glycine receptors contribute to cytoprotection of glycine in myocardial cells. Chin. Med. J. 120(10):915-21.
Qiao F, Atkinson C, Song H, y col. (2006) Complement plays an important role in spinal cord injury and represents a therapeutic target for improving recovery following trauma Am. J. Pathol. 169: 1039-47.

Qu W, Ikejima K, Zhong Z, Waalkes MP, Thurman RG. (2002) Glycine blocks the increase in intracellular free $\mathrm{Ca} 2+$ due to vasoactive mediators in hepatic parenchymal cells. Am. J. Physiol. Gastrointest. Liver Physiol. 283(6): G1249-56.

Rada BK, Geiszt M, Van Bruggen R, Nemet K, Roos D, Ligeti E. (2003) Calcium signalling is altered in myeloid cells with a deficiency in NADPH oxidase activity. Clin. Exp. Immunol. 132(1): 53-60.

Redondo PC, Salido GM, Pariente JA, y col. (2004) Dual effect of hydrogen peroxide on store-mediated calcium entry in human platelets. Biochem. Pharmacol. 67: 1065-76.

Reeves EP, Lu H, Jacobs HL, y col. (2002) Killing activity of neutrophils is mediated through activation of proteases by $\mathrm{K}^{+}$flux. Nature 416(6878): 291-7.

Reumaux D, Duthilleul P, Roos D. (2004) Pathogenesis of diseases associated with antineutrophil cytoplasm autoantibodies. Hum. Immunol. 65: 1-12.

Ridley AJ. (2001) Rho family proteins: coordinating cell responses. Trends Cell Biol. 11(12): 471-7

Rink TJ, Sage So. (1990) Calcium signalling in human platelets. Ann. Rev. Physiol. 52: 431-9.

Rizoli SB, Kapus A, Parodo J, Fan J, Rotstein OD. (1999a) Hypertonic immunomodulation is reversible and accompanied by changes in CD11b expression. J. Surg. Res. 83:130-5

Rizoli SB, Kapus A, Rotstein OD. (1999b) Cell volume dependent regulation of Lselectin shedding in neutrophils. A role for p38 mitogen-activated protein kinase. J. Biol. Chem. 274:22072-80.

Roit I, Brostoff J, Male D: Inmunología. 2a ed. Barcelona: Salvat, 1992.

Roland CR, Naziruddin B, Mohanakumar T, Flye MW. (1999) Gadolinium blocks rat Kupffer cell calcium channels: relevance to calcium-dependent prostaglandin E2 synthesis and septic mortality. Hepatology 29(3): 756-65.

Root RK, Cohen MS. (1981) The microbicidal mechanisms of human neutrophils and eosinophils. Rev. Infect. Dis. 3: 565-98. 
Root RK, Metcalf J, Oshino N, Chance B. (1975) $\mathrm{H}_{2} \mathrm{O}_{2}$ release from human granulocytes during phagocytosis. I. Documentation, quantitation, and some regulating factors. J. Clin. Invest. 55(5): 945-55.

Rosado JA, Redondo PC, Salido GM, Pariente JA. (2006) Calcium signalling and reactive oxygen species in non-excitable cells. Mini Rev. Med. Chem. 6(4): 409-15.

Rosado JA, Redondo PC, Salido GM, y col. (2004) Hydrogen peroxide generation induces pp60src activation in human platelets: evidence for the involvement of this pathway in store-mediated calcium entry. J. Biol. Chem. 279: 1665-75.

Rosado JA, Jenner S, Sage SO. (2000) A role for the actin cytoskeleton in the initiation and maintenance of store-mediated calcium entry in human platelets. J. Biol. Chem. 275: 7527-33.

Rose JJ, Foley JF, Murphy PM, Venkatesan SJ. (2004) On the mechanism and significance of ligand-induced internalization of human neutrophil chemokine receptors CXCR1 and CXCR2. Biol. Chem. 279 (23): 24372-86.

Roth J, Vogl T, Sorg C, Sunderkötter C. (2003) Phagocyte-specific S100 proteins: a novel group of proinflammatory molecules. Trends Immunol. 24(4): 155-8.

Saklatvala J. (2004) The p38 MAP kinase pathway as a therapeutic target in inflammatory disease. Curr. Opin. Pharmacol. 4: 372-7.

Salmon MD, Ahluwalia J. (2009) Swell activated chloride channel function in human neutrophils. J: Biochem. Biophys. Res. Commun. En prensa.

Särndahl E, Lindroth M, Bengtsson T, y col. (1989) Association of ligand-receptor complexes with actin filaments in human neutrophils: a possible regulatory role for a Gprotein. J. Cell Biol. 109: 2791-9.

Scapini P, Lapinet-Vera JA, Gasperini S, Calzetti F, Bazzoni F, Cassatella MA. (2000) The neutrophil as a cellular source of chemokines. Immunol. Rev. 177: 195-203.

Schaff UY, Yamayoshi I, Tse T, Griffin D, Kibathi L, Simon SI. (2008) Calcium flux in neutrophils synchronizes beta2 integrin adhesive and signaling events that guide inflammatory recruitment. Ann Biomed Eng. 36(4): 632-46.

Schemmer P, Bradford BU, Rose ML, y col. (1999) Intravenous glycine improves survival in rat liver transplantation. Am. J. Physiol. 276: G924-32.

Scholz W, Albus U, Lang HJ, y col. (1993) Hoe 694, a new $\mathrm{Na}^{+} / \mathrm{H}^{+}$exchange inhibitor and its efects in cardiac ischaemia. Br. J. Pharmacol. 109: 562-8.
Schrenzel J, Serrander L, Bánfi B, y col. (1998) Electron currents generated by the human phagocyte NADPH oxidase. Nature 392: 734-7.

Seely AJ, Pascual JL, Christou NV. (2003) Science review: Cell membrane expression (connectivity) regulates neutrophil delivery, function and clearance. Crit. Care 7(4): 291307.

Sengeløv H, Follin P, Kjeldsen L, Lollike K, Dahlgren C, Borregaard N. (1995) Mobilization of granules and secretory vesicles during in vivo exudation of human neutrophils. J. Immunol. 154: 4157-65.

Sheppard FR, Kelher MR, Moore EE, McLaughlin NJ, Banerjee A, Silliman CC. (2005) Structural organization of the neutrophil NADPH oxidase: phosphorylation and translocation during priming and activation. J. Leukoc. Biol. 78(5): 1025-42.

Shi J, Gilbert GE, Kokubo Y, Ohashi T. (2001) Role of the liver in regulating numbers of circulating neutrophils. Blood 98(4): 1226-30.

Simchowitz L, Davis AO. (1990) Intracellular pH recovery from alkalinization. Characterization of chloride and bicarbonate transport by the anion exchange system of human neutrophils. J. Gen. Physiol. 96(5): 1037-59.

Simchowitz L, Foy MA, Cragoe EJ Jr. (1990) A role for $\mathrm{Na}^{+} / \mathrm{Ca}^{2+}$ exchange in the generation of superoxide radicals by human neutrophils. J. Biol. Chem. 265(23): 13449-5.

Simchowitz L. (1985) Intracellular pH modulates the generation of superoxide radicals by human neutrophils. J. Clin. Invest. 76: 1079-89.

Simon HU. (2003) Neutrophil apoptosis pathways and their modifications in inflammation. Immunol. Rev. 193: 101-10

Slayton WB, Juul SE, Calhoun DA, Li Y, Braylan RC, Christensen RD. (1998) Hematopoiesis in the liver and marrow of human fetuses at 5 to 16 weeks postconception: quantitative assessment of macrophage and neutrophil populations. Pediatr. Res. 43(6): 774-82.

Sonoda Y, Mukaida N, Wang JB, y col. (1998) Physiologic regulation of postovulatory neutrophil migration into vagina in mice by a C-X-C chemokine(s). J. Immunol. 160(12): 6159-65.

Spitznagel JK, Chi MS. (1963) Cationic proteins and antibacterial properties of infected tissues and leukocytes. Am. J. Pathol. 43:697-711. 
Stachlewitz RF, Li X, Smith S, Bunzendahl H, Graves LM, Thurman RG. (2000) Glycine inhibits growth of T lymphocytes by an IL-2-independent mechanism. J. Immunol. 164(1): 176-82

Stahel P, Smith W, Moore E. (2007) Role of biological modifiers regulating the immune response after trauma. Injury 38(12): 1409-22.

Staudenmayer KL, Maier RV, Jelacic S, Bulger EM. (2005) Hypertonic saline modulates innate immunity in a model of systemic inflammation. Shock 23:459-63.

Steel HC, Anderson R. (2004) Itraconazole antagonizes store-operated influx of calcium into chemoattractant-activated human neutrophils. Clin Exp Immunol. 136(2): 255-61.

Streb H, Irvine RF, Berridge MJ, Schulz I. (1983) Release of $\mathrm{Ca}^{2+}$ from nonmitochondrial intracellular store in pancreatic acinar cells by inositol-1,4,5trisphosphate. Nature 306(5938): 67-9

Suratt BT, Young SK, Lieber J, Nick JA, Henson PM, Worthen GS. (2001) Neutrophi maturation and activation determine anatomic site of clearance from circulation. Am. J. Physiol. Lung Cell Mol. Physiol. 281(4): L913-21.

Suwa T, Hogg J, English D, Van Eeden S. (2000) Interleukin-6 induces demargination of intravascular neutrophils and shortens their transit in marrow. Am. J. Physiol. Heart Circ. Physiol. 279(6): H2954-60.

Takai Y, Sasaki T, Matozaki T. (2001) Small GTP-binding proteins. Physiol. Rev. 81(1): 153-208.

Takeda H, Tomita M, Tanahashi N, y col. (1998) Hydrogen peroxide enhances phagocytic activity of ameboid microglia. Neurosci. Lett. 240: 5-8.

Thurman JM, Royer PA, Ljubanovic D, y col. (2006) Treatment with an inhibitory monoclonal antibody to mouse factor $B$ protects mice from induction of apoptosis and renal ischemia/reperfusion injury. J. Am. Soc. Nephrol. 17: 707-15.

Tintinger G, Steel HC, Anderson R. (2005) Taming the neutrophil: calcium clearance and influx mechanisms as novel targets for pharmacological control. Clin. Exp. Immunol. 141: $191-200$.

Tintinger GR, Anderson R. (2004) Counteracting effects of NADPH oxidase and the $\mathrm{Na}^{+} / \mathrm{Ca}^{2+}$ exchanger on membrane repolarisation and store-operated uptake of $\mathrm{Ca}^{2+}$ by chemoattractant-activated human neutrophils. Biochem. Pharmacol. 67: 2263-71.
Tkalcevic J, Novelli M, Phylactides M, Iredale JP, Segal AW, Roes J. (2000) Impaired immunity and enhanced resistance to endotoxin in the absence of neutrophil elastase and cathepsin G. Immunity 12(2): 201-10.

Todd RF III, Arnaout MA, Rosin RE, Crowley CA, Peters WA, Babior BM. (1984) Subcellular localization of the large subunit of Mo1 (Mo10; formerly gp 110), a surface glycoprotein associated with neutrophil adhesion. J. Clin. Invest. 74:1280-90.

Tonks NK. (2005) Redox redux: revisiting PTPs and the control of cell signaling. Cell 121(5): $667-70$

Touyz RM. (2005) Reactive oxygen species as mediators of calcium signaling by angiotensin II: implications in vascular physiology and pathophysiology. Antioxid. Redox Signal 7(9-10): 1302-14.

Treacher DF, Sabbato M, Brown KA, Gant VA. (2001) The effects of leucodepletion in patients who develop the systemic inflammatory response syndrome following cardiopulmonary bypass. Perfusion 16: S75-84.

Trevani A, Andonegui M, Giordano D y col. (1999) Extracellular acidification induces human neutrophil activation. J. Immunol. 162: 4849-57.

Trujillo ME, Scherer E. (2006) Adipose tissue-derived factors: impact on health and disease. Endocr. Rev. 27: 762-78.

Van Furt R. (1977) Cell kinetics during inflammation. Agents Actions 3: 51-9.

Van Haastert PJ, Devreotes PN. (2004) Chemotaxis: signalling the way forward. Nat. Rev. Mol. Cell Biol. 5(8): 626-34.

Vazquez G, Lievremont JP, Bird G, Putney JW Jr. (2001) Human Trp3 forms both inositol trisphosphate receptor-dependent and receptor-independent store-operated cation channels in DT40 avian B lymphocytes. Proc. Natl. Acad. Sci. USA 98: 11777-82.

Verghese MW, Boucher CR. (1998) Effects of ion composition and tonicity on human neutrophil antibacterial activity. Am. J. Respir. Cell Mol. Biol. 19: 920-8.

Vermeulen M, Giordano M, Trevani AS, y col. (2004) Acidosis improves uptake of antigens and MHC class I-restricted presentation by dendritic cells. J. Immunol. 172(5): 3196-204.

Villa P, Saccani A, Sica A, Ghezzi P. (2002) Glutathione protects mice from lethal sepsis by limiting inflammation and potentiating host defense. J. Infect. Dis. 185(8): 111520. 
Waddell TK, Fialkow L, Chan CK, Kishimoto TK, Downey GP. (1994) Potentiation of the oxidative burst of human neutrophils: A signaling role for L-selectin. J. Biol. Chem. 269: 18485-91.

Wang G, Zhao M, Wang EH. (2004) Effects of glycine and methylprednisolone on hemorrhagic shock in rats. Chin. Med. J. 117: 1334-41.

Wang JP, Tsai JJ, Chen YS, y col. (2005) Stimulation of intracellular $\mathrm{Ca}^{2+}$ elevation in neutrophils by thiol-oxidizing phenylarsine oxide. Biochem. Pharmacol. 69: 1225-34.

Ward C, Dransfield I, Chilvers ER, Haslett C, Rossi A. (1999) Pharmacological manipulation of granulocyte apoptosis: potential therapeutic targets. TiPS 20: 503-9.

Watson RW. (2002) Redox regulation of neutrophil apoptosis. Antioxid. Redox Signal 4(1): 97-104.

Wehage E, Eisfeld J, Heiner I, y col. (2002) Activation of the cation channel long transient receptor potential channel 2 (LTRPC2) by hydrogen peroxide. A splice variant reveals a mode of activation independent of ADP-ribose. J. Biol. Chem. 277: 23150-6. Weiss SJ. (1989) Tissue destruction by neutrophils. N. Engl. J. Med. 320: 365-76.

Welsh IRH, Spitznagel JK. (1971) Distribution of lysosomal enzymes, cationic proteins, and bactericidal substances in subcellular fractions of human polymorphonuclear leukocytes. Infect. Immun. 4: 97-102.

Wenger RH, StiehI DP, Camenisch G. (2005) Integration of oxygen signaling at the consensus HRE. Sci. STKE 2005(306):re12.

Wheeler M, Stachlewitz RF, Yamashina S, Ikejima K, Morrow AL, Thurman RG. (2000a) Glycine-gated chloride channels in neutrophils attenuate calcium influx and superoxide production. FASEB J. 14: 476-84.

Wheeler MD, Rose ML, Yamashima S, y col. (2000b) Dietary glycine blunts lung inflammatory cell influx following acute endotoxin. Am. J. Physiol. Lung Cell. Mol. Physiol. 279: L390-8.

Windsor AC, Mullen PG, Fowler AA, Sugerman HJ. (1993) Role of the neutrophil in adult respiratory distress syndrome. Br. J. Surg. 80: 10-7.
Winterbourn CC, Vissers MC, Kettle AJ. (2000) Myeloperoxidase. Curr. Opin. Hematol. 7(1): 53-8.

Wolpe SD, Davatelis G, Sherry B, y col. (1988) Macrophages secrete a novel heparinbinding protein with inflammatory and neutrophil chemokinetic properties. J. Exp. Med. 167:570-81.

Xu H, Uysal T, Becherer D, Arner P, Gökhan S, Hotamisligil GS. (2002) Altered tumor necrosis factor- $\alpha$ processing in adipocytes and increased expression of transmembrane TNF- $\alpha$ in obesity. Diabetes 51: 1821-30.

Yamamoto S, Shimizu S, Kiyonaka S, y col. (2008) TRPM2-mediated Ca2+influx induces chemokine production in monocytes that aggravates inflammatory neutrophil infiltration. Nat. Med. 14(7): 738-47.

Yamauchi T, Kamon J, Waki H, y col. (2001) The fat-derived hormone adiponectin reverses insulin resistance associated with both lipodistrophy and obesity. Nat. Med. 7: 941-6.

Yin M, Zhong Z, Connor HD, y col. (2002) Protective effect of glycine on renal injury induced by ischemia-reperfusion in vivo. Am. J. Physiol. Renal Physiol. 282: F417-23.

Yui S, Nakatani Y, Mikami M. (2003) Calprotectin (S100A8/S100A9), an inflammatory protein complex from neutrophils with a broad apoptosis-inducing activity. Biol. Pharm. Bull 26(6): 753-60.

Zhang D, Shooshtarizadeh P, Laventie BJ, y col. (2009) Two chromogranin a-derived peptides induce calcium entry in human neutrophils by calmodulin-regulated calcium independent phospholipase A2. PLOS ONE 4(2): e4501.

Zheng LM, Sjolander A, Eckerdal J, Andersson T. (1996) Antibody-induced engagement of beta(2) integrins on adherent human neutrophils triggers activation of p21(ras) through tyrosine phosphorylation of the protooncogene product Vav. Proc. Natl. Acad. Sci. USA 93: 8431-36.

Zhong Z, Enomoto N, Connor HD, Moss N, Mason RP, Thurman RG. (1999) Glycine improves survival after hemorrhagic shock in the rat. Shock 12: 54-62. 


\section{ANEXO I}

RESUMEN DE LOS TRABAJOS

PUBLICADOS 


\title{
Hydrogen peroxide activates calcium influx in human neutrophils
}

Miriam S. Giambelluca - Oscar A. Gende

\begin{abstract}
The correlation between an increased production of reactive oxygen species (ROS) and an enhanced calcium entry in primed neutrophils stimulated with fMLP suggests that endogenous ROS could serve as an agonist to reinforce calcium signaling by positive feedback. This work shows that exogenous $\mathrm{H}_{2} \mathrm{O}_{2}$ produced a rapid influx of $\mathrm{Mn}^{2+}$ and an increase of intracellular calcium. The $\mathrm{H}_{2} \mathrm{O}_{2}$ was insufficient to produce significant changes in the absence of extracellular calcium but addition of $\mathrm{Ca}^{2+}$ to $\mathrm{H}_{2} \mathrm{O}_{2}$-treated cells suspended in a free $\mathrm{Ca}^{2+} /$ EGTA buffer resulted in a great increase in $\left[\mathrm{Ca}^{2+}\right]_{\mathrm{i}}$ reflecting influx of $\mathrm{Ca}^{2+}$ across the cell membrane. The increase of intracellular calcium was inhibited by $\mathrm{Ni}^{2+}, \mathrm{La}^{3+}$, and hyperosmotic solutions of mannitol and other osmolytes. This raises the possibility that the secretion of $\mathrm{H}_{2} \mathrm{O}_{2}$ by activated neutrophils could act as an autocrine regulator of neutrophil function through the activation of calcium entry.
\end{abstract}

Keywords Neutrophils - Hydrogen peroxide - ROS .

Intracellular calcium

Giambelluca M, Gende OA. (2008) Hydrogen peroxide activates calcium influx in human neutrophils. Mol. Cell. Biochem. 309(1-2): 151-6. 


\section{INHIBITION OF CYTOCHALASIN-PRIMED NEUTROPHILS BY HYPEROSMOLARITY}

\section{Miriam S. Giambelluca and Oscar A. Gende}

Centro de Investigaciones Cardiovasculares, Facultad de Ciencias Médicas, UNLP, La Plata, Argentina

Received 30 Oct, 2007; first review completed 14 Nov 2007; accepted in final form 21 Dec 2007

ABSTRACT-Experimental and clinical investigations using hyperosmotic solutions for resuscitation of hemorrhagic shock demonstrated modulation of the inflammatory response. Decreased postinjury hyperinflammation has been attributed to a reduction in neutrophil-mediated tissue damage. This study shows that cytoskeletal disruption with cytochalas inB did not reverse or prevent the inhibitory effect of an osmolarity increase on the neutrophil cytotoxic response to a formyl peptide. In cytochalasin-primed neutrophils, the hyperosmolarity-dependent inhibition promptly reversed after returning to iso-osmotic levels. Paradoxically, an increase in osmolarity after stimulation produced an increase in the release of reactive oxygen species to the extracellular medium. The inhibitory effect of hyperosmotic $\mathrm{NaCl}$ can be reproduced by solutions of similar osmolarity containing $\mathrm{N}$-methyl glucamine or sucrose, but solutions containing mannitol allowed an almost complete response to $\mathrm{N}$-formyl methionyl leucyl phenylalanine. The effects on the release of reactive oxygen species to the extracellular media found with the OxyBURST-bovine serum albumin assay correlated with the changes of the intracellular calcium signal, indicating that the inhibition by hyperosmolarity occurs near the receptor level.

KEYWORDS - Innate immunity, cytoskeleton, hypertonic, oxidative stress, calcium signa

Giambelluca M, Gende OA. (2008) Inhibition of cytochalasin-primed neutrophils by hyperosmolarity. Shock 30:473-80. 
International Immunopharmacology 9 (2009) 32-37

\begin{tabular}{|c|c|}
\hline & Contents lists available at ScienceDirect \\
\hline ELSEVIER & International Immunopharmacology \\
\hline
\end{tabular}

Effect of glycine on the release of reactive oxygen species in human neutrophils

Miriam S. Giambelluca *, Oscar A. Gende

centro de investigaciones Cardiovasculares, CONCET, CCT, La Plata, Argentina

A R T I C L E I N F O

\section{Artide history:}

Received 18 July 2008

Received in revised form 21 August 2008

Accepted 13 September 2008

Keywords

Polymorphonuckear leukocytes

Oxidative stress

Glycine

\section{A B S T R A C T}

The increase of extracellular glycine concentration prevents or mitigates a variety of pathological dysfunctional inflammatory responses. To eliminate the systemic effects of glycine as the reduction in the release of cytokines, this study was performed in isolated human neutrophils. The increase of the

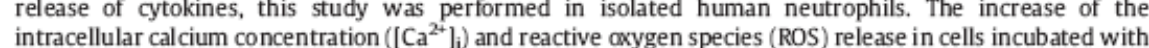
glycine $(01$ to $10 \mathrm{mM}$ ) and stimulad with $\mathrm{MLP}$. PMA were inhibited ROS production but increased $\left[\mathrm{C}^{2+}\right]$, signal produed by was observed even when glycine was added after he waste was inenstive to eflect was inenty channel, presumably at the membrane level.

Q 2008 Elsevier B.V. All rights reserved.

Giambelluca M, Gende OA. (2009) Effect of glycine on the release of reactive oxygen species in human neutrophils. International Immunopharmacology 9: 32-37. 